Portland State University

PDXScholar

Spring 1-1-2012

\title{
Conscientiousness as a Moderator of the Relationship Between Work Autonomy and Job Satisfaction
}

Kyle Garret Mack

Portland State University

Follow this and additional works at: https://pdxscholar.library.pdx.edu/open_access_etds

Part of the Industrial and Organizational Psychology Commons, and the Other Psychiatry and Psychology Commons

Let us know how access to this document benefits you.

\section{Recommended Citation}

Mack, Kyle Garret, "Conscientiousness as a Moderator of the Relationship Between Work Autonomy and Job Satisfaction" (2012). Dissertations and Theses. Paper 238.

https://doi.org/10.15760/etd.238

This Dissertation is brought to you for free and open access. It has been accepted for inclusion in Dissertations and Theses by an authorized administrator of PDXScholar. Please contact us if we can make this document more accessible: pdxscholar@pdx.edu. 
Conscientiousness as a Moderator of the Relationship Between Work Autonomy and

Job Satisfaction

by

Kyle Garret Mack

A dissertation submitted in partial fulfillment of the requirements for the degree of

\author{
Doctor of Philosophy \\ in \\ Applied Psychology
}

Dissertation Committee:

Donald Truxillo, Chair

Talya Bauer

Todd Bodner

Wayne Wakeland

Liu-Qin Yang

Portland State University

(C)2012 
Conscientiousness as a Moderator i

\begin{abstract}
Autonomy is one of the most commonly studied job characteristics in the work design literature and is commonly associated with large and positive effects on job satisfaction. There is reason to believe that autonomy may interact with personality characteristics to affect attitudinal outcomes, but prior research has tended to focus on the original growth-need-strength construct as a potential moderator with mixed results. One glaring gap in the literature is the lack of research that examines the Big Five constructs of personality as a potential class of moderators. Grant, Fried, and Juillerat (2010) have suggested additional research into the Big Five as moderators of individuals' attitudinal reactions to job characteristics. Moreover, several researchers (e.g., Dudley, Orvis, Lebiecki, \& Cortina, 2006; Judge, Heller, \& Mount, 2002; Major, Turner, \& Fletcher, 2006) have called for increased attention to the facets of the Big Five in conducting such research.
\end{abstract}

This dissertation addressed these two gaps in the research literature. First, the study examined conscientiousness as a potential moderator of the relationship between the job design characteristic of autonomy and the outcomes of job satisfaction and person-job fit. Second, the study tested specific hypotheses regarding these interactions using both the global construct of conscientiousness and the narrower subtraits—or facets — that exist underneath the broader trait. This dissertation also contributes to the research literature by creating a new measure of person autonomy fit adapted from an existing person job fit measure (Cable \& DeRue, 2002) and by showing that person autonomy fit mediates the effect of autonomy and job satisfaction 
Conscientiousness as a Moderator ii

and person job fit.

Data were collected at two time points from 181 employees at a national wholesale distribution cooperative. Participants came from the corporate office and 10 independently owned locations across the United States, and held a wide variety of jobs. The results indicated strong main effects for autonomy and conscientiousness and its facets on job satisfaction, and a strong effect of autonomy on person-job fit, but did not find evidence of interactions between autonomy and conscientiousness or any of its facets. Moreover, the results indicate that person autonomy fit mediates the effect of autonomy on these two attitudinal outcomes. Based on these results, I suggest that organizations interested in creating work environments that foster high levels of job satisfaction can do so using at least two mechanisms: 1) by selecting individuals with higher levels of conscientiousness and 2) by providing high levels of autonomy in the workplace. I also argue that the potential payoff of providing autonomous work environments is far higher than for selecting workers predisposed to be more satisfied with their jobs. Finally, I suggest that more research is needed to understand the complex interaction between individual differences and workplace environments. 
Conscientiousness as a Moderator iii

\section{Acknowledgements}

I would first like to thank my dissertation chair and academic advisor, Donald Truxillo, for his mentorship and support over the last five years. He is both an exceptional scholar and a great human being. Donald was always there at virtually any time — day or night — to answer emails, take phone calls, and talk me through thorny academic issues. When the going got tough, a kind word of encouragement, a loud cackle, and a brief whiteboard session was all that was needed to set me right. He gives all he has all the time, and I can't thank him enough for his tireless attention, his humor, and his drive to get the very best out of me and the rest of his students. I did it, DT.

I would also like to thank Todd Bodner, thesis and dissertation committee member, teacher, quantitative mentor and statistical guru. I had the pleasure of taking Todd's year-long graduate statistics program twice: once as a student and once as a teaching assistant. Todd has an exceptional ability to explain difficult statistical methods on an engaging, conceptual, almost philosophical level. I always enjoyed seeing him step inside my lab door for a quick chat, a smile, and a few positive words. I would next like to thank: Talya Bauer for her service on both my thesis and dissertation committees, her high standards, her helpful suggestions throughout the process, and her strong impact on the quality of this work; Liu-Qin Yang for her help with the theoretical development of this dissertation and for exposing me to IRT; and Wayne Wakeland for his positive, helpful, and friendly presence on the committee.

I could not have completed this study without the help and support of Johanna 


\section{Conscientiousness as a Moderator iv}

Glode and Kevin Dier at Johnstone Supply, and the individual owners and participants at the Johnstone Supply member stores who graciously gave their time. In addition to helping with the study, Kevin has been a coach, mentor, and facilitator of my early I-O career. Johanna provided a great environment for my work at Johnstone and she did more legwork than she should have to make this study possible. In addition, she has been a continued source of inspiration and delight to me, and it has been a pleasure to get to know her both personally and professionally. The next one is on me, Johanna.

I would also like to thank the graduate students across the various disciplines of psychology at Portland State University. There are too many to name. Elizabeth McCune and David Cadiz helped me find my way when I first started the program. Jenn Rineer brought some sunshine and a fresh coat of blue paint to the lab, and helped serve as courier for some of my printed drafts. Bing Lin was one of my two comprehensive exam study-buddies and I am not sure I could have gotten through the process without him. Ana Costa was my other comps study-buddy and also provided a huge amount of laughter, listening, friendship and support in many matters academic and personal.

I owe a huge debt of gratitude to my parents, Richard and Linda Mack, for their incredible love, patience and support throughout my life, and especially in the last five years. Even when times got really hard, there wasn't much that a quick (or lengthy) call with mom and dad couldn't fix. The older I get, the more I appreciate them as parents and as people and I feel lucky to call myself their son. I would also like to thank Susan Captein for lending a hand when I needed it most, and for helping 
Conscientiousness as a Moderator v

me find the courage to live out loud, move on and finish up.

Finally, I'd like to thank Serena Batten, in whom I found a kindred spirit and with whom everything is richer, fresher and more vibrant. 
Table of Contents

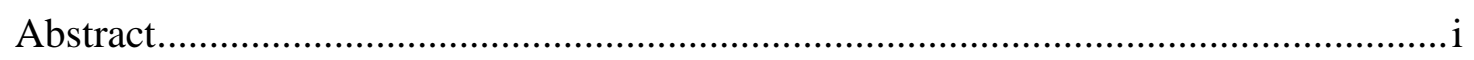

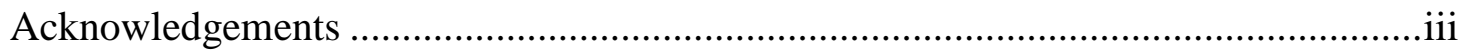

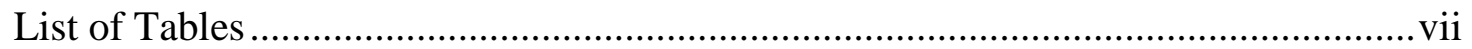

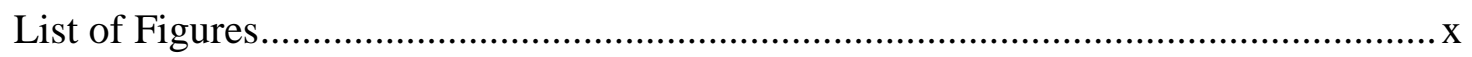

Chapter 1: Introduction................................................................................. 1

Chapter 2: Work Design ............................................................................... 13

Chapter 3: The Five Factor Model of Personality and Its Facets .............................. 32

Chapter 4: Trait-Activation Theory and Person-Environment Fit Theory ...................50

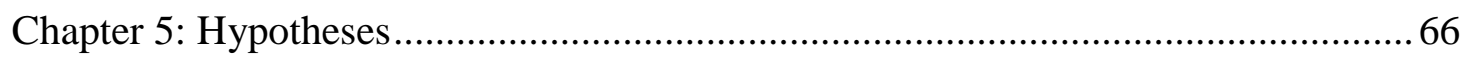

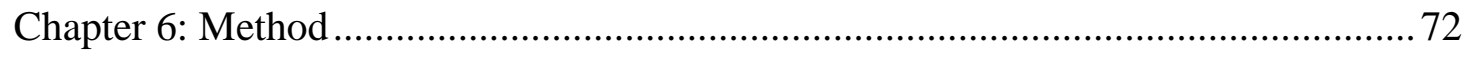

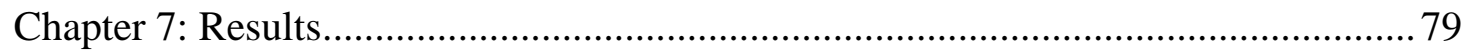

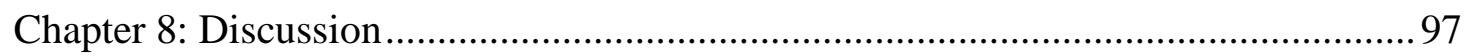

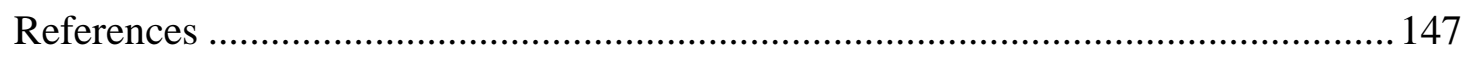

Appendix A: Items Used in the Dissertation ..................................................... 164

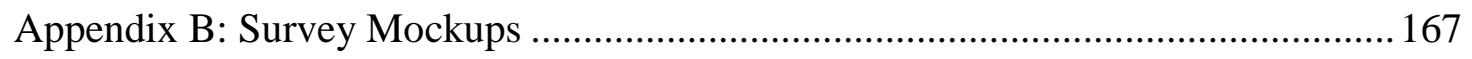


List of Tables

Table 1. Factors and Facets of Costa and McCrae (1992) Five Factor Model of

Personality

Table 2. Hypotheses Regarding Personality as a Moderator of the Relationship

between Autonomy and Job Satisfaction

Table 3. Hypotheses Regarding PJ Fit as a Mediator of the Autonomy x

Personality Interaction

Table 4. Intercorrelations and Alpha Reliability Statistics for Study Variables

Table 5. Means and Standard Deviations for All Study Variables 126

Table 6. Summary of Hierarchical Regression Analysis for Variables Used to Answer RQ1 Regarding the Interaction between Conscientiousness and

Autonomy on Job Satisfaction.

Table 7. Summary of Hierarchical Regression Analysis for Variables Used to

Answer H1a Regarding the Interaction between Orderliness and Autonomy on

Job Satisfaction. 128

Table 8. Summary of Hierarchical Regression Analysis for Variables Used to Answer H1b Regarding the Interaction between Dutifulness and Autonomy on Job Satisfaction. 129

Table 9. Summary of Hierarchical Regression Analysis for Variables Used to Answer H1c Regarding the Interaction between Deliberation and Autonomy on

Job Satisfaction. 130

Table 10. Summary of Hierarchical Regression Analysis for Variables Used to 
Conscientiousness as a Moderator viii

Answer H3a Regarding the Interaction between Achievement and Autonomy

on Job Satisfaction

Table 11. Summary of Hierarchical Regression Analysis for Variables Used to Answer H3b Regarding the Interaction between Competence and Autonomy

on Job Satisfaction

Table 12. Summary of Hierarchical Regression Analysis for Variables Used to

Answer H3c Regarding the Interaction between Discipline and Autonomy on

Job Satisfaction.

Table 13. Summary of Hierarchical Regression Analysis for Variables Used to Answer RQ2 Regarding the Interaction between Conscientiousness and

Autonomy on PJ Fit.

Table 14. Summary of Hierarchical Regression Analysis for Variables Used to Answer H2a Regarding the Interaction between Orderliness and Autonomy on

PJ Fit. 135

Table 15. Summary of Hierarchical Regression Analysis for Variables Used to Answer H2b Regarding the Interaction between Dutifulness and Autonomy on PJ Fit. 136

Table 16. Summary of Hierarchical Regression Analysis for Variables Used to Answer H2c Regarding the Interaction between Deliberation and Autonomy on PJ Fit. 137

Table 17. Summary of Hierarchical Regression Analysis for Variables Used to Answer H4a Regarding the Interaction between Achievement and Autonomy 
Conscientiousness as a Moderator ix

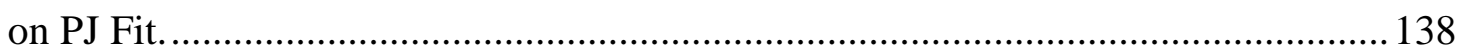

Table 18. Summary of Hierarchical Regression Analysis for Variables Used to Answer H4b Regarding the Interaction between Competence and Autonomy on PJ Fit.

Table 19. Summary of Hierarchical Regression Analysis for Variables Used to Answer H4c Regarding the Interaction between Discipline and Autonomy on

PJ Fit. 140 


\section{List of Figures}

Figure 1. Different Ways of Conceptualizing PE Fit .......................................... 141

Figure 2. Conceptual model of relationships hypothesized in this dissertation ......... 142

Figure 3. Personality as a Moderator of the Relationship between Autonomy

and the Outcomes of Job Satisfaction and PJ Fit. .................................................. 143

Figure 4. Example of Disordinal Interaction Based on Hypothesis 1a that Order

Will Moderate the Relationship between Autonomy and Job Satisfaction................ 144

Figure 5. Person-Autonomy Fit as a Mediator of the Autonomy x Personality

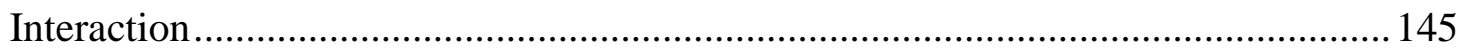

Figure 6. Study Design and Variables Collected at Each Time Point....................... 146 


\section{Conscientiousness as a Moderator 1}

\section{Chapter 1: Introduction}

The initial idea for this dissertation started with an interaction I had with a friend regarding our preferred work styles. I was explaining how one of the things I enjoyed about being a graduate student was the tremendous amount of autonomy I had over my work schedule and my almost limitless array of potential research topics and interests. "I am the master of my own time," I said, "and who doesn't want that?" "I don't," she said. "You have to worry all the time about what you are going to do, when you are going to do it, and how it has to be done. Just tell me what to do and how to do it. I'll get it done and then I can go home and relax."

This interaction dovetailed with another experience I had, albeit in a different context. In my previous role as a salesperson, I worked from home, was responsible for sales in a fairly large regional territory and was managed by a regional director who was located 1500 miles away from my home office. The first time we met face to face, he opened the conversation with a single question: "How do you like to be managed?" I looked at him quizzically, not understanding what he meant. "Some people like lots of feedback," he said. "They like deadlines, check-ins and direct management. Others like to be left alone and will let me know when they need help. Which type are you?"

These anecdotes suggest that the experience of work — and attitudes regarding work-may be best understood as stemming from an interaction between the unique characteristics and experiences of an individual and the unique characteristics of a job nested within the unique culture of an organization. The anecdotes also revolve 
Conscientiousness as a Moderator 2

around the notion of autonomy at work. The first example suggests that individuals differ in their preferences for the amount of autonomy they receive at work. The second example suggests that the amount of autonomy provided by the work place differs, at times even within the same job. Strangely, however, much modern research into work design focuses exclusively on the main effects of work attributes on job attitudes. If the desire for autonomy differs among individuals according to their personality, and the amount of autonomy provided by the work place differs as well, wouldn't an interactionist approach to work design be warranted?

The aim of the study conducted for this dissertation was to investigate the Big Five personality facets as moderators of the relationship between autonomy (an oftstudied work design characteristic) and job satisfaction. In so doing so, it sought to fill two significant gaps in the current I-O literature, by responding to explicit calls for future research from two different sub-fields. In chapter 6 , I outline two sets of hypotheses, with each set aimed at one of the two gaps in the literature. The first set of hypotheses investigated the role that the facets of conscientiousness have in moderating the effect of work place autonomy on the outcomes of job satisfaction and person-job fit, while the second set investigated the individual's perceived fit as a potential mediating mechanism.

\section{Personality Characteristics and Job Design.}

In their recent chapter on job design, Grant, Fried, and Juillerat (2010) suggest that "it is time for researchers to move beyond growth need strength as the primary individual difference moderator of reactions to job characteristics" (p. 438). They also 
Conscientiousness as a Moderator 3

recommend additional research into the Big Five as moderators of individuals' attitudinal reactions to job characteristics. This dissertation addressed their recommendation by investigating the facets of conscientiousness as moderators of a work design element (autonomy) and an attitudinal outcome (job satisfaction.)

Based on my own review of the work design literature, I agreed with Grant et al.'s (2010) assertion that more research into the Big Five as a moderator of the relationship between job design and attitudinal reactions to work characteristics was warranted. Indeed, the job characteristics model (Hackman \& Oldham, 1975), on which much current work design theory is based, specifies that the effect of job design on such outcomes as satisfaction is moderated by individual differences in a person's need for personal growth on the job (i.e., growth need strength). Strangely, however, the modern work design literature has all but thrown out the question of individual differences, and continues to focus almost exclusively on the main effects of work design on such outcomes as job satisfaction, various indicators of job performance, and stress. For example, in their review of the work design literature, Morgeson and Campion (2003) acknowledged that there are most likely individual differences in the potential of work design to motivate and satisfy employees, but also suggested that individual differences can be largely ignored for three reasons. First, they argued, existing evidence of moderation effects in work design is based on outdated constructs such as growth need strength, and outdated analytical techniques such as subgroup analysis. Second, they opined that it is best to design jobs with the average or typical employee in mind because it is impractical to design jobs to fit the needs, attributes, 
Conscientiousness as a Moderator 4

preferences and personality characteristics of each potential incumbent. Third, they suggested that moderation can be largely ignored because the effects of enriching jobs through job redesign tends to have positive outcomes for all employees, even though there are differences in the magnitude of these positive effects. These three challenges to the notion of researching individual differences as moderators in the context of work design were later echoed by Morgeson and Humphrey (2006).

I believed these challenges to individual differences as moderators of work design outcomes are both unfortunate and premature, as the work design literature has a long history of considering individual differences as moderators (e.g., Hackman \& Oldham, 1975; Hulin \& Blood, 1968; Loher, Noe, Moeller, \& Fitzgerald, 1985; Tiegs, Tetrick, \& Fried, 1992), and there are large gaps regarding the types of individual differences that have been considered. Indeed, in the same article in which they argued that individual differences need not be considered in work design research, Morgeson and Humphrey (2006) concluded that "clearly, future research should examine how the relationships between the expanded set of constructs measured by the WDQ [Work Design Questionnaire] and outcomes might be moderated by individual differences" (p. 1335). One glaring gap in the research investigating individual differences as moderators of work design outcomes was the lack of research that examines the Big Five constructs of personality as a potential class of moderators.

Although the five-factor model has emerged as the dominant taxonomy for personality research in I-O psychology (Barrick \& Mount, 1991; Tett, Jackson, \& Rothstein, 1991), there are only a handful of studies that have utilized Big Five 
Conscientiousness as a Moderator 5

constructs in the context of work design (Barrick \& Mount, 1993; deJong, van der Velde, \& Jansen, 2001; Grant, 2008), and two of the three examined performancebased outcomes. Barrick and Mount investigated the moderating effect of autonomy on the relationship between conscientiousness and extraversion as predictors of job performance. They found that conscientiousness and extraversion had greater validities in the prediction of performance for jobs that featured high autonomy. Grant described an experiment in which conscientiousness was shown to moderate the relationship between task significance (a task-based job characteristic) and performance, such that the effect of task significance on performance was stronger for employees with lower conscientiousness. Only one study to date has investigated a Big Five construct as a moderator of the relationship between job characteristics and satisfaction. In that study, deJong et al. (2001) provided evidence that openness to experience moderated the effect of skill variety (a job characteristic) on job satisfaction and that openness was highly related to the oft-studied growth need strength construct. Although research using the Big Five constructs as potential moderators of work design outcomes remains scant, the studies outlined above suggest that personality characteristics may be key components in understanding the relationship between job characteristics and attitudes such as job satisfaction.

By answering the call from Grant et al. (2010), the study conducted for this dissertation sought to make two important contributions to the research literature. First, the study examined conscientiousness as a potential moderator of the relationship between the job design characteristic of autonomy and the outcome of job 
Conscientiousness as a Moderator 6

satisfaction. As such, it followed the recommendation from Grant et al. (2010) and Morgeson and Humphrey (2006) to consider the moderating potential of the Big Five in job design research. Second, my study tested specific hypotheses regarding the interaction using both the global construct of conscientiousness and the narrower subtraits — or facets - that exist underneath the broader traits. Research into the facets of the five factor model has been gaining some steam recently (e.g., Dudley, Orvis, Lebiecki, \& Cortina, 2006; Judge, Heller, \& Mount, 2002; Major, Turner, \& Fletcher, 2006); still, studies are quite sparse, especially when compared to the volumes of research that examine the Big Five at the global construct level. Each of the researchers cited above has called for increased research into the facets of the Big Five and this dissertation answers their calls as well.

Person-Environment (PE) Fit as a Mediating Mechanism.

Cable and DeRue (2002) suggested that further research is necessary on the antecedents of PE fit perceptions. The second set of hypotheses in the study conducted for this dissertation involved perceptions regarding PE fit as a mediating mechanism, which sought to explain how the autonomy x personality interaction affects job satisfaction. These hypotheses attempted to fill the gap in the PE literature noted by Cable and DeRue.

On a more theoretical level, examining PE fit as a mediator is important because it integrates two theoretical perspectives that have existed relatively independently of each other. The PE fit literature is based on the notion of commensurate measurement, which suggests that variables in the person domain and 
variables in the environment domain must be measured using the same constructs in order to analyze the degree of misfit between the person and environment (Edwards, Caplan, \& Van Harrison, 1998). However, most studies that include the examination of interactions (e.g., Barrick \& Mount, 1993) use non-commensurate measures, which focus on variance in the criterion explained by the interaction, but do not explicitly measure fit on commensurate dimensions. Studies that collect and analyze P and E variables on commensurate dimensions fall under the auspices of PE fit theory, while those that hypothesize more general interactions between a personality characteristic and an environmental variable cannot be explained through a direct application of PE fit theory. The study conducted for this dissertation adds to the literature by using a form of fit on commensurate dimensions as a mediator of an interaction on noncommensurate dimensions.

\section{Contributions of This Dissertation to Practice}

The study was conducted with the intention of providing practical applications as well. In a recent commentary on job design research, Oldham and Hackman (2010) noted that the original job characteristics model was built on the assumption that jobs could be described as a set of tasks relatively independent of their context within the organization. They also noted that the nature of work has changed, and suggest that the modern workplace is characterized by increased flexibility, inconsistency, complexity and change. An example of the increased flexibility of the modern workplace is the notion of job crafting, which suggests that while jobs may be described as a series of tasks and activities, employees often have the latitude to define 
Conscientiousness as a Moderator 8

and enact the job by extending the boundaries of their job tasks and their on-the-job relations (Wrzesniewski \& Dutton, 2001). Moreover, as I-O research continues to include professional and managerial jobs and jobs featuring knowledge-oriented outputs, each of which features varying levels of autonomy and latitude, it may be time to move on from the idea that jobs are nothing but a collection of tasks.

On a practical level, if the interactions hypothesized in the study were supported, it would have suggested that managers and employers may be able to individually "tune" existing job characteristics such as autonomy to complement the individual differences in worker personalities so as to create a more satisfying workplace.

\section{Person-Oriented Work Psychology}

In addition to filling gaps in the research literature, the study conducted for this dissertation is also in keeping with the call from Weiss and Rupp (2011) for continued person-oriented research in I-O psychology. Weiss and Rupp contrast what they call the prevailing paradigm in I-O psychology (which they suggest is centered on outcomes of interest to the organization) with the possibility of research that focuses squarely on the individual experiences of work and outcomes that are relevant to the individual rather than the organization. They describe the prevailing paradigm in terms of two key elements. First, they suggest that the current paradigm is based on the between-entities assumption, which they describe as the "belief that explanation is best accomplished when properties are assigned to people and the association of those properties is examined" (p. 85). In the prevailing paradigm, they propose, individuals 
Conscientiousness as a Moderator 9

are described in terms of collections of variables or dimensions, which are then analyzed in a between-subjects framework. In the analysis of the associations among these variables, differences in the core experiences of individuals-differences in the individuals themselves — are lost. The second element of the prevailing paradigm, according to Weiss and Rupp, is the collective purpose agenda. They suggest that I-O psychology has generally been concerned with research that views people (or rather, variables and behaviors) as mere things that can either help or hurt the organization. Taken to the extreme, their view implies that the collective purpose agenda denies the humanity of individuals in favor of a collection of good and bad personality traits, as well as positive and negative behaviors. In this extreme view, selection is the process of acquiring things that will help the organization, and management is the process figuring out how to align those things to the larger goals of the organization.

It is important to point out, as Weiss and Rupp do, that not all research in I-O psychology views the collective purpose as central. Occupational health psychology, for example, is often concerned with the effect of the workplace on the individual and the justice and application reactions literatures often take a person-centered approach to inquiry. However, it is also true that within each of these topics, a large body of work exists that is primarily concerned with the effect of these individual personcentered outcomes on organization-centered outcomes for organization-centered purposes.

While this study does not address all aspects of their suggested person-centered approach—for example, it still features the between-entities assumption—it is in the 
Conscientiousness as a Moderator 10

spirit of their call for research that focuses on the lived experience of individuals. First, the central outcome of interest is individuals' satisfaction with their work environment as an end itself. In keeping with the philosophy articulated by Weiss and Rupp, job satisfaction is a worthy outcome because it represents an overall appraisal of the work environment resulting from the individual's lived experience. Barring this philosophical position, job satisfaction is also important because it is antecedent to several beneficial outcomes for the organization, which enables us to "have our cake and eat it too". Prior research has shown strong links using meta-analytic methods between satisfaction and outcomes beneficial to the organization such as motivation, citizenship behaviors, intentions to leave the organization, absenteeism, turnover, lateness, and both objective and subjective performance criteria (Kinicki, McKeeRyan, Schriesheim, \& Carson, 2002).

Second, the objective of this dissertation as a whole was to show that a) job satisfaction is produced via an interaction between an individual's personality and the characteristics of the environment and b) individuals' perceptions regarding their subjective fit with the environment mediate that relationship. The description of individuals in terms of their differences on personality traits and facets, and the use of the construct of job satisfaction as a stable descriptor of an unstable phenomenon, retains a bit of the between-entities assumption that has characterized the prevailing paradigm according to Weiss and Rupp (2010). However, this study focuses on the individual's subjective perceptions of their environment and is in keeping with recommendation for a more person-centered approach because it focuses on the 
Conscientiousness as a Moderator 11

individual's subjective perceptions of their environment.

Overview of the Dissertation

The dissertation proceeds as follows. In Chapter Two, I explore the history of research into work design and its relationship with outcomes such as job satisfaction. I also highlight the utility of using the Work Design Questionnaire (Morgeson \& Humphrey, 2006) and suggest autonomy as a key job characteristic. I chose autonomy as a key job characteristic because it has a long history in the job design literature, and evidence suggests that it is the most important work characteristic across a wide array of jobs (Lohar et al., 1985). In Chapter Three, I describe past research into the five factor model of personality as the dominant personality taxonomy in I-O research and note some potential challenges to its continued use. I then explore the use of facets in current research and suggest that focusing on sub-traits at the facet level may alleviate some of these challenges. Finally, I provide evidence of the relationship between conscientiousness and job satisfaction, and suggest that situational specificity may exist in these relationships. In Chapter Four, I suggest trait activation (Tett \& Burnett, 2003) as a potential theoretical explanation for why the Big Five should moderate the relationship between autonomy and job satisfaction. I then explore two types of person-environment fit—person-autonomy fit and person-job fit—as additional constructs that are relevant to the joint effect of autonomy and personality on job satisfaction. Finally, I suggest that person-autonomy fit provides a mediating mechanism by which the effect of the autonomy $\mathrm{x}$ personality interaction on both job satisfaction and person-job fit can be understood. In Chapter Five, I provide two sets 
Conscientiousness as a Moderator 12

of hypotheses and research questions. The first set provides predictions regarding the interaction between autonomy and the facets conscientiousness on job satisfaction and person-job fit. The second set predicts that person-autonomy fit will mediate the paths between the personality $\mathrm{x}$ autonomy interaction and the outcomes of job satisfaction and person-job fit. Chapter Six describes the study design, explains the measures used, and outlines the participant recruitment strategy. Chapter Seven provides the core hypothesis tests and also several supplemental and exploratory analyses to further examine the relationships among variables collected for this study Finally, Chapter Eight provides a general discussion of the results and their implications for both research and practice in the field of I-O psychology, followed by a discussion of the potential limitations and suggestions for future research. 
Conscientiousness as a Moderator 13

\section{Chapter 2: Work Design}

The purpose of this chapter is to describe existing research into work design and its associated outcomes. I start by providing a brief history of work design research including the job characteristics model (Hackman \& Oldham, 1975) and alternative approaches to studying work. I then discuss the role of individual differences in the job characteristics model and describe research that both supports and fails to support interactions between individual differences and job characteristics in predicting important work outcomes. Next, I discuss the movement toward an interdisciplinary model of work design and the arrival of the Work Design Questionnaire (Morgeson \& Humphrey, 2006). Finally, I argue for the importance of the construct of autonomy and its relationship to job satisfaction.

History of Work Design

The history of work design began with the efficiency-oriented approaches of Taylor (1911) and Gilbreth (1911), who were responsible for creating scientific management, a work design approach characterized by a focus on work specialization and simplification (Morgeson \& Campion, 2003). The evolution of scientific management was concurrent with the introduction of the assembly line, and one could argue that scientific management tended to treat people as machines. Unfortunately, according to Morgeson and Campion, these approaches led to work that was designed to be repetitive, boring and tedious, in order to reduce worker distraction and to realize small but cumulative organizational gains in efficiency. Hackman and Lawler (1971) noted that the overall expectation of the scientific management approach was that 
Conscientiousness as a Moderator 14

organizational profits would be enhanced by creating simplified jobs that could be performed efficiently and would require less skill from the employee, thus increasing management's control over production rates and quality. Hackman and Lawler reviewed the research literature on scientific management and noted that jobs comprised of simple, routine tasks led to increased turnover and absenteeism and decreased employee satisfaction. Thus, whatever organizational gains in efficiency that might have been produced by scientific management were offset by poor individual outcomes (Humphrey, Nargahng, \& Morgeson, 2007).

\section{Job Enlargement}

Taking note of the failures of scientific management to produce the hypothesized organizational gains, researchers began to examine the effects of job enlargement on worker productivity. At the time, the concept of job enlargement referred to interventions that gave workers relatively more control over their work pace, greater responsibility for quality control, the ability to repair their own mistakes, and greater control over their choice of work method (Hulin \& Blood, 1968). I use the word "relatively" because the types of work on which job enlargement focused tended to be assembly line jobs that had already been specialized and simplified in accordance with principles of scientific management. As noted by Oldham and Hackman (2010), work at the time was often a linked series of specific tasks undertaken within a well-defined organizational structure. A series of case studies in the 1960s provided some initial indication that the introduction of enlarged jobswhich were seen as generally more meaningful and challenging—led to increased 
Conscientiousness as a Moderator 15

worker productivity and satisfaction (Hackman and Lawler, 1971).

Hulin and Blood (1968) reviewed this series of studies and provided a scathing critique of their methodology. They concluded that the studies "do not support the hypothesis that job size and job level is positively correlated in general with job satisfaction" (p. 53), and suggested that individual differences must be taken into account when examining job enlargement. It is important to note two elements of their article. First, at the time of their review, the notion that job enlargement led to increases in satisfaction and performance was well accepted in the research literature and their review can be read as a defense of at least some of the initial principles of scientific management. Second, and most important for the purposes of this dissertation, the review suggests that there exist several possible individual differences that could influence whether enlarged jobs are satisfying and motivating to the worker. Hulin and Blood referenced two studies that suggest that some employees found simple and repetitive tasks satisfying: Argyris (1959) suggested that employees with lower skill levels tended to be associated with a desire to experience routine and sameness, while Walker and Marriot (1951) indicated that some assembly line workers liked their work because it was simple and carried no responsibility. Job Characteristics Theory and the Job Diagnostic Survey (JDS)

Partially in response to the criticisms articulated by Hulin and Blood (1968), researchers (e.g., Hackman \& Lawler, 1971; Hackman \& Oldham, 1975; Turner \& Lawrence, 1965) began to develop better measures of job characteristics and sought to articulate theories regarding the psychological mechanisms that would make enlarged 
jobs more motivating and satisfying to employees. Prior to this work, the concept of job enlargement was driven primarily by motivator-hygiene theory (Herzberg, 1966), also referred to as two factor theory. Briefly, two factor theory divides aspects of work into two classes or factors: motivators and hygienes. Motivators include aspects of work that are intrinsic to the job such as recognition, challenge, responsibility and opportunity for advancement. Hygienes refer to aspects of work that are extrinsic to the job and include work conditions, pay, company policies and peer/supervisor relationships. Herzberg contended that the two motivating factors were differentially associated with employee satisfaction. Specifically, motivators influence satisfaction in a positive direction while hygienes would only serve to decrease dissatisfaction. Thus, according to the theory, increasing pay or providing a better work environment (hygienes) may lead to employee satisfaction, however it would only do so by decreasing the level of their dissatisfaction. On the contrary, according to the theory, providing more recognition or responsibility on the job provides increases in satisfaction through intrinsic motivation to satisfy higher-order needs.

While motivation-hygiene theory was instrumental in leading to later formulations of job characteristics theory, research has generally not supported its basic assumptions (Morgeson \& Campion, 2003), and criticisms have been mostly on methodological grounds. For example, one of the most salient criticisms of motivatorhygiene theory is that the results are an artifact of the critical incidents technique used to collect the data (Dunnette, Campbell, \& Hakel, 1967). In a similar vein, Schneider and Locke (1971) challenge the theory on the grounds that the results stem from the 
classification system used to describe the work events. Both cases provide strong evidence that the results supporting the theory are based on methodological artifacts.

Later research (e.g., Hackman \& Lawler, 1971; Turner \& Lawrence, 1965;) seized on the notion that the intrinsic characteristics of jobs could be motivating, while acknowledging the insufficiency of motivator hygiene theory. One particular point of contention with motivator-hygiene theory was the insufficient attention paid to individual differences in the needs for workers to experience intrinsic job motivators such as autonomy, recognition and responsibility on their jobs. Hackman and Lawler created a measure of "individual need strength" formulated as the employee's desire for these types of elements in their work, and found that it moderated the motivating effect of job design elements. This concept was later articulated as growth need strength by Hackman and Oldham (1975).

Hackman and Oldham (1975) opined that the redesign and enrichment of jobs had been held back by the paucity of effective strategies for measuring and classifying work design. They developed job characteristics theory and the Job Diagnostic Survey (JDS) to fill this void. Job characteristics theory proposes that there are three critical psychological states that influence positive work and personal outcomes such as high internal motivation, high quality performance, high satisfaction, and low absenteeism and turnover. The psychological states are: experienced meaningfulness of the work, experienced responsibility for work outcomes, and knowledge of the results of one's work. These psychological states are influenced by five core job characteristics: 1) Autonomy refers to the degree to which freedom, independence and 
Conscientiousness as a Moderator 18

discretion in scheduling work and determining procedures. This dimension influences a worker's experienced responsibility for work outcomes. 2) Feedback refers to the degree to which the employee obtains information about his or her performance from the work itself. This dimension influences a worker's knowledge of work results. 3) Skill variety refers to the degree to which a job requires a variety of different activities and the use of a variety of skills. 4) Task identity refers to the degree to which the job supplies a visible outcome to the worker or the degree to which the job requires completion of a whole piece of work. 5) Task significance refers to the extent to which the job has a substantial impact on the lives and work of other people. Skill variety, task identity and task significance influence a worker's experienced meaningfulness of the work. In the original theory, Hackman and Oldham (1975) suggested that the five core job characteristics could be multiplied to arrive at an overall measure of the motivating potential of the job (i.e., the motivating potential score or MPS). One corollary to forming a product of the five terms is that if any single characteristic receives a low score, then the overall motivating potential of the job will also be low.

Recognizing that there may be individual differences in the effectiveness of the motivating potential of the five core job characteristics, Hackman and Oldham (1975) suggested that the effectiveness of work characteristics would be moderated by the strength of the worker's desire to achieve personal growth from work. They called this desire growth need strength (GNS) and theorized that it was a malleable individual difference. Workers who were higher in GNS would derive greater 
Conscientiousness as a Moderator 19

motivation and satisfaction from enriched jobs, while workers lower in GNS would not be affected as much. They then developed the JDS to measure the five core job characteristics, the three critical psychological states, as well as GNS.

Until a recent resurgence in work design research (e.g., Edwards, Scully, \& Brtek, 2000; Humphrey et al., 2007; Morgeson \& Humphrey, 2006), job characteristics theory had been the dominant approach for research on job enrichment and attitudinal outcomes. While some of the tenets of the model have been criticized and have not been supported by research, the five core job characteristics have generally been positively associated with affective outcomes, and to a lesser extent, behavioral outcomes (Morgeson \& Campion, 2003). For example, Loher et al. (1985) provided meta-analytic evidence that each of the five core job characteristics were associated with job satisfaction and estimated their true correlation to be .39 , which is quite high considering the many factors that may lead to job satisfaction outcomes. These findings were replicated by a later meta-analysis which showed even higher correlations between the five job characteristics and measures of job satisfaction, growth satisfaction, and internal work motivation (Humphrey et al., 2007).

However, the role of GNS in moderating attitudinal and behavioral reactions to job design characteristics is questionable. Some meta-analytic research has supported the moderating effect of GNS (e.g., Fried \& Ferris, 1987; Loher et al., 1985). However, Morgeson and Campion (2003) note that these findings involved comparing correlations among high and low GNS workers, which is analytically inferior to treating GNS as a continuous moderating variable. A later meta-analytic study (Tiegs 
Conscientiousness as a Moderator 20

et al., 1992) which employed larger sample sizes and more sophisticated regression techniques failed to replicate the previous findings. Moreover, the relevance and adequacy of need-based explanations has been questioned on theoretical grounds in general, and the construct validity of GNS has been questioned on both theoretical and methodological grounds. For example, Steers and Spencer (1977) challenge GNS on the grounds that the needs for achievement, self-esteem and autonomy, have not been found to be highly related in the past. They also note that little evidence exists regarding the discriminant or predictive validity of the GNS construct.

\section{Individual Differences in the Effectiveness of Job Design}

Johns, Lin Xie, and Fang (1992) found little evidence for the moderating effect of GNS. However, they elected to collapse the five core job characteristics into a single factor and focused their analysis instead on the relationship between the critical psychological states on the one side, and performance and satisfaction outcomes on the other. Similarly, in a large sample study of 6405 participants across a wide range of jobs, Tiegs et al. (1992) found virtually no evidence of the moderating role of GNS as originally specified in the Hackman and Oldham (1975) model. The complexity of the model tested in these two studies—a mediated moderation with five predictors, three mediators, two points of moderation, and both attitudinal and performance outcomes-may provide some insight into why the role of GNS has received inconsistent results as a moderator. While the original job characteristics model specifies that GNS serves as a moderator between job characteristics and critical psychological states, and between critical psychological states and outcomes, newer 
Conscientiousness as a Moderator 21

models in the work design paradigm do not specify such a complicated relationship. Nevertheless, it may be appropriate to conclude that GNS does not function as the Hackman and Oldham model specified.

Researchers have examined several other individual differences as potential moderators of job design on individual outcomes such as job performance and satisfaction. However, research into individual differences other than GNS remains relatively limited given the long history of research into job design. For example, although the five factor model (FFM; McCrae \& Costa, 1992) has been widely accepted as a useful model for capturing individual differences in personality, I am aware of only one study (de Jong et al., 2001) that has examined FFM factors as potential moderators of the job characteristics/outcome relationship.

Vough and Parker (2008) noted that research into individual differences as moderators of job design characteristics has led to inconsistent results, and this conclusion is supported by extant research. Prior to the focus on GNS as a potentially useful moderator, researchers examined several other potential individual differences that may serve as moderators. These include: the role of urban vs. rural background (Turner \& Lawrence, 1965), adherence to middle class norms (Hulin \& Blood, 1968), job involvement (Ruh, White, \& Wood, 1975), and need for achievement (Steers, 1975; Steers \& Spencer, 1977). Evidence of the effect of individual differences in moderating the job characteristics/outcomes relationship was found in some of these studies but not in others, and in some cases moderation was present only for specific outcomes. For example, Steers and Spencer found that need for achievement 
Conscientiousness as a Moderator 22

moderated the effect of high scope jobs (i.e., jobs characterized by larger amounts of the five core job characteristics) on supervisors' ratings of performance but not on organizational commitment, although the direct effect of job scope on organizational commitment was quite strong with a zero order correlation of .42. Moreover, the relationship between skill variety and performance was negative for workers with low need for achievement but positive for workers with high need for achievement, suggesting that there are some cases in which high scope jobs have a negative relationship with important outcomes.

In sum, the role of individual differences in moderating the relationships between job characteristics and outcomes related to attitudes and performance remains unknown, and has been put forth as a critical area for future research. For example, Grant et al. (2010) explicitly call for research into personality as a potential moderator of the relationship between work characteristics and outcomes such as job satisfaction and performance. Moreover, trait activation theory (Tett \& Burnett, 2003) provides a theoretical method by which the moderating potential of personality can be explained. Briefly, the theory suggests that people are most satisfied and productive when their work enables them to express their personality traits. More generally, the theory is based on the assumption that the expression of personality traits is intrinsically rewarding, and work features that offer the opportunity to express traits will be seen as desirable. Although the original focus of their work was aimed at the use of personality testing in selection, the basic tenets of theory should apply equally to work design and its outcomes. 
Conscientiousness as a Moderator 23

Other Approaches to Studying Work

While motivational aspects (which are roughly aligned with the original job characteristics model) of work have been the most often studied in the I-O and management literature, several researchers have also examined other social and contextual work characteristics that have influences on important work outcomes. There are several additional approaches to work design that do not stem from the JCM tradition that are worthy of mention, even though they are not the focus of this dissertation.

Job demands models. One popular family of models common in occupational health and stress research includes the job demands-control model (JD-C; Karasek, 1979), job demands-control-support model (JD-C-S; Johnson \& Hall, 1988), and the job demands-resources model (JD-R; Schaufeli \& Bakker, 2004). These models evolved somewhat contemporaneously with the JCM, although their main focus is on job stressors and their effects rather than on work design per se. Briefly, the JD-C model suggests that work stress results from the interaction between job demands (workload demands placed on the individual) and job control (authority over decisions and skill discretion), with the most stress resulting from jobs that have high demands and low control. The JD-C-S adds social support as another potential buffer of strain produced by high demands and high control. The JD-R focuses primarily on the independent effects of job demands and resources in producing the psychological states of burnout and disengagement (Grant et al., 2010). These models are all similar in that they view stress as a product of an interaction between some class of on-the-job 
Conscientiousness as a Moderator 24

stressor (e.g., time pressure, workload, role ambiguity) and some class of resource, whether the resource is considered an individual characteristic (e.g., resilience, coping style) or an environmental feature of the job (e.g., control, social support). Moreover, each model suggests that there is an interaction effect such that the effect of high levels of stressors on strain can be buffered by commensurately high levels of resources.

Sonnentag and Fried (2003) indicated that research generally supports the main effects of these models - that is, high levels of job demands generally produce more stress, and high levels of resources are generally associated with lower stress levels. However, they noted that support for the interaction effect is mixed, with the majority of studies failing to find an interaction. This conclusion is corroborated by de Lange, Taris, Kompier, Houtman, and Bongers (2003), who reviewed 45 longitudinal studies, 19 of which they deemed high quality based on five evaluation factors. Of the 19 high quality studies, only eight displayed an interaction effect between job demands and control on stress outcomes, and in most cases the effects were additive rather than the multiplicative effects hypothesized by the JD-C and JD-C-S models. In spite of the mixed support for the hypothesized interaction, these models offer a useful approach to the study of the effect of job elements on stress and well being. However, their main focus is on the cumulative effect of job stressors which can lead to physical and psychological strain, and are thus not appropriate for this dissertation which is primarily concerned with attitudinal outcomes.

Social information processing approach. The social information processing 
Conscientiousness as a Moderator 25

(SIP) approach views attitudinal outcomes at work as a product of social information and cues rather than as a response to the objective characteristics of the job. In so doing, it emphasizes the effects of the social context at work and the outcomes of previous decisions and actions over individual dispositions and rational decision making processes (Salincik \& Pfeffer, 1978). The SIP was received as a fairly major challenge to the JCM on at least two fronts: First, the SIP attacked the notion of needs (and thus the concept of GNS) as a believable explanation for attitudes and behaviors. Second, the SIP views attitudes and behaviors as the product of a more subjective sense-making "social and personal construction of reality" (Salincik \& Pfeffer, 1978, p. 227), rather than either internal personal characteristics or external characteristics of the environment. Thus, according to the SIP model, needs and attitudes are byproducts of the social context, and must be interpreted in relation to that social context (Zalesny \& Ford, 1990).

Research throughout the late 70s and early 80s provided mixed support for the SIP model (Morgeson \& Campion, 2003), and these studies tended to be lab-based experimental investigations in which social cues were experimentally manipulated (Zalesny \& Ford, 1990). For example, one study examined the interaction between enriched tasks and social information cues on affective outcomes, and found that both social cues and aspects of the work environment were important influences on affective outcomes (Griffin, Bateman, Wayne, \& Head, 1987). Moreover a series of studies conducted by Oldham and colleagues examined the role of social comparisons in determining worker satisfaction and found that social comparisons influence worker 
Conscientiousness as a Moderator 26

satisfaction, employees tend to select more complex jobs as their referents, and employees who felt equitable or advantage in relation to others tended to have lower absenteeism and turnover (Morgeson \& Campion, 2003). Zalesny and Ford reviewed 27 studies and found consistent support for the effect of social information on satisfaction, although no other outcome was consistently supported throughout the studies reviewed. Results such as these led Grant et al. (2010) to conclude that while social cues have effects on attitudes and behaviors, they are generally weaker than the effects of the job itself. Morgeson and Campion (2003) draw four additional conclusions with regard to job attitudes: 1) Attitudes are influenced by social cues; 2) workers compare their jobs to others and these comparisons affect job attitudes; 3 ) task characteristics seem to be more important than social information in forming job attitudes; and 4) social information primarily influences job attitudes, while task characteristics influence both attitudes and behaviors.

These results suggest that SIP may provide insight into the role of social contextual features in the formation of job attitudes. However, the JCM and other task-based approaches offer a far more practical approach to studying work because they allow for interventions that have the potential to provide beneficial effects on attitudes and performance. Furthermore, setting aside the need-based underpinnings of the JCM (i.e., GNS), the basic tenets of the SIP are not in conflict with task-based work design models and thus may be considered an adjunct to, rather than a replacement for, task-based job measurement strategies. Beyond the Job Characteristics Model: Multi-Disciplinary Approaches 
Conscientiousness as a Moderator 27

After a significant lull, job design has received renewed attention in recent years, leading to new paradigms in job design research, including more robust contextual models of work that attempt to combine several models into a multidisciplinary approach. In a recent commentary on issues in job design research, Oldham and Hackman (2010) noted that the renewed interest in work design can be attributed to the fact that "the very phenomena being studied are changing" (p. 465). They argued that their original job characteristics model was developed at a time when the primary focus of work design research was on jobs that could be broken down into specific, linked tasks performed by independent workers in bounded organizations. Recent job design research, however, has expanded the focus to include more complex, professional and managerial jobs, which are no longer treated as collections of work tasks. Moreover, they contended that work in general has changed, and noted that work today involves much more flexibility, social interaction, inconsistency, and change.

One example of this increased attention to the flexibility of the modern workplace is the notion of job crafting, which suggests that while jobs may be described as a series of tasks and activities, employees often have the latitude to define and enact the job by extending the boundaries of their job tasks and their on-the-job relations (Wrzesniewski \& Dutton, 2001). Job crafting is an offshoot of earlier work by Ilgen and Hollenbeck (1991), which suggests that research should move away from viewing jobs as a series of tasks, and toward the notion of work as the enactment of a role. Instead of a simple and straightforward collection of tasks, roles include 
Conscientiousness as a Moderator 28

informal, contextual, and emergent elements that may work either in contrast or in combination with assigned tasks. In short, modern research into work design has recognized that employees do not necessarily passively enact the jobs they are assigned to do, but may take the initiative to alter their own jobs and roles (Grant et al., 2010).

Perhaps presaging the modern expansion of work roles, Campion (1988) attempted to combine the several extant job design perspectives into an interdisciplinary job design framework with four factors. He classified work design approaches into motivational, biological, perceptual, and mechanistic strategies and demonstrated that each approach could be associated with a specific set of outcomes. He then concluded that the different approaches to job design influence different outcomes, that each had its own costs and benefits, and that job design needed to be approached from an interdisciplinary perspective. Edwards et al. (2000) reanalyzed and replicated the initial findings of Campion using structural equation modeling. However, they also expanded the framework to include 10 factors, instead of the four originally specified by Campion. The researchers found that the strength of the relationships between work design approaches and their attendant outcomes were strengthened when measurement error was removed, and also found that certain work design approaches were beneficial for some outcomes but detrimental for others. For example, whereas the motivational approach focuses on skill development, the mechanistic approach focuses on simplification, which decreases the skill required to perform a job (Edwards et al., 2000). 
Conscientiousness as a Moderator 29

Studies such as these led to an increasingly multi-contextual approach to work design, which culminated with the Work Design Questionnaire (WDQ; Morgeson \& Humphrey, 2006). The WDQ has effectively replaced the JDS in much recent research. Morgeson and Humphrey cited three reasons for developing the WDQ. First, they indicated that they wanted to find a middle ground between the specific task measures (such as those measured by Hackman \& Oldham, 1975) and the much more generalized attribute oriented measures (e.g., Peterson, et al., 2001), which attempt to describe jobs using broad strokes. Second, they noted that the potential of redesigning jobs is limited by the range of job characteristics measured, and suggested that some of the tradeoffs observed in the job design literature (e.g., those indicated by Campion, 1988 and Edwards et al., 2000) may be mitigated by considering a wider range of work characteristics. Third, and perhaps most importantly, Morgeson and Humphrey sought to stimulate, extend and integrate work design theory beyond the JCM by offering a comprehensive measure of work characteristics.

The WDQ expands the original five core work characteristics to seven. Task variety, task significance, task identity and feedback from the job are included in the model, but autonomy has been broken into three constructs: work scheduling autonomy, which measures the amount of latitude available in work time and place; decision making autonomy, which measure the latitude available to make important decisions on the job; and work methods autonomy, which measures the latitude available to select from a range of processes to complete a task. These seven constructs were then renamed task characteristics to reflect that they are related to the 
Conscientiousness as a Moderator 30

performance of work tasks rather than broader attributes of the work environment. In addition to task characteristics, the WDQ measures broader attributes of the work environment, which include: knowledge characteristics, such as job complexity and information processing requirements; social characteristics such as social support, interdependence and feedback from others; and work context, such as ergonomics, physical demands and work conditions.

Although Morgeson and Humphrey (2006) put task characteristics and knowledge characteristics into two separate dimensions, and indeed their factor analysis suggests that the two are separate factors, they noted that knowledge characteristics are generally aligned with motivational outcomes. In fact, skill variety, which is one of the factors originally measured by Hackman and Oldham (1975), is located in the knowledge characteristics group. The WDQ thus extends the JDS to include knowledge characteristics, while maintaining a focus on the motivating potential of these characteristics.

Autonomy as a Key Characteristic of Enriched Jobs

In spite of the growing movement toward expanding the work design paradigm to include factors outside of the original JCM, the construct of autonomy remains a core feature of extant research and practical interventions. In their recent review of the work design literature, Vough and Parker (2008) argued that "autonomy is the foundation of most work design research" (p. 20). They cite as examples studies by Karasek (1990), who found that increased control at work had health benefits, and Janz, Colquitt, and Noe (1997), who found that autonomy increased the group 
Conscientiousness as a Moderator 31

effectiveness of knowledge workers. Other studies appear to support Vough and Parker's arguments. For example, Fried and Ferris (1987) provided meta-analytic evidence that autonomy had a larger effect than any other work characteristic in the JCM. Another meta-analysis on 28 studies conducted in the 70 s and early 80 s suggested that the relationship between autonomy and job satisfaction was the highest among the five job design constructs articulated by Hackman and Oldham (1975) with a corrected validity of .46 (Loher et al., 1985). Loher and colleagues also found that GNS moderated the relationship between autonomy and satisfaction such that those with high GNS were more likely to derive satisfaction from highly autonomous jobs. However, Loher et al. used sub-group analysis, which has been challenged by other researchers (e.g., Fried \& Ferris, 1987) as a method insufficient to show the moderating effects of GNS. A study by Barrick and Mount (1993) also showed that autonomy mediated the validities of conscientiousness and extraversion in predicting job performance for managerial jobs. Their results suggested that while conscientiousness and extraversion were related to job performance, in both cases validities were significantly higher for managerial jobs with increased levels of autonomy. Although Barrick and Mount used job performance as the criterion of interest, their results are particularly important for this dissertation because they suggest that autonomy interacts with personality variables to predict workplace outcomes. 
Conscientiousness as a Moderator 32

Chapter 3: The Five Factor Model of Personality and Its Facets

In the preceding chapter I discussed research and theory in regards to job

design. The purpose of this chapter is to develop the Big Five model of personality and its facets as potential moderators of the relationship between autonomy and job satisfaction. I will begin by discussing the origins and development of the Big Five as useful taxonomy of personality, while paying heed to some of the remaining challenges and issues with its use. I will then argue for the use of narrower sub-traits, or facets, in research that uses personality variables as predictors, and describe some benefits to conceptualizing the Five Factor Model as a collection of many narrow facets rather than a few global traits. Finally, I will suggest that conscientiousness and its facets will moderate the relationship between autonomy and job satisfaction and PJ fit.

The Five Factor Model of Personality (FFM)

The overall claim of five-factor theorists is that the Big Five factors are at the very least a necessity for adequately describing individual differences, although they do not go so far as to say that the Big Five traits are all that is needed (McRae \& John, 1992). While there remains some disagreement about the names used to describe each of the five factors, there is rough consensus about the content of each of the five basic factors. McRae and John describe the five factors as Extraversion, which includes such characteristics as warmth, gregariousness, assertiveness, activity and excitement seeking; Agreeableness, which includes such characteristics as trust, straightforwardness, altruism, compliance, modesty and tendermindedness; 
Conscientiousness, which includes such characteristics as competence, order, dutifulness, achievement striving, self-discipline, and deliberation; Neuroticism, which includes such characteristics as anxiety, hostility, depression, selfconsciousness, impulsiveness, and vulnerability; and Openness which includes such characteristics as fantasy, aesthetics, feelings, actions, ideas and values. History

The origins of the FFM stems from the lexical hypothesis (Galton, 1884), which suggests that any meaningful difference in personality will be coded into language, and that a comprehensive taxonomy of personality could be created by analyzing these linguistic descriptors. In 1934, Thurstone suggested that a list of adjectives he had created to describe personality could be reduced to five factors. Around this time, a study was also conducted by Allport and Odbert (1936), which identified over 4500 English adjectives that could be used to describe personality traits, and these adjectives formed the basis of later work by Cattell and colleagues (e.g., Cattell, Marshall, \& Georgiades, 1957) who used the then new technology of factor analysis to empirically derive factors from data obtained using personality test items written from the list. The result of this work was the 16PF Personality Questionnaire. Later researchers (e.g., Norman, 1963; Tupes \& Christal, 1961) used Cattell's original trait measures and obtained five factors, rather than Cattel's 16. Following these discoveries, the notion that traits could be used to predict human behavior fell out of favor, and research instead focused on environmental and situational predictors of behavior (Digman, 1990). 
Conscientiousness as a Moderator 34

Trait-based personality research largely languished until it was picked up again in earnest during the 80 s by researchers. For example, Goldberg (1981) performed his own lexical analysis and arrived at a set of five factors similar to those derived by researchers in the 60s, which he dubbed the "Big Five" dimensions of personality (Digman, 1990). As Digman pointed out, although there was reasonably strong agreement at the time that there were five basic factors, there was less agreement regarding the best way to interpret each of the factors, and the factors were frequently referred to as Dimensions $\mathrm{I}-\mathrm{V}$. The difficulty in interpreting the factors comes primarily from the arbitrary nature of exploratory factor analysis (EFA), which provides information about the strength of the covariance among items, but does not provide any indication of the logic behind their covariance. This difficulty in interpretation is particularly pertinent for conscientiousness (then known as Dimension III), which appears to contain indicators that suggest orderliness and dutifulnesselements most closely aligned with the dictionary definition of conscientiousness. However, "Dimension III" also contains indicators that suggest the drive or motivation to succeed. As Digman noted, some personality theorists interpreted this dimension as Will to Achieve, which appears, at least intuitively, to capture a different construct or set of constructs than those related to orderliness and dutifulness. The issues will become more relevant as the facet level constructs are discussed later in this chapter. In a series of studies designed to determine markers of the Big Five factors, Goldberg (1990) demonstrated the generality of the five factor model by obtaining virtually identical factor structures across a wide variety of factor analytic techniques, 
Conscientiousness as a Moderator 35

lexical analysis strategies, and several samples of self- and peer ratings. Based on these analyses, Goldberg suggested that "it now seems reasonable to conclude that analyses of any reasonably large sample of English trait adjectives in either self- or peer descriptions will elicit a variant of the Big Five factor structure, and therefore that virtually all such terms can be represented within this model" (p. 1223). Moreover, the five factor structure has been shown to generalize across cultures, measures, and rating sources (McCrae \& John, 1992).

While research using the FFM to predict a wide range of outcomes flourished in the 90s, the FFM was also emerging as the dominant model of explaining personality in I-O psychology. The origins of this emergence can be traced back to a meta-analysis published in 1991 by Barrick and Mount on 231 criterion-related validity studies showing the effectiveness of the model in predicting job performance and training proficiency across a wide range of jobs. Specifically, Barrick and Mount linked each of the five factors in the FFM to relevant workplace outcomes such as supervisor ratings of job performance, training proficiency, and other objective indicators of performance such as salary level and tenure. They then averaged the validities of the FFM across all the criteria and arrived at the following corrected validity coefficients (in descending order of magnitude): conscientiousness $(\rho=.22)$, extraversion $(\rho=.13)$, neuroticism $(\rho=.08)$, agreeableness $(\rho=.07)$, and openness to experience $(\rho=.04)$. This meta-analysis was critical for selection research because it provided strong evidence that such factors as conscientiousness and extraversion could be used as efficient and inexpensive predictors of workplace performance. The importance 
Conscientiousness as a Moderator 36

of the FFM for selection research was further cemented when Schmidt and Hunter (1998) provided meta-analytic evidence that FFM variables such as conscientiousness provided incremental validity over $g$ in predicting job performance. Research at the close of the decade showed that Big Five traits predicted 36\% of variance in job success 30-50 years after personality was assessed (Judge, Higgins, Thoresen, \& Barrick, 1999), suggesting that personality constructs are stable measures of performance throughout one's career.

Later research after the turn of the century showed that Big Five traits were useful in predicting outcomes across a wide range of jobs, situational contexts, and outcomes (see Hough \& Oswald, 2008 for a detailed listing of major findings). In addition to the results of the studies performed in the 90s, Big Five traits have been shown to predict various types of job performance, including: overall and objective job performance (Barrick, Mount, \& Judge, 2001; Dudley et al., 2006), training performance and skill acquisition (Barrick et al., 2001; Colquitt, LePine, \& Noe, 2000), entrepreneurial status (Zhao \& Seibert, 2006), counter-productive work behaviors (Berry, Ones, \& Sackett, 2007), and creativity and innovation (Feist, 1998), among many others. Also, in the performance domain, Big Five traits have been linked to motivation (Judge et al., 2002) and leadership (Bono \& Judge, 2004). Outside of the performance domain, Big Five traits have also been shown to predict job satisfaction (Judge et al., 2002); subjective well-being (Steel, Schmidt, \& Shulz, 2008); major life outcomes such as mortality, divorce, and occupational attainment (Roberts, Kuncel, Shiner, Caspi, \& Goldberg, 2007); health behaviors and drug use 
Conscientiousness as a Moderator 37

(Bogg \& Roberts, 2004; Roberts et al., 2007); and alcoholism (Cooper-Hakim \& Viswesvaran, 2002).

\section{Challenges to the FFM}

In spite of the wide-spread adoption of the FFM, the model does have its detractors (e.g., Block, 1995; Hough, 1992; Hough \& Furnham, 2003; Hough \& Ones, 2001; Morgeson, Campion, Dipboye, Hollenbeck, Murphy, \& Schmitt, 2007). These challenges fall into at least three categories. First, there are those who challenge the lexical approach to describing personality in general and the atheoretical use of factor analysis to derive the Big Five constructs (Hough \& Ones, 2001). For example, Block (1995) noted that the FFM is rooted in the methodology of factor analysis and challenges the approach as entirely atheoretical. He further noted that "although the method of factor analysis has been used for almost a century, there is still not a clear, unequivocal basis for deciding on the number of 'factors' to extract or to obtain an 'optimum' rotation of the particular factors settled upon" (p. 190). The difficulty in interpreting the factors comes primarily from the arbitrary nature of exploratory factor analysis (EFA), which provides information about the strength of the covariance among items, but does not provide any indication of the logic behind their covariance. Hough and Ones (2001) suggested that the results of factor analyzing linguistic descriptors of personality may lead to nothing more than "folk concepts" (p. 236) rather than psychological constructs derived through rigorous scientific methods.

These methodological issues drive many of the challenges in the second category, which relate to the overall adequacy of the model in describing human 
Conscientiousness as a Moderator 38

personality, including the breadth and number of the factors. For example, Hough (1992) summarized the personality taxonomies of several personality theorists who applied similar factor analytic methods in order to classify linguistic descriptors. The number of factors in these taxonomies varied from nine (Hough, Eaton, Dunnette, Kamp, \& McCloy 1990) to the six suggested by Hogan (1986), to the original five suggested by Norman (1963). Moreover, these taxonomies were in disagreement about which content domains load onto which factors. For example, Hough et al. (1990) specify the constructs of achievement and dependability as two separate factors, which are combined in several other models (e.g., McCrae, Costa, \& Bush, 1986; Norman, 1963) to form the Big Five construct of conscientiousness. Similarly, Hough et al. specify the constructs of affiliation and potency which are combined into the Big Five construct of extraversion in the Norman model and the McCrae et al. model. The Hogan model, on the other hand, combines the potency construct (which is considered by the Big Five to be part of the conscientiousness construct) and achievement construct (which is considered by the Big Five to fall on the extraversion construct) into a different construct called ambition. In short, in spite of the fairly widespread acceptance of the Big Five taxonomy, it remains impossible to specify a final number of criteria based on the use of exploratory factor analysis.

The FFM has also been criticized as non-comprehesive and insufficient to describe the multitude of possible personality variables (Hough, 1992; Hough \& Furnham, 2003; Hough \& Ones, 2001). Hough and Furnham cite sixteen personality variables that are not included within the Big Five taxonomy, which include variables 
Conscientiousness as a Moderator 39

such as rugged individualism, aggression and hostility, social adroitness and social insight, religiosity, villainy, orthodoxy, egotism, snobbery, aesthetic sensitivity, and positive and negative valence (c.f., Hough \& Furnham, 2003 for a complete list of personality variables and research supporting their inclusion in personality taxonomies). Moreover, Hough and Furnham suggest that the FFM confounds narrower personality constructs, merging constructs that are too heterogeneous to be included within the same construct. They specifically attack the Big Five factors of conscientiousness and extraversion as overly heterogeneous and suggest that they should be split into at least two constructs each, which is consistent with the evidence noted in the preceding paragraph. They suggest that the use of the Big Five facets in research may help with this confusion.

The third category challenges the utility of the model and personality testing in general for predicting workplace outcomes, especially in the context of personnel selection. Morgeson et al. (2007) argued that the continued use of personality tests for selecting employees needs to be reconsidered for two primary reasons. First, the validities cited for the effectiveness of personality variables in predicting work place performance are extremely low and these validities are corrected for range restriction, as well as unreliability in both the predictor and the criterion domains, which, according to Morgeson et al., leads to an inflated and misleading conclusion regarding the utility of personality measures. Their challenge makes sense when one considers that the highest validity found in the Barrick and Mount (1991) meta-analysis was for conscientiousness $(\rho=.22)$, indicating that conscientiousness accounts for only $4 \%$ of 
the variance in job performance. Moreover, this validity was highly corrected. The uncorrected validity is $\rho=.13$, which suggests that conscientiousness accounts for only $1.7 \%$ of the variance in job performance. The second reason relates to the possibility that applicants may intentionally distort their answers on personality inventories in order to appear more desirable as candidates. The issue of faking on personality tests remains highly controversial, with some researchers suggesting that faking is problematic and widespread (e.g., McFarland \& Ryan, 2000; Ross, Stecher, Miller, \& Levin, 1998), and others suggesting that faking is rare and/or unimportant to the observed validities of personality tests (Ellingson, Sackett, \& Connelly, 2007; Hogan, Barret, \& Hogan, 2007). Several researchers (e.g., Tett \& Christianson, 2007; Ones, Dilchert, Viswesvaran, \& Judge, 2007) disagreed with the statements of Morgeson et al., citing meta-analytic evidence of the utility of personality instruments in predicting workplace performance.

While the controversies related to the use of personality testing in selection contexts are important for practitioners and researchers in the selection domain, they are less important for the purposes of this dissertation. For example, part of the controversy involves the use of corrected validity coefficients, which is relevant when observed test scores are used to predict workplace criteria, but less relevant when researchers are interested in understanding the relationships between constructs such as personality and satisfaction. However, in their response to Morgeson et al. (2007), Tett and Christianson (2007) indicate that a key element in understanding metaanalytic results is the $S D \rho$ statistic, which represents the degree to which the validity 
( $r$ ) varies across studies. They suggest that the presence of a wide $S D \rho$ indicates situational specificity, and can be used to estimate the variability in validity across situations. They conclude that greater attention should be given to the interaction between the personality variables and performance for specific jobs and specific criteria. Although this dissertation is focused on personality as a moderator in the prediction of job satisfaction rather than its use in predicting performance, the notion that the association between personality and workplace criteria varies according to the situation is critical to understanding how personality might moderate the relationship between autonomy and satisfaction.

\section{The Facets of the FFM}

I have suggested that the challenges to the FFM on the basis of its utility in predicting workplace performance are largely irrelevant to the purpose of this dissertation, but the confusion over the proper bandwidth and number of factors is harder to ignore. One solution is to retain the organizational structure of the FFM, while focusing on the personality facets which are sub-traits of the five global factors, with a much narrower bandwidth. Indeed, some of the most vocal critics of the FFM (e.g., Hough \& Furnham, 2003) have called for increased use of the facets in I-O research, although there remains relatively few studies that employ these narrower sub-traits. When facets are utilized, the Big Five factor structure becomes hierarchical - the five global factors exist at the top of the hierarchy, and various lower level personality facets or subcomponents exist below the global factors (Costa \& McCrae, 1995). 
Conscientiousness as a Moderator 42

Arguing against the broad Big Five factors, Hough and colleagues suggested that the Big Five is inadequate because the factors consist of components that are differentially related to criteria (Hough \& Ones, 2001). For example, Hough and Ones cited research supporting the separation of the factor of conscientiousness into dependability and achievement constructs (e.g., Hough, Ones \& Viswesvaran, 1998; Vinchur, Shippmann, Switzer, \& Roth, 1998), and extraversion into the constructs of surgency, which reflects concepts such as assertiveness and activity, and affiliation, which reflects the concepts of warmth and gregariousness (e.g., Hough, 1992; Hough et al., 1998). Additionally, researchers have challenged the content of the Big Five factors as overly heterogeneous (Hough \& Ones, 2001; Hough \& Oswald, 2008), and there appear to be some similarities among facets of different Big Five constructs. For example, the facets of conscientiousness (as described by Costa \& McCrae, 1995) include the construct of achievement striving, which appears intuitively to be more similar to the facet of assertiveness found under the extraversion factor, than such facets as dutifulness and deliberation found under the conscientiousness factor. In keeping with this line of reasoning, Paunonen, Rothstein, and Jackson (1999) suggest that the best constellation of predictors may be selected narrow facets of several of the higher order factors, rather than all of the facets of one of the Big Five. The differences in the conceptualization of the broader factors can thus be largely ignored when facets are used. This is because the researcher is free to select the narrower subtraits that are theoretically linked to relevant outcomes regardless of the global factor to which they are thought to belong, thus sidestepping much of the controversy 
regarding how best to conceptualize the Big Five.

In addition to resolving issues regarding the structure of the Big Five, the use of facets may also improve the predictive utility of personality measures. However, at this time there remains little research that definitively suggests whether a broad or narrow bandwidth approach is more appropriate and useful. For example, Ones and Viswesveran (1996) maintain that broad personality factors are preferable to narrow facets in the prediction of broad and complex criteria, such as job performance. Although not specifically addressed by Ones and Viswesvaran, it can be assumed that the same recommendation could be applied to such criteria as job satisfaction because the criterion domain is also broad. Costa and McCrae (1992) indicated that the inclusion of facets underneath the global factors is desirable in order to measure specific traits with greater fidelity. Paunonen et al. (1999) suggest that narrow predictors, such as Big Five facets, may be the best predictors even when broad criteria are used because the facets may account for unique variance not explained by the higher order factors. Additionally, as suggested by the principle of correspondence (Ajzen \& Fishbein, 1977), narrow facets should also be more powerful in predicting narrow criteria. This makes them particularly useful in the study conducted for this dissertation because the WDQ provides narrow measures of work characteristics.

Although the benefits to using facets are clear, there is some controversy regarding how best to capture the more narrow-bandwidth personality constructs within the Big Five. Goldberg (1997) notes that although there is rough agreement on 
the factor structure of the higher level Big Five factors, there is very little agreement regarding the number and descriptions of the lower level facets, which vary depending upon which conceptualization of the Big Five is used. He cites as examples the AB5C (Hofstee, de Raad, \& Goldberg, 1992), which contains 45 dimensions within its five factor structure, the Revised NEO Personality Inventory (NEO-PI-R; Costa \& McRae, 1992), which specifies six facets below each global factor for a total of 30 dimensions, and the California Psychological Inventory which according to Goldberg implies 30 to 35 facets. Unfortunately, there is little research suggesting which model is most appropriate. However, Paunanon and Ashton (2001) showed that the facets of the NEO-PI-R were more accurate predictors of forty behavioral criteria than the global Big Five factors, which suggests that the model specified by the NEO-PI-R provides useful predictive power at the facet level. A personality measure based on the NEOPI-R will thus be used in the study for this dissertation. Table 1 describes the global factors of the NEO-PI-R with each of their attendant facets.

Research utilizing facets as predictors is much more sparse, and several researchers have called for increased attention to facet level relationships of Big Five traits, such as conscientiousness and extraversion. Dudley et al. (2006) conducted one of the few extant studies using facets to predict workplace criteria rather than the broad behavioral criteria examined by Paunanon and Ashton (2001). They performed a meta-analysis on the usefulness of the narrow traits of conscientiousness in predicting job performance and concluded that the narrow facets are useful provided they are used to predict specific outcomes to which they are theoretically related. It is 
notable that Dudley et al. operationalized conscientiousness as consisting of four narrow traits—achievement, order, cautiousness and dependability—rather than the six originally specified by Costa and McCrae (1995), which also include competence and self discipline. They later indicated that the four facets only accounted for $65 \%$ of the variance in the global conscientiousness factor and suggested that global conscientiousness is broader than the aggregate of the four facets. One wonders whether at least some of the remaining $35 \%$ could be accounted for by the facets of competence and self-discipline, which were not included in the Dudley et al. model. However, these results were consistent with the Paunanon and Ashton (2001) study, which suggested that both the global factors and the facets contributed unique variance to the prediction of behavior.

In another study, Major et al. (2006) investigated whether the Big Five facets and another construct—proactive personality—predicted motivation to learn. They performed hierarchical regression analysis, entering all six facets of extraversion, conscientiousness, and openness to experience in the prediction in step one. The facets of activity and positive emotion (extraversion), ideas and values (openness), and competence, dutifulness, and achievement striving (conscientiousness) were significantly related to motivation to learn, with dutifulness displaying the only negative relationship. After proactive personality was entered in the second step, only positive emotions and competence retained significant relationships with motivation to learn.

Their results suggest two important conclusions. First, the results indicate that 
Conscientiousness as a Moderator 46

there are strong differences between facets in their ability to predict specific criteria, providing further support for the use of facets in research that uses the Big Five.

Second, their research provides support for the existence of important constructs that are not well represented by the Big Five, even when facets are included. Major et al. (2006) found that proactive personality was a composite of nine facets of the Big Five, with at least one facet from each of the five global factors. With respect to conscientiousness and extraversion, proactive personality includes the facets of assertiveness and activity (extraversion) and dutifulness and achievement striving (conscientiousness). However, the nine facets only account for $26 \%$ of the variance in proactive personality, suggesting that the construct is something more than the sum of the Big Five facets (Major et al., 2006). While this finding suggests that proactive personality may describe elements of personality beyond the Big Five, it makes it difficult to use for the current study because it shares variance with the facets of extraversion and conscientiousness, which are the focus of this dissertation.

\section{Conscientiousness and Its Relation to Job Satisfaction}

For the purposes of this dissertation, the Big Five factors of conscientiousness and its facets are the most important due to the likelihood that they will be related to important motivational elements of the WDQ, and because they have been shown to be related to job satisfaction. Conscientiousness is one of the most widely studied of the Big Five, and the global factor has been shown to be positively related to performance across a wide range of jobs with the strongest correlation coefficients of any of the Big Five (Barrick \& Mount, 1991; Barrick et al., 2001). For example, 
Barrick and Mount (1991) averaged the validity of conscientiousness across a wide range of performance criteria, including job performance and training proficiency and arrived at an estimated true score correlation of .22. This study was followed by several additional studies that confirmed the utility of personality in predicting performance based outcomes (e.g., Hough et al., 1998; Tett et al., 1991), each of which showed that conscientiousness was the strongest predictor of performance across jobs. Barrick et al. (2001) meta-analytically summarized these and other metaanalyses into a "meta-analysis of meta-analyses." They estimated that conscientiousness predicted performance across a wide range of criteria (e.g., supervisor ratings, objective performance) and occupations (e.g., sales, professional, skilled, semi-skilled) with estimated true score correlations ranging from .19 to .26 . It thus appears that conscientiousness is a robust predictor of job performance across a number of different performance criteria and occupational classifications.

Most research on conscientiousness as a predictor has been focused on performance criteria, but meta-analytic evidence also suggests that both conscientiousness and extraversion may be useful predictors of job satisfaction as a disposition (Judge et al., 2002). In their study, neuroticism emerged as the strongest and most consistent trait-based predictor of job satisfaction $(\rho=-.29)$, followed closely by conscientiousness $(\rho=.28)$ and extraversion $(\rho=.25)$. The link between neuroticism and job satisfaction is expected, because the construct contains facets related to depression, hostility and anxiety. The link between extraversion and satisfaction is also expected because the construct includes facets related to warmth 
and positive emotions. As Judge et al. note, "one would expect that factors that cause emotionally stable and extraverted individuals to be happy in life would also lead them to be happy in their jobs (p. 534)." It would be interesting to examine whether the facets of extraversion unrelated to positivity, such as gregariousness and assertiveness, were also related to job satisfaction. Unfortunately, there were not enough studies measuring the Big Five constructs at the facet level to figure into the meta-analysis, leading Judge et al. to explicitly call for more research into the relationship between the Big Five and job satisfaction at the facet level.

The relationship between conscientiousness and job satisfaction is also notable, albeit for different reasons. First, there is little in the measure that suggests an intuitive relationship with job satisfaction. Judge et al. (2002) argue from a theoretical perspective that conscientiousness may relate to job satisfaction because conscientiousness represents a general tendency toward involvement in work with a subsequently higher likelihood of obtaining work-based rewards such as increased pay, promotion, and informal recognition. While this makes sense on a conceptual level, there appears to be no research that directly supports this conclusion. Second, the correlations between conscientiousness and job satisfaction showed the highest variance across studies $(\mathrm{SD} \rho=.22)$, with 9 of the 79 correlations suggesting a negative relationship between conscientiousness and satisfaction. Judge et al. suggest that sampling error may explain these vexing results. However, it is also possible that the relationship between conscientiousness and satisfaction depends upon the work context, especially if SD $\rho$ is viewed as a marker of variance due to situational 
Conscientiousness as a Moderator 49 specificity, as Tett and Christianson (2007) have suggested. Work characteristics, such as autonomy, may provide an explanation for some of this observed variance. 
Conscientiousness as a Moderator 50

Chapter 4: Trait-Activation Theory and Person-Environment Fit Theory

In the preceding chapters, I have described the construct of autonomy and its relationship to job satisfaction, and noted the long tradition of investigating individual differences as moderators of this relationship. I have also argued for the use of facets in research using the Big Five; established an argument suggesting that conscientiousness and its facets are related to job satisfaction; and suggested that differences in the work environment, such as the amount of decision latitude and autonomy over work methods, may interact with personality to predict job satisfaction. I now outline trait activation (Tett \& Burnett, 2003; Tett \& Gutterman, 2000) as a possible theoretical explanation for the proposed interaction between personality and autonomy. I then discuss person-environment interaction models, and suggest that person-environment (PE) fit provides a useful set of constructs that may be conceptualized as both an outcome and as a means by which the effect of the autonomy x personality interaction on job satisfaction can be explained. Finally, I argue that a form of perceived PE fit (conceptualized as person-autonomy fit) may mediate the relationship between the autonomy x personality interaction and the more generalized constructs of both person-job (PJ) fit and job satisfaction.

\section{Trait-Activation Theory}

One way to explain the proposed interaction is by using a person-situation interactionist model of personality, which suggests that an outcome is driven not just by personality factors or situational factors, but by the interaction of specific individual differences with specific dimensions of the work environment that are 
Conscientiousness as a Moderator 51

theoretically linked to the outcome of interest. Tett and Burnett (2003) developed the model of trait activation in order to explain how the elements of a situation may provide the opportunity for trait expression, thus eliciting different responses from individuals depending upon the traits they possess. Although this model is used to explain the relationship between personality and job performance, the framework is generalizable to job attitudes as well. As Tett and Burnett note, "the conceptual core of the model is the interactionist process by which personality traits are expressed" (p. 501). This interactionist perspective leads to a nuanced definition of personality that explicitly includes the features of a given situation. In their framework, personality traits are defined as: "intraindividual consistencies and interindividual uniqueness in propensities to behave in identifiable ways in light of situational demands" (Tett \& Gutterman, 2000, p. 398, emphasis mine). In light of this definition, Tett and Burnett highlight five key points relevant to the use of personality in predicting workplace outcomes. The most important among these for the purposes of this dissertation are that a) traits are propensities or latent potentials inherent to an individual that are triggered by the environment, and b) behavioral interpretation of traits is contextdependant and one must consider relevant situational features when attempting to understand the behavioral expression of traits. Although the focus of the trait activation model is on the use of personality in predicting workplace performance, the overall proposition that situations elicit expression of traits can be extended to include attitudinal outcomes, such as job satisfaction as well.

Before proceeding, it is important to point out that the trait activation model is 
Conscientiousness as a Moderator 52

based on something of a postulate regarding the intrinsic value of personality expression. Tett and Burnett (2003) note the long history of treating personality traits as needs or drives, which lead to satisfaction and pleasure when there is an opportunity to express them and dissatisfaction or displeasure when the need to express a personality trait is thwarted. They also note that interpersonal approaches to personality (e.g., Leary, 1957) and circumplex models of personality (e.g., Plutchik, 1997) start with the assumption that the expression of personality traits is fundamental to human nature and the inability to express them leads to anxiety in the individual. Based on these foundations, they put forth the assumption that individuals will be most satisfied with the organizational features (including such things as work tasks, people, and organizational values) that enable the expression of their unique personality traits. This assumption is critical to the hypotheses that will be developed later in this chapter.

Two additional features of the model are the concepts of situation strength and situation-trait relevance. Situation strength refers to the magnitude with which a given situation demands specific behaviors, whereas situation trait relevance refers to which traits will be activated by situational demands. Consider, for example, a typical classroom scenario in a large lecture hall at a university. In most universities, the norm for large lectures is for the instructor to provide information by talking and for the students to passively receive that information, without a lot of social interaction or activity on their part. The situation is fairly strong in terms of the expectations regarding social interaction during class-it is understood that, in general, a lot of 
Conscientiousness as a Moderator 53

activity and gregariousness is not acceptable within the context of the situation. The situation is thus strong in relation to the trait of extraversion, and exerts pressure on highly extraverted people to act in a more introverted manner. In this way, the demands of the situation suppress the expression of differences in extraversion because the expected behavior (to remain silent and passive) is homogeneous and the situational influence is fairly strong. Now imagine the instructor leaves for a few minutes and tells the students to "talk among themselves about the material." The strength of the situation vis a vis extraversion has now been largely eliminated, and students now have the latitude to express their individual differences in extraversion. Those who are highly introverted will be more likely to sit quietly and study by themselves, while those who are highly extroverted will be more likely to actively engage in animated discussion.

As Tett and Burnett (2003) suggest, the strength of a situation should impact the ability of a personality trait to predict a given job performance criterion, because strong situations limit the expression of individual differences in behavior. Trait relevance also impacts the ability of a personality trait to predict job performance, simply because not all traits are relevant for predicting behavior in all situations. In order to extend this model to job satisfaction, one needs to include the assumption (discussed above) that people find the expression of traits intrinsically rewarding. With this assumption in mind, one might conclude that highly extraverted students would find the lecture hall unsatisfying because the situation does not enable them to express their natural inclination toward active and gregarious behavior. More 
Conscientiousness as a Moderator 54

introverted students, on the other hand, should be more satisfied with the lecture hall scenario because the type of behavior demanded by the situation (to remain silent and passive) is more in line with their natural tendencies.

\section{Person-Environment Fit}

At its most basic level, person-environment (PE) fit theory suggests that outcomes such as stress or dissatisfaction result from a misfit between the characteristics of a person and the characteristics of an environment (Edwards, 1996). The larger class of PE fit content domains includes person-organization (PO) fit, person-group (PG) fit, person-supervisor (PS) fit, in addition to person-job (PJ) fit. While each of these elements of fit is important to conceptualizing the interactive relationship between the person and the work environment, $\mathrm{PJ}$ fit is most relevant to this dissertation because it attempts to describe the degree of fit between a person and the unique tasks of the job itself-which is the focus of my study. Edwards (1991) defined PJ fit as the fit between the abilities of the person and the demands of a specific job or the desires of a person and the attributes of the job. Kristof (1998) offers a slightly more general definition of PE fit as it pertains to organizations, stating that it is: "the compatibility between people and organizations that occurs when: (a) at least on entity provides what the other needs, or (b) they share similar fundamental characteristics, or (c) both" (p. 5).

Measurement concepts and distinctions. The conceptualization and measurement of PE fit are rife with variety, disagreements, and heterogeneity. There are at least four core distinctions that together define the operationalization of PE fit. 
Conscientiousness as a Moderator 55

Figure 1 presents several different methods for conceptualizing PE fit in the organizational context. The first core distinction distinguishes whether the person or the environment is more salient to the interaction, leading to two different ways of conceptualizing the fit between the person and the environment. The first way, dubbed demands-abilities fit, focuses on the level of congruence between the demands of the environment and the abilities of the individual (Edwards et al., 1998). As such, it tends to be organization-centric, and is the model underlying much of the activity in job selection because the person is viewed as a set of abilities that will complement or supplement the work environment. The second method of conceptualization, dubbed needs-supplies fit, focuses on the level of congruence between the needs of the individual and the supplies offered by the environment to fulfill those needs (Edwards et al., 1998). As such, it is a more person-centric conceptualization of fit, because the environment is viewed as a set of characteristics that must complement or supplement the needs of the individual.

The second core distinction, according to Kristof-Brown, Zimmerman, and Johnson (2005), is between how one views congruence between the person and environment, which can either be complementary or supplementary. Complementary fit occurs when the characteristics of either the person or the environment fill a gap in one another. For example, in the demands-abilities framework, a manager who selects a highly ordered individual to work with a team of creative "idea people" is basing this decision on the idea that the characteristic of orderliness will fill the gap in, or complement, the characteristics of the rest of the work team. As this example implies, 
Conscientiousness as a Moderator 56

complementary fit is often associated with a demands-abilities perspective (Muchinsky \& Monahan, 1987). However, Kristof-Brown et al. note that complementary fit can apply to the needs-supplies perspective as well. In this conceptualization, individual needs are seen as gaps that must be filled by a supply from the environment. For example, complimentary fit in the needs-supplies perspective would occur when an individual's need or desire for autonomy on the job is filled by an adequate level of autonomy supplied by the job.

Supplementary fit occurs when the characteristics of the person or the environment add to, or supplement, characteristics that are already featured in the other. In other words, supplemental fit occurs when the characteristics of the environment and the individual are similar (Kristof-Brown et al., 2005). This type of fit is often associated with a PO fit because it implies a level of congruence between the organizational environment and personal characteristics. For example, supplementary fit occurs when individuals who value social responsibility work for organizations that also value social responsibility. This type of fit forms the basis of the attraction-selection-attrition model (Schneider, 1987) of organizational culture.

The third core distinction is between objective and subjective representations of the person environment interaction (Edwards et al., 1998). Objective representations focus on the level of congruence between the objective characteristics of the environment (e.g., job tasks) and the objective needs, desires, values, or attributes of the individual (e.g., personality traits). As such, they are considered indirect measures of fit because the level of fit must be calculated based on the degree 
Conscientiousness as a Moderator 57

of misfit between the individual and the environment. A researcher using objective measures of fit would sample objective characteristics of the environment and objective characteristics of the individual. These indirect measures require fit to be calculated as some form of difference score between the person and environment variables or can be analyzed using polynomial regression. Subjective representations of PE fit focus on the perceptions of the individual regarding his or her fit with the environment. As such, they were originally considered direct measures of fit because the degree of perceived fit is obtained directly from the individual (Edwards et al., 1998). Kristof-Brown et al. (2005) further refined this distinction by breaking subjective representations of fit into two additional components. She distinguishes between perceived fit, in which individuals report their perceptions of their own fit with the environment, and subjective fit wherein the individual is asked to provide information regarding attributes of their environment in addition to themselves. The former is thus a direct measure of subjective fit, while the latter is an indirect measure of subjective fit and must be analyzed using the same techniques that apply to indirect objective measures. For the sake of clarity, I use the term indirect-subjective to refer to fit that is assessed by comparing self-reported characteristics of the person with characteristics of the environment also reported by the individual. I use the term direct-perceptual when individuals are asked to assess fit using self report measures of their perceptions.

One final distinction should be mentioned with regard to PE fit. PE fit theory is based on the notion of commensurate measurement, which distinguishes the PE fit 
Conscientiousness as a Moderator 58

paradigm from more general interactionist models of the relationship between a person and the environment (Kristof-Brown et al., 2005). Commensurate measurement indicates that both person and environment variables must be measured along the same dimensions. Edwards (1996) suggest that commensurate measurement is required because PE fit theory is primarily concerned with the distance between $\mathrm{P}$ and E variables as an indicator of the degree of fit between the person and the environment. Studies that collect and analyze P and E variables on commensurate dimensions fall under the auspices of PE fit theory, while those that hypothesize more general interactions between a personality characteristic and an environmental variable cannot be explained through a direct application of PE fit theory. This distinction does not deprecate studies that rely on non-commensurate measures-indeed the I-O literature is packed with well designed studies that investigate interactions between the person and the environment outside of a PE fit framework--but it does set a boundary between PE fit theory and other interactionist theories. In preceding chapters, I have suggested that Big Five personality facets will interact with autonomy to predict satisfaction, which would indicate a form of fit on non-commensurate dimensions. While the associations of these interactions with job satisfaction are relevant in their own right, PE fit theory, along with commensurate measurement, may provide a more direct explanatory mechanism by which these effects can be understood. Measuring PE fit as a Predictor of Satisfaction

The evidence regarding PE fit as a useful predictor of job satisfaction is robust in the literature. Many studies have shown that PE fit-whether conceptualized in 
terms of fit with the job, fit with the organization, or fit with the work group-is related to job satisfaction. For example, Verquer, Beehr, and Wagner (2003) metaanalytically examined the utility of PO fit in predicting attitudinal outcomes such as job satisfaction and found a moderate effect size. The results suggested an average correlation between PO fit and job satisfaction of .25. However, there were differences in these correlations depending on measurement strategy, and these differences were especially apparent for subjective measurement strategies. The correlation for indirect-subjective measurement was .30 and the correlation for directperceptual measurement strategy was .57. These results suggest that an individual's experience of their PO fit (as quantified by direct perceptual measurement) is a more robust predictor of their job satisfaction. This makes sense theoretically, as perceptions of fit should be more cognitively accessible and thus more proximally related to job attitudes than indirect-objective measures of fit (Cable \& DeRue, 2002). Moreover, the perception of fit has, by definition, been filtered through an individual's own internal cognitive and sensory apparatuses, and thus represents an individual's experienced reality. As I have suggested in the introduction to this dissertation, the focus on the individual's perceptions and felt experience regarding their environment is central to Weiss and Rupp's (2010) call for a more person-centered approach to I-O psychology.

It should be noted that the Verquer et al. (2003) meta-analysis was focused exclusively on PO fit, which is qualitatively different from other PE fit content domains, such as PJ fit. However, Kristof-Brown et al. (2005) meta-analytically 
summarized $47(\mathrm{~N}=12,960)$ studies and found an average correlation between PJ fit and job satisfaction across studies of .44. Moreover, they investigated fit measurement strategy (indirect-objective, indirect-subjective, and direct-perceptual) as a moderator of the PJ fit/satisfaction relationship. Although the correlation for the indirect-objective measurement strategy (.22) was substantially and significantly lower than the correlation for indirect-subjective (.44) and direct-perceptual (.45) measurement strategies, there were virtually no differences between the latter two. According to these results, there appears to be little difference in measuring subjective PJ fit using indirect or direct methods for the prediction of job satisfaction. However, they found results similar to that of Verquer et al. for the PO fit/job satisfaction relationship, with an average correlation of .45 for direct-perceptual measurement, .37 for indirect-subjective measurement, and .23 for indirect-objective measurement, which suggests that for at least some conceptualizations of PE fit, direct perceptual measures yield the largest correlations with attitudinal outcomes.

The results of the Kristof-Brown et al. (2005) meta-analysis also suggest the various content domains examined using a fit framework (e.g., PJ fit, PO fit, PG fit, and PS fit) offer the strongest predictive utility when attitudinal outcomes are related to their content domains. For example, PJ fit was the strongest predictor of job satisfaction, PO fit was the strongest predictor of organizational commitment, and PG fit was the strongest predictor of satisfaction with coworkers. These findings make sense because in each place the measurement of fit is associated with an outcome at the same level of analysis. For example, PO fit (which samples fit at the 
organizational level) is associated with an organizational level variable, while PJ fit (which samples fit at the job level) is associated with job satisfaction.

\section{PE Fit as a Mediator}

In previous chapters, I have suggested that autonomy and facet level descriptions of personality will interact to predict job satisfaction. Although this view is consistent with an overall interactionist approach to psychological inquiry, it implies that perceptions regarding PE fit may be driving the effect of the person $\mathrm{x}$ environment interaction but does not explicitly test this implication. For example, it has been well established in the literature that autonomy in the work environment has an overall positive effect on satisfaction (e.g., Hackman and Lawler, 1971; Humphrey et al., 2007; Loher et al., 1985). However, I formally hypothesize later in this dissertation that the inclusion of the facets of conscientiousness as moderators of this relationship results in a series of disordinal interactions. I suggest that the facets of self-discipline, achievement striving, and competence increase the effect of autonomy on job satisfaction. That is, those high on these facets will find more highly autonomous environments more satisfying than those low on these facets. I will also suggest, however, that some of the facets of conscientiousness (i.e., order, dutifulness, and deliberation) will reverse the slope between autonomy and job satisfaction. That is, those high on the facets of orderliness, dutifulness and deliberation will find more highly autonomous environments less satisfying than those low on these facets. Underlying this series of predictions regarding disordinal interactions is an inferred difference in desire or need for autonomy between orderliness, dutifulness, and 
deliberation on the one hand, and competence, achievement striving, and selfdiscipline on the other.

In viewing $\mathrm{PE}$ fit as a mediator of the effect of the autonomy $\mathrm{x}$ personality interaction on job satisfaction, two practical issues must be addressed regarding how best to measure fit between the person and the environment. The first issues involves whether to measure fit indirectly, using either objective or subjective methods, or whether to measure fit using direct measurement of fit perceptions. While direct measurement (in which $\mathrm{P}$ and $\mathrm{E}$ variables are measured separately) is championed by some (e.g. Edwards, 1996; Edwards et al., 1998) as the most theoretically rigorous method, direct measures would make data analysis unwieldy because they must be analyzed using difference scores or polynomial regression. However, difference scores are no longer considered acceptable in most modern PE fit studies due to issues such as range restriction (Edwards, 1996), and the complexity of the model examined in the current study precludes the use of polynomial regression. Moreover, as discussed above, Kristof-Brown et al. (2005) showed meta-analytically that there was virtually no difference between direct-perceptual measures of PE fit and indirectsubjective measures of PE fit in their relationship to job satisfaction. For these reasons, a direct-perceptual measure will be used in the current study.

\section{“Person-Autonomy” Fit}

The second, and perhaps most pressing issue, involves the appropriate content domain of $\mathrm{P}$ and $\mathrm{E}$ variables to sample. In the context of the current study, PE fit could be conceptualized as the person's perceptions regarding the congruence between 
Conscientiousness as a Moderator 63

desired autonomy $(\mathrm{P})$ and autonomy provided by the job (E). This conceptualization of fit, which I will call person-autonomy fit, limits the focus of the fit measure to the variables explicitly contained within the current study. This method has conceptual appeal because it only samples the fit between the specific job facet of autonomy and the individual desire or need for autonomy. However, PE fit can also be conceptualized in terms of a broader overall fit with the job (i.e., PJ fit), which measures the overall fit of the individual with the many facets of the job, of which autonomy is only one. Although these measures are appealing because they have been used successfully in the research literature (e.g., Cable \& Judge, 1996; Cable \& DeRue, 2002), they were less appealing as measures of the mediating variable for the current study because they sample the fit of unspecified supplies from the entire job with the entire range of individual needs. For example, an item used in the Cable and DeRue study was: "The job I currently hold gives me about everything I want from a job.” These supplies could include virtually anything, including instrumental attributes such as pay, promotion opportunities, and scheduling flexibility; social attributes, such as support and opportunities for friendship; and psychological attributes such as achievement opportunities, decision latitude, and challenging work. Some of these attributes, such as scheduling flexibility and decision latitude are reflected in the autonomy measures used for my study, but the others are not.

As Kristof-Brown et al. (2005) point out, the primary mechanism of needssupplies models of PE fit can be explained by the theories of need fulfillment, which suggest that people will be more satisfied with their work when their needs for various 
working conditions (such as autonomy) are satisfied. If the desire or need for autonomy is indeed related to these personality constructs as suggested above, then differences in the need for autonomy should manifest as differences in perceptions of PE fit in terms of the autonomy provided by the job. Differences in satisfaction would thus occur when a person's need or desire for autonomy (the "need" side of the needssupplies model) is matched with a commensurate level of autonomy from the work environment (the "supplies" side of the needs-supplies model), and should thus mediate the effect of the autonomy $\mathrm{x}$ personality interaction on job satisfaction.

\section{PJ Fit as an Outcome}

The needs-supplies model of person-autonomy fit provides the most theoretically relevant mediating mechanism for the effect of the autonomy $\mathrm{x}$ personality interaction on job satisfaction. However, the broader construct of PJ fit should also be affected by the interaction of personality with the environment. If an individual's personality traits, and their subsequent needs, are not complimented by supplies provided by the job, the result will be a misfit between the person and the job. The level of misfit between the person and the job should be reflected in their perceptions regarding PJ fit.

PJ fit is also important to understanding the relationship between personautonomy fit and job satisfaction. Because PJ fit is measured as the level of congruence between the needs and traits of the individual and the supplies provided by the job, it exists at a more general level than person-autonomy fit. PJ fit also occupies the same conceptual level of analysis as job satisfaction because it measures the 
Conscientiousness as a Moderator 65

overall fit of the person with the job, just as job satisfaction measures an individual's overall satisfaction with the job. As such, it can be viewed as a potential outcome of both the personality $\mathrm{x}$ autonomy interaction and person-autonomy fit. Treating PJ fit as an outcome in addition to job satisfaction results in the model represented in Figure 2, which forms the basis for the hypotheses in Chapter $5^{1}$.

\footnotetext{
${ }^{1}$ A s indicated earlier in this chapter, PJ fit has historically been treated as an antecedent to job satisfaction based on theories of need fulfillment. These theories suggest that individuals will have more positive attitudes toward their work when their needs are satisfied by the supplies of the workplace (Kristof-Brown et al., 2005). In the context of the proposed study, it could be argued that PJ fit performs its own mediating role and is both an outcome of person-autonomy fit and an antecedent to job satisfaction, thus mediating the effect person-autonomy fit on job satisfaction. In this alternative conceptualization, PJ fit would be a more proximal antecedent to job satisfaction than person-autonomy fit. While this conceptualization may be theoretically relevant, it would make data analysis unwieldy and is thus out the scope of this dissertation.
} 
Chapter 5: Hypotheses

The purpose of this chapter is to outline the research questions and hypotheses contained in this dissertation. These hypotheses fall into two general categories. The first category involves predictions regarding the effect of the autonomy x personality interaction on both job satisfaction and PJ Fit. The second category involves predictions regarding person-autonomy fit as a mediator between the autonomy $\mathrm{x}$ personality interaction and the outcomes of job satisfaction and PJ fit. A full list of the hypotheses and research questions in the first category is presented in tabular form as Table 2 and those in the second category are presented as Table 3.

Hypothesis and Research Questions Regarding the Personality x Autonomy

\section{Interaction}

Based on the trait-activation model, and the inherent assumption that people find the expression of their traits satisfying, it is reasonable to suggest that different people will find different workplace features motivating and satisfying. A highly conscientious person, for example, will enjoy and be satisfied with features of the work environment that enable them to behave in a manner consistent with their natural behavioral tendencies toward orderliness and achievement striving, while an extraverted person will enjoy and be satisfied with features of the work environment that allow them to express their natural behavioral tendencies toward gregariousness, activity, and assertiveness.

Previous research (e.g., Hackman and Lawler, 1971; Humphrey et al., 2007; Lohar et al., 1985) provides strong support for the link between autonomy (as a work 
characteristic) and job satisfaction as a main effect, and there is a long tradition of examining individual differences that may moderate the relationship between autonomy and satisfaction. The results, however, have been mixed, which may speak more to the insufficiency of the GNS construct, rather than the lack of a moderation effect based on individual differences. Previous research (e.g., Judge et al., 2002) has also shown that the Big Five personality trait conscientiousness is linked to job satisfaction, again indicating a main effect of personality on job satisfaction. Moreover, the SD $\rho$ statistic for conscientiousness reported in the Judge et al. metaanalyisis was fairly wide $(\mathrm{SD} \rho=.22)$ and the $80 \%$ credibility interval crossed zero. These results may indicate the presence of a personality-situation interaction in the prediction of job performance. Additionally, it is reasonable that autonomy may be just such a situational predictor because it has been shown to be associated with job satisfaction.

One more piece of evidence suggests that conscientiousness may moderate the relationship between autonomy and satisfaction. Barrick and Mount (1993) examined the role of autonomy in moderating the validity of personality in predicting job performance for managers. They found that autonomy increased the validity of conscientiousness in predicting performance. Although they chose to view autonomy as the moderator, rather than conscientiousness, their choice is a conceptual rather than statistical one. They could have just as easily chosen to interpret the interaction with the personality variable as a moderator. Finally, Lee, Ashford, and Bobko (1990) examined the interaction between personality (conceptualized as Type A vs Type B) 
and found that satisfaction was highest among Type A people who worked in highly autonomous environments, which suggests an interaction between personality and autonomy in predicting job satisfaction.

Based on this evidence, I believed that conscientiousness would moderate the effect of autonomy on job satisfaction. A graphical representation of the proposed relationships is included in Figure 3. However, given the heterogeneity of some of the facets of conscientiousness, it remained difficult to predict which direction the moderation would take. On the one hand, it is reasonable to conclude that increased levels of conscientiousness will attenuate or reverse the relationship between autonomy and satisfaction because highly autonomous environments provide less structure, which may frustrate behaviors based on dutifulness, order, and deliberation. On the other hand, it is reasonable to conclude that increased levels of conscientiousness will strengthen the relationship between autonomy and satisfaction because more autonomous environments provide opportunities to behave in ways stemming from achievement striving, competence, and self-discipline. Because there was no clear direction indicated by either research or theory, I did not hypothesize a direction for the interaction. I thus state this proposed interaction as a research question:

RQ1: Conscientiousness will moderate the relationship between autonomy and job satisfaction.

A similar relationship should emerge with respect to PJ fit. If differences in conscientiousness imply differing levels of need or desire for autonomy, then the 
Conscientiousness as a Moderator 69

interaction between conscientiousness and autonomy should be reflected in perceptions of PJ fit. As with RQ1, I am unable to predict the direction of the interaction, so I state the following as a research question:

RQ2: Conscientiousness will moderate the relationship autonomy and PJ fit.

Consideration of the facets of conscientiousness enables more specific predictions regarding the direction of the proposed interactions. I suggest that the facets of orderliness, dutifulness, and deliberation will result in a disordinal interaction with autonomy such that low scores on these facets will result in a positive effect of autonomy on job satisfaction and PJ fit, while high scores on these facets will result in a negative effect of autonomy on satisfaction and PJ fit. I also suggest that the facets of achievement striving, competence, and self discipline will result in disordinal interactions. However, in this case, high scores on these facets should result in a positive effect of autonomy on job satisfaction and PJ fit, while low scores on these facets should result in a negative effect of autonomy on satisfaction and PJ fit. I have presented a graphical example of these disordinal interactions based on Hypothesis 1a as Figure 4:

H1 a-c: The facets of a) order, b) dutifulness, and c) deliberation will moderate the relationship between autonomy and job satisfaction. Specifically, low scores on these facets will result in a positive effect of autonomy on job satisfaction, while high scores on these facets will result in a negative effect of autonomy on satisfaction.

H2 a-c: The facets of a) order, b) dutifulness, and c) deliberation will 
Conscientiousness as a Moderator 70

moderate the relationship between autonomy and PJ fit. Specifically, low scores on these facets will result in a positive effect of autonomy on PJ fit, while high scores on these facets will result in a negative effect of autonomy on PJ fit.

H3 a-c: The facets of a) achievement striving, b) competence, and c) selfdiscipline will moderate the relationship between autonomy and satisfaction. Specifically, high scores on these facets will result in a positive effect of autonomy on job satisfaction, while low scores on these facets will result in a negative effect of autonomy on satisfaction.

H4 a-c: The facets of a) achievement striving, b) competence, and c) selfdiscipline will moderate the relationship between autonomy and PJ fit. Specifically, high scores on these facets will result in a positive effect of autonomy on PJ fit, while low scores on these facets will result in a negative effect of autonomy on satisfaction. Hypotheses Regarding Person-Autonomy Fit as a Mediator of the Effect of the Autonomy x Personality Interaction on Job Satisfaction

The second set of hypotheses investigates person-autonomy fit as a mediator of the effect of the autonomy x personality interaction on job satisfaction. The overall model tested is presented as Figure 5. I argued in Chapter 4 that person-autonomy fit provides a useful mechanism by which the relationship between the autonomy $\mathrm{x}$ personality interactions and job satisfaction can be understood. The interaction between autonomy and personality should be reflected in individual perceptions 
Conscientiousness as a Moderator 71

regarding how well the environment supplies the needed or desired amount of autonomy (which is measured by person-autonomy fit). The level of fit experienced by individuals should in turn predict their job satisfaction and the overall fit with their job. This argument results in a series of formal hypotheses, which predict that PJ fit will mediate the relationship between the interactions hypothesized previously and job satisfaction:

H5: Person-autonomy fit will mediate the relationship between the autonomy $x$ conscientiousness interaction and job satisfaction.

H6: Person-autonomy fit will mediate the relationship between the autonomy $x$ conscientiousness interaction and PJ fit.

H7 a-f: Person-autonomy fit will mediate the relationship between the autonomy $x$ ( a) orderliness b) dutifulness c) deliberation d) achievement striving e) competence and f) self-discipline] interaction and job satisfaction. H8 a-f: Person-autonomy fit will mediate the relationship between the autonomy $x$ ( a) orderliness b) dutifulness c) deliberation d) achievement striving e) competence and f) self-discipline] interaction and PJ fit. 
Conscientiousness as a Moderator 72

\section{Chapter 6: Method}

\section{Initial Power Analysis}

Prior to conducting the study, a power analysis was conducted using G*Power 3 software (Faul, Erdfelder, Lang, \& Buchner, 2007) to determine a sufficient sample size to achieve statistical power of .80 . The power analysis was conceptualized using a hierarchical regression framework with two predictors entered in step 1 (i.e., autonomy and a personality facet) and the interaction term entered in step 2 . In this context, the effect size $\Delta R^{2}$ represents the unique variance in the outcome variable accounted for by the interaction term. Because there is little research available regarding the Big Five and its facets as moderators of the relationship between autonomy and such as outcomes as job satisfaction and person-job fit, it was difficult to predict an expected effect size for the moderation term. I chose a $\Delta R^{2}$ of .03 as the effect size because Barrick and Mount (1993) found a $\Delta R^{2}$ of .03 in a similar study for conscientiousness as a moderator of the autonomy/job performance relationship. According to the power analysis, 256 data points are necessary to detect a $\Delta R^{2}$ of .03 with a power of .80 , which was the goal of the current study.

\section{Design Overview}

Data for the study were collected at two time points with 2-5 weeks between Time 1 (T1) and Time 2 (T2) in order to minimize spurious effects due to common method variance (CMV). This strategy was recommended by Podsakof (2003) as a good method for controlling CMV. Data collected at T1 included self-report measures of constructs that are theoretically antecedent (e.g., autonomy, conscientiousness 
Conscientiousness as a Moderator 73

facets) to the self-report outcome measures collected at T2 (e.g., job satisfaction, person-job fit). T1 and T2 data were then matched based on the participant's answers to three identifying questions (e.g., "what are the first two letters of your father's first name ?"). Because I was not sure how well the codes would work to match the data, I also collected the outcome variables (job satisfaction, PJ Fit) at T1. There were thus two data sets: one in which the antecedent and outcome variables were collected at the same time $(N=256)$, and a subset which contained outcome variables separated in time ( $N=181)$. The second data set was preferred because it separated the antecedent and outcome variables in time, thus reducing the potential for inflation due to CMV. However, it was underpowered according to the initial power analysis. I performed an additional power analysis using G*Power 3 (Faul et al., 2007) on the smaller matched data set to determine the power provided by the existing 181 participants to achieve significance given the projected $\Delta R^{2}$ of .03 . The software indicated that the smaller matched data set provided statistical power of .64. The first data set contained the identical number of records suggested by the power analysis, thus retaining sufficient statistical power, but did not provide safeguards against CMV.

This situation presented something of a conundrum, especially because upper management at the firm where the study was conducted had asked that the data collection be closed. I reasoned that the problem of the potential impact of CMV was greater than running analyses with insufficient power, and thus decided to make the smaller matched data set $(N=181)$ my primary source. However, because I had access to data that met the goal for statistical power, I performed supplemental analyses on 
Conscientiousness as a Moderator 74

the larger dataset. This means that any non-significant outcome could be tested on a data set that had been determined a priori to have sufficient power. The possibility that a lack of power led to non-significant results could thus be explored, although CMV would still remain a possible problem in the larger data set. The smaller data set was thus used for all analyses, which are discussed in the main portion of Chapter 7. In the case of non-significant findings, I re-ran the analyses on the larger data set in case a lack of power led to an inability to detect effects. These analyses are discussed in the supplemental area of the Chapter 7.

Figure 6 illustrates the study design and lists the variables that were measured at each time point. The specific measures to be used for each variable are discussed in the measures section in this chapter.

\section{Participants}

Participants were recruited from a national wholesale distribution company with headquarters in Portland, OR. The firm functions as a co-operative with 300 independently owned locations throughout the United States. The sample of participants was comprised of employees at the corporate headquarters and 10 independently owned stores and groups.

The matched data set was comprised of 181 participants, with an average age of $44.9(S D=11.6)$. The participant population was $74 \%$ male and $90.1 \%$ Caucasian, 3.9\% Latino, 1.7\% African American, .6\% Asian, and .6\% American Indian. An additional $2.8 \%$ of participants chose "Other" or provided multiple responses. For education, $21.5 \%$ had finished high school, $54.1 \%$ of participants had some college or 
Conscientiousness as a Moderator 75

an AA degree, $20.4 \%$ held BA degrees, and 3.9\% held graduate degrees.

In terms of their jobs, $32.6 \%$ of participants indicated that they had a supervisory role, and $23.5 \%$ indicated that their position was at or above "Manager" level. Approximately $40 \%$ indicated that they were salaried workers, with the remaining earning hourly wages. The median salary was $\$ 55,000 /$ year $(M=59,663$; $S D=20,756)$ and the average wage was $\$ 16.74 /$ hour $(S D=2.92)$. Participants had been working in their current jobs for an average of 6.9 years $(S D=6.51)$, and had been working for the company for an average of 9.1 years $(S D=7.2)$.

\section{Procedure}

Participants were recruited via email from within the organization and were offered the chance to win $\$ 50$ as an incentive. The email described the study and contained a link to the first online survey (i.e., T1). An email reminder was sent approximately one week later. Between two and five weeks after the reminder, participants were sent a second email with a link to the second survey (i.e., T2) and a reminder was also sent approximately one week later. The difference in lag time between the first and second survey was due to the holiday season. All participants who submitted both surveys were invited to provide their name and email address to be entered into the random drawing for $\$ 50$. A winner was selected and paid on $2 / 15 / 2012$.

The data for T1 and T2 were then matched using three questions described above, with some loss of data due to mismatches on these questions. There were seven cases in which the codes were very close but differed by one digit on one question 
(“How many siblings do you have?"). Because this question may have caused some confusion as to whether or not to include oneself, I allowed those cases into the data set. I spot checked several analyses and found only trivial differences in effect size and no differences in significance when these records were not included. I thus decided to include these cases in order to maximize sample size.

\section{Measures}

A full list of the items used in each of the measures discussed below are included in Appendix A, and mockups of the two surveys, are included in Appendix B. Alpha statistics for all measures were above .8 ,except for deliberation which had an alpha statistic of .76. Specific alpha statistics for each scale are listed on the diagonal in Table 4.

Facets of conscientiousness. The six facets of conscientiousness were assessed using the International Personality Item Pool (IPIP; Goldberg et al., 2006) which is based on the FFM. The facet scale in the original measure contains five positively worded items and five negatively worded items for each of the six facets, for a total of 60 items. Due to space constraints imposed by the organization, I limited the items to those that are positively worded. The measure used for this study thus contained 31 positively worded items. The facets were measured as follows: Competence, 5 items; orderliness, 5 items; dutifulness, 5 items; achievement striving, 7 items; selfdiscipline, 5 items; deliberation, 3 items.

Work autonomy. Autonomy at work was assessed using the WDQ (Morgeson \& Humphrey, 2006), which provides three sub-scales of three items each, for a total of 
Conscientiousness as a Moderator 77

nine items. Work scheduling autonomy refers to the discretion an employee has over their work planning. An example is "The job allows to plan how I do my work." Decision-making autonomy refers to the latitude an employee has to make decisions. An example is "The job allows me to make a lot of decisions on my own." Work methods autonomy refers to the discretion an employee has in choosing their work methods. An example is "The job allows me to decide on my own how to go about doing my work.

Job satisfaction. Job satisfaction was measured globally using five items suggested by Judge et al. (2001). An example is "I feel fairly satisfied with my present job."

Person-autonomy fit and PJ fit perceptions. PJ fit was assessed using three items from Cable and DeRue (2002). A sample item is "The job that I currently hold gives me just about everything that I want from a job.” Person-autonomy fit was assessed with three items created for the proposed study based on the Cable and DeRue items. These items were altered by limiting the focus to aspects of the job related to autonomy only. An example is "There is a good fit between how much freedom I have at work and how much freedom I want from a job."

Earnings. Participants were asked to provide information about their compensation. Some participants in the sample were paid according to a yearly salary schedule, while others were paid hourly wages. Those that were salaried were asked to provide their yearly salary in an open response. Those that were paid an hourly wage were asked to provide their hourly wage in an open response. I calculated an 
earnings variable in order to create a single scale covering both wages and salary. In the case of salaried workers, earnings is defined as their yearly salary. In the case of workers who earn wages, earnings is defined as wage multiplied by 40 (a standard work week) and then again by 48 (the standard number of weeks worked per year).

Variables for supplemental analyses: Although there were no formal hypotheses regarding these variables, I collected data on leader member exchange (LMX) and proactive personality to enable supplemental analyses. I collected data on these variables because they provided alternative conceptualizations of an individual difference variable (i.e., proactive personality rather than conscientiousness) and an environmental variable (i.e., LMX rather than autonomy) that were potentially related to job satisfaction and PJ Fit. LMX was assessed using 12 items from Liden and Maslyn (1998; e.g., "I like my supervisor very much as a person.”) Proactive personality was measured with 10 items from Seibert, Crant and Kraimer (1999; e.g., "I am constantly on the lookout for new ways to improve my life.") 
Conscientiousness as a Moderator 79

\section{Chapter 7: Results}

Intercorrelations and alpha reliability statistics among all study variables are presented in Table 4. Means and Standard Deviations for all study variables are presented in Table 5.

\section{Correlations among Study Variables}

An initial examination of the correlation table (Table 4) showed several interesting associations, some of which bear directly on the hypotheses. In general, the data appeared to behave in ways that would be expected given my a priori assumptions regarding the measures used and proposed relationships. Only a few demographic variables were associated with the outcomes: salaried status $(r=.19, p<$ $.01)$ and hours worked per week $(r=.18, p<.05)$ were correlated with job satisfaction, and years at current job $(r=.15, p<.05)$ and hours worked per week $(r=$ $.15, p<.05)$ were correlated with PJ Fit. These variables were thus investigated as

potential control variables for later analyses. Decision autonomy, scheduling autonomy, work methods autonomy, and autonomy itself were also associated with salaried status $(r=.28, p<.01$ to $r=.32, p<.01)$, earnings $(r=.24, p<.01$ to $r=.32$, $p<.01)$, and hours worked per week $(r=.16, p<.05$ to $r=.25, p<.01)$. This makes sense because jobs which pay in salary, have higher compensation, and more hours worked per week often feature higher levels of on-the-job autonomy.

The six facets of conscientiousness were correlated with one another with values ranging from $r=.49, p<.01$ to $r=.70, p<.01$, and the six facets were associated with the higher-order conscientiousness variable, with values ranging from 
$r=.76, p<.01$ to $r=.90, p<.01$. These high intercorrelations between facets and with the higher-order conscientiousness variable are in line with its higher-order/facet factor structure. The three sub scales of autonomy were also associated with each other with values ranging from $r=.61, p<.01$ to $r=.79, p<.01$ and the three subscales were associated with global autonomy with values ranging from $r=.87, p<$ .01 to $r=.92, p<.01$. These values also appeared to be indicative of a higher order factor structure. I thus performed a confirmatory factor analysis (CFA) to confirm a higher order factor structure, the results of which are discussed below. Finally, job satisfaction and PJ Fit were highly correlated $(r=.75, p<.01)$. Although this is expected given that they both measure job attitudes with similar content, the high correlation prompted me to perform a CFA on these variables as well to confirm that they were separate constructs. I discuss the results of this CFA below as well.

Regarding conscientiousness, Judge et al. (2002) provided meta-analytic evidence of a relationship between conscientiousness and job satisfaction of $\rho=.28$, but did not examine the relationship at the facet level. The current study found a similar relationship between conscientiousness and job satisfaction $(r=.23, p<.01)$. At the facet level, most of the associations were also significant: competence $(r=.15$, $p<.05)$, dutifulness $(r=.22, p<.01)$, achievement striving $(r=.21, p<.01)$, discipline $(r=.21, p<.01)$ and deliberation $(r=.23, p<.01)$. The exception was $\operatorname{order}(r=.11, p>.05)$ which was not significantly related to job satisfaction. These correlations are consistent with Judge and colleague's suggestion that job satisfaction is likely partially dispositional in nature, and is associated with conscientiousness. 
Conscientiousness as a Moderator 81

These associations are examined more fully in the tests of hypotheses below.

\section{CFA of Autonomy}

As described above, the WDQ (Morgeson \& Humphrey, 2006) measures autonomy using three constructs: work scheduling autonomy, work methods autonomy, and decision autonomy. However, many studies (e.g. Hackman \& Oldham, 1975; Janz, Colquitt, \& Noe, 1997; Karasek , 1990) have viewed autonomy as a single global construct, which includes autonomy of scheduling, work methods and decisions, but does not break these aspects of autonomy into distinct constructs. Morgeson and Humphrey performed several rounds of confirmatory factor analysis to derive the factor structure of the WDQ. A close examination of the fit statistics in their study shows that models in which autonomy was split and models in which autonomy was treated as a unitary construct did not differ substantially from each other in terms of overall fit. In fact, the model in which autonomy was treated as a unitary construct had better fit according to RMSEA, CFI, and SRMR fit statistics, although the split model showed a small reduction in chi-square, which may have indicated better fit. Which of these models fit better is thus equivocal, and depends on how you choose to interpret the fit statistics. Moreover, in the Morgeson and Humphrey study, the three types of autonomy were intercorrelated at about .78, which suggests that even if they can be viewed as different constructs, they are highly related.

In order to figure out how best to proceed, I performed a confirmatory factor analysis (CFA) using the nine autonomy items collected for this study. I first tested 
the one-factor model which views the nine items as indicators of a single autonomy factor. The chi-square test was significant, $\chi^{2}(27, \mathrm{~N}=251)=311.0, p<.001$, indicating a poor fit to the data. However, the chi-square statistic is problematic as an index of model fit because it is sensitive to sample size (Joreskog \& Sorbom, 1989). Other model fit statistics were thus used to evaluate the fit of the model to the data. Hu and Bentler (1999) suggest that comparative fit index (CFI) values above .95 and root mean square error of approximation (RMSEA) values of .06 or less are indicative of good model fit. Moreover, Kline (1998) suggested that a $\chi^{2} / d f$ ratio of less than two or three is indicative of good model fit. The $\chi^{2} / d f$ ratio was 11.52 , the CFI value was .85 and RMSEA was .21. These model fit statistics suggest that the one-factor model fits the data poorly.

I next tested a hierarchical factor model in which the three factors of work scheduling autonomy, work methods autonomy, and decision autonomy were nested within a higher-order autonomy factor. The chi-square test was once again significant, $\chi^{2}(24, N=251)=37.77, p<.05$. However, $\chi^{2} / d f$ ratio was 1.57 , the CFI value was .99 and RMSEA was .05. All model fit statistics suggest that the hierarchical factor structure shows good fit to the data. The standardized factor loadings of the three endogenous factors on the higher-order factor were reasonably balanced (scheduling autonomy: .65; decision autonomy: .57; work methods autonomy: .70). Moreover, the intercorrelations (see Table 4) among the three factors and the higher order global factor range from .61 to .92 , indicating a strong relationship among the three subfactors. Using the higher-order autonomy variable, rather than its three subscales 
Conscientiousness as a Moderator 83

independently is thus warranted for the current study.

\section{CFA of Satisfaction and PJ Fit}

PJ Fit and job satisfaction were correlated at .75, which makes sense because they both measures of job attitudes and, as outcomes, were both collected at the same time. With a correlation this high, it was necessary to ascertain whether PJ Fit and job satisfaction should be treated as separate variables. I had assumed a priori that PJ Fit and job satisfaction would be separate variables, and in order to test this, I performed a CFA using the five items for satisfaction and the three items for PJ Fit. In the first model, PJ Fit and job satisfaction were assumed to be separate correlated latent variables, with their respective items serving as indicators. The chi-square test was significant, $\chi^{2}(19, N=180)=58.80, p<.001$. The CFI value was .95 indicating good fit to the data, but the RMSEA was .10, higher than the value of .06 recommended by Hu and Bentler (1999). Additionally, the $\chi^{2} / d f$ ratio of 3.09 approaches the cutoff of three suggested by Kline (1998). At least some indicators thus suggest that the twofactor correlated model provides reasonably good fit to the data.

I next tested a single factor model, which assumed that all items indicated a single latent variable. The chi-square test was significant, $\chi^{2}(20, N=180)=84.60, p$ $<.001$. The CFI value was .92 and the RMSEA was .13, both of which do not meet Hu and Bentler's (1999) criteria for surmising good model fit. Furthermore, the $\chi^{2} / d f$ ratio of 3.09 for the two factor model is lower than the 4.23 for the single factor model, which indicates that the two factor model fits the data better than the one factor model. Based on this evidence, I concluded that it was appropriate to treat job 
Conscientiousness as a Moderator 84

satisfaction and PJ Fit as separate variables.

\section{CFA on PA Fit and PJ Fit}

Because I adapted the PA fit scale from the PJ Fit scale developed by Cable and Derue (2002), I wanted to confirm that PA fit and PJ fit formed separate factors. In order to test this assumption, I performed a CFA on the PA fit and PJ fit scales. The model tested consisted of two correlated latent factors-one for PA fit and one for PJ fit—with each containing their three items as indicators. The model showed good fit to the data according to $\mathrm{Hu}$ and Bentler's (1998) criteria. The CFI value was .92 and the RMSEA was .998. Moreover, the chi-square statistic was not significant, despite a sample size of $180, \chi^{2}(13, N=180)=10.2, p>.001$. These statistics confirm that the PA fit and PJ fit scales are measuring different constructs, despite their relatively high correlation of .71 (see Table 4).

Nested Data Structure

Because I did not have a sufficient number of groups to perform HLM analysis, I investigated other ways to control for the nested structure of the data. I first calculated the ICC (.08) using location as the grouping variable, which suggested that there may be dependence in the data. However, the intercepts-only model indicated that the variance in intercepts was not significant $($ Wald $Z=1.35, p=.13$ ), which suggests that there was not a significant difference in group means on the outcome variables.

I next entered the 15 dummy coded location variables into a regression equation predicting job satisfaction and another predicting PJ fit. These regressions 
Conscientiousness as a Moderator 85

showed that the location variables accounted for significant variance in job satisfaction $\left(R=.39\right.$, Adjusted $\left.\mathrm{R}^{2}=.07, F(14,165)=1.91, p<.05\right)$ and $\mathrm{PJ}$ fit $(R=.41$, Adjusted $\left.R^{2}=.10, F(14,165)=2.14, p<.05\right)$. For the sake of parsimony, I also examined whether a single predictor-corporate vs. store membership—could be used instead of the 15 dummy codes. This predictor did not account for significant variance in job satisfaction $\left(R=.12\right.$, Adjusted $\left.R^{2}=.01, F(1,178)=2.73, p>.05\right)$ but the result for PJ Fit was significant $\left(R=.18\right.$, Adjusted $\left.R^{2}=.04, F(1,178)=6.55, p<.05\right)$. In spite of the significant effects of the more parsimonious variable for PJ Fit, which would have saved 14 degrees of freedom, I elected to use the 15 dummy codes because they accounted for more variance in the outcome than the single predictor.

All hypothesis tests were thus conducted using the 15 dummy coded location variables as controls.

\section{Identification of Additional Control Variables}

In order to identify variables that would potentially be useful as additional controls in the regression analyses to follow, I examined the correlation table for all study variables (Table 4). In order to be considered for use as a control, a demographic variable had to show a significant correlation with and be theoretically related to the outcome of interest. For job satisfaction, only hours worked per week ( $r$ $=.18, p<.01)$ and whether or not the participant was a salaried employee $(r=.19, p<$ .01) were significantly related to the outcome. Interestingly, earnings was not significantly associated with job satisfaction. For PJ Fit, only hours worked per week $(r=.15, p<.01)$ and years at current job $(r=.15, p<.01)$ were significant. These 
Conscientiousness as a Moderator 86

relationships make sense when one considers that those who feel they fit with their jobs are more likely to work longer hours and stay at their jobs for longer periods of time. Hours per week and salaried status were thus used as control variables for regressions involving job satisfaction. Hours per week and years at current job were used as control variables for regressions involving PJ Fit.

I also examined whether differences in time between the first and second survey were predictive of any outcomes of interest. To do this, I created the "Timelapse" variable (which represented the length of time between surveys) by subtracting the date and time of the end of the first survey from the beginning of the second survey. I then examined the correlations between this variable and the variables used for my hypotheses (both predictors and outcomes). The length of time between surveys was not significantly correlated with any variable used in the hypotheses. Therefore, I did not use this variable as a control in the regressions. I also investigated gender, yearly earnings, supervisor status, and managerial status as potential controls. None of them yielded changes in significance for the hypotheses. All results are thus reported in the document with the 17 control variables identified above.

\section{Research Questions 1 and 2 and Hypotheses 1 through 4}

In order to test the hypotheses and research questions, I performed moderated multiple regression analysis. For each regression, the predictor variable and the moderator variable were centered prior to analysis to reduce the potential for multicollinearity. An interaction term was then created by multiplying the predictor 
and the moderator variable. The 15 dummy coded location variables were entered in Step 1, followed by the controls in Step 2, followed by three predictors of interest in Step 3, to test their relationship with the outcome variable.

Regressions on job satisfaction. For the sake of parsimony I will discuss all RQs and Hs related to job satisfaction first, and discuss those related to PJ Fit second. RQ 1 asked whether conscientiousness would moderate the relationship between autonomy and job satisfaction, but did not predict a specific direction for the moderated effect. H1a-c predicted that a) order, b) dutifulness, and c) deliberation would moderate the relationship between autonomy and job satisfaction and that the effect of the moderation would be negative. $\mathrm{H} 3 \mathrm{a}-\mathrm{c}$ predicted that a) achievement striving, b) competence, and c) self-discipline would moderate the relationship between autonomy and satisfaction and that effect of the moderation would be positive. Results of these analyses, including $R^{2}$ for the final equation, $\Delta R^{2}$ for each regression step, and $\beta$ and $t$ values for individual effects, are presented in Tables 6-12. As the tables indicate, for each of the seven regressions tested, the variables explained significant variance in job satisfaction ranging from $33 \%$ to $36 \%$. When controlling for salaried status and job tenure as well as location, the main effect of autonomy on job satisfaction was significant and substantial in all regressions tested, with effect sizes ranging from $\Delta R^{2}=.10, \beta=.38, p<.001$ to $\Delta R^{2}=.13, \beta=.43, p<.001$, depending on which personality variable was included in the regression. The main effect of conscientiousness was also significant $\left(\Delta R^{2}=.03, \beta=.19, p<.01\right)$, as were the main effects of duty $\left(\Delta R^{2}=.04, \beta=.21, p<.01\right)$, achievement $\left(\Delta R^{2}=.02, \beta=.15\right.$, 
Conscientiousness as a Moderator 88

$p<.05)$, discipline $\left(\Delta R^{2}=.03, \beta=.18, p<.05\right)$, and deliberation $\left(\Delta R^{2}=.04, \beta=.21, p\right.$

$<.01)$. The main effects of order $\left(\Delta R^{2}=.01, \beta=.12, p>.05\right)$ and competence on job satisfaction were not significant $\left(\Delta R^{2}=.01, \beta=.11, p>.05\right)$.

However, as Tables 6-12 indicate, none of the interaction terms was

significant. The answer to RQ 1 is thus negative and H1a-c and H3a-c were not supported. That is, neither conscientiousness nor any of its facets interacted with autonomy to affect job satisfaction.

Regressions on PJ fit. RQ 2 asked whether conscientiousness would moderate the relationship between autonomy and PJ Fit, but did not predict a specific direction for the moderated effect. H2a-c predicted that a) order, b) dutifulness, and c) deliberation would moderate the relationship between autonomy and PJ Fit and that the effect of the moderation would be negative. $\mathrm{H} 4$ a-c predicted that a) achievement striving, b) competence, and c) self-discipline would moderate the relationship between autonomy and PJ Fit and that effect of the moderation would be positive. Results of these analyses, including $R^{2}$ for the final equation, $\Delta R^{2}$ for each regression step, and $\beta$ and $t$ values for individual effects, are presented in Tables 13-19. As the tables indicate, for each of the seven regressions tested, the variables explained significant variance in PJ Fit ranging from $35 \%$ to $36 \%$. When controlling for years at current job and hours worked per week as well as location, the main effect of autonomy on PJ Fit was once again significant and substantial in all regressions tested, with effect sizes ranging from $\Delta R^{2}=.10, \beta=.38, p<.001$ to $\Delta R^{2}=.13, \beta=.44, p<$ .001. However, as Tables 13-19 indicate, neither conscientiousness nor any of its 
Conscientiousness as a Moderator 89

facets had a significant main effect on PJ Fit. Moreover, none of the interaction terms was significant. The answer to RQ 2 is thus negative and $\mathrm{H} 2 \mathrm{a}-\mathrm{c}$ and $\mathrm{H} 4 \mathrm{a}-\mathrm{c}$ were not supported. In other words, neither conscientiousness nor any of its facets interacted with autonomy in its relationship to PJ fit.

\section{Hypotheses 5 through 8}

Hs 5 and 7 predicted that person-autonomy fit (PA Fit) would act as a mediator between the personality - autonomy interactions and job satisfaction, while Hs 6 and 8 predicted that PA fit would mediate the same relationship on PJ Fit. The hypothesized relationships are termed mediated moderation (Muller et al., 2005) because the effect of the moderation on the outcome is believed to be mediated by an additional variable (in this case, PA Fit). In order for an effect to be mediated, there must be an effect to begin with. Because none of the autonomy-personality interactions tested above were significant, PA Fit cannot be a mediator. Hs 5-8 are thus not supported.

\section{Supplemental Analysis}

Analysis of larger data set (Time 1 only). As discussed in the limitations section below, there was the potential that the study had insufficient power to detect some relationships, based on the power analysis conducted before beginning the study. The analyses conducted above were performed using a matched data set $(N=181)$ that separated the predictors (i.e., autonomy, conscientiousness and its facets, control variables) from the outcomes (i.e., job satisfaction, PJ Fit) in time. However, the outcome variables were also collected at T1, which resulted in a larger data set $(N=$ 256) with which to test the core hypotheses. Obviously, in the larger T1 only data set, 
Conscientiousness as a Moderator 90

the predictors were not separated in time, which might also have a tendency to inflate observed associations due to CMV. Even with the larger data set providing more statistical power and the possibility of inflated associations between variables, none of the interaction terms was significant. It is thus unlikely that the non-significant results are due to insufficient power.

Tests of hypotheses within non-managerial sub-group. Because different job types could be expected to have different levels of both autonomy and job satisfaction, it was suggested that I perform the hypothesis tests within specific jobs or job types. Participants were asked to select among nine job categories to describe their job. These categories were: Executive, Manager, Branch Manager, Sales Manager, Outside Sales, Inside Sales, Warehouse Worker, Office Worker, and Other. The largest of these categories (counter sales) only contained 51 participants, making tests of moderation in the job categories impractical due to insufficient power. However, I used an intercepts only model with job satisfaction as the dependant variable and job category as the grouping variable to calculate the ICC. The ICC (.03) was fairly near zero, which indicates only minor differences in job satisfaction across job categories.

I next examined the data collected on managerial status. There were 42 managers and 139 individual contributors in the data set. I reasoned that managers would have more autonomy than non-managers and thus examined managerial status as a moderator of the relationship between autonomy and job satisfaction, and autonomy and PJ Fit. While the effect of autonomy on satisfaction was substantial and consistent with my previous findings, neither the effect of managerial status nor 
Conscientiousness as a Moderator 91

the effect of the interaction was significant for satisfaction. The same pattern of results was produced with PJ Fit as the outcome: the main effect of autonomy was significant, but neither managerial status nor the interaction was significant. I then examined whether the hypothesized interactions were present in the subset of 139 nonmanagerial jobs. I used this group because it had the largest sample size, and also because I expected that non-managerial jobs would have a lower average level of autonomy and a greater level of consistency within this group than throughout the sample as a whole. As expected, the data showed that non-managerial jobs had a mean autonomy of $3.80(S D=.78)$ while managerial jobs had a mean autonomy of 4.11(SD=.63), and the difference was significant $(F(1,179)=5.66, p<.05)$ Moreover, autonomy in non-managerial jobs had a slightly greater standard deviation. In spite of these differences within the groups, the pattern of results for hypothesis tests within the group of non-managerial jobs was consistent with those found for the sample as a whole. I limited the tests to the interaction between conscientiousness and autonomy because the facets are so highly correlated with one-another and the results have been so consistent across the facets thus far. The interactions were not significant for either PJ fit or job satisfaction.

Exploratory Analyses

The following analyses were conducted to more fully explore the relationships among variables collected for this study. It should be noted that these relationships were not hypothesized a priori and should thus be interpreted with care. 
Conscientiousness as a Moderator 92

LMX and proactive personality as potential moderators of the effect of autonomy on satisfaction and PJ Fit. As in the other regressions, I used the dummy coded region indicators as controls. The pattern of effects was similar to those found for the regressions conducted for the tests of hypotheses in that there were some main effects but no interaction was significant.

When LMX was tested as a moderator of autonomy on satisfaction, the regression explained $38 \%$ of variance in satisfaction. The main effect of autonomy $\left(\Delta R^{2}=.07, \beta=.33, p<.001\right)$ and $\operatorname{LMX}\left(\Delta R^{2}=.07, \beta=.31, p<.001\right)$ were both significant. However, the interaction was not significant $\left(\Delta R^{2}=.00, \beta=.-01, p>.05\right)$. When LMX was tested as a moderator of autonomy on PJ fit, the regression explained $42 \%$ of variance in PJ fit. The main effect of autonomy $\left(\Delta R^{2}=.04, \beta=.26, p<.01\right)$ and LMX $\left(\Delta R^{2}=.09, \beta=.35, p<.001\right)$ were both significant. However, the interaction was not significant $\left(\Delta R^{2}=.00, \beta=.04, p>.05\right)$.

When proactive personality was tested as a moderator of autonomy on satisfaction, the regression explained $42 \%$ of variance in satisfaction. The main effect of autonomy $\left(\Delta R^{2}=.04, \beta=.26, p<.01\right)$ and proactive personality $\left(\Delta R^{2}=.09, \beta=\right.$ $.35, p<.001)$ were both significant. However, the interaction was not significant $\left(\Delta R^{2}\right.$ $=.00, \beta=.-08, p>.05)$. When proactive personality was tested as a moderator of autonomy on PJ fit, the regression explained 33\% of variance in PJ fit. The main effect of autonomy $\left(\Delta R^{2}=.13, \beta=.40, p<.001\right)$ was significant. However, neither the effect of proactive personality $\left(\Delta R^{2}=.00, \beta=.02, p<.05\right)$ nor the interaction were significant $\left(\Delta R^{2}=.00, \beta=.03, p>.05\right)$. 
Conscientiousness as a Moderator 93

PA Fit as a mediator of autonomy on job satisfaction. Hs 5a-c and 7a-c

predicted that PA Fit would mediate the moderated effect of autonomy and conscientiousness on job satisfaction. Because there was no evidence of this moderation on job satisfaction, it is impossible for PA Fit to function as a mediator, and these hypotheses were thus not supported. However, as discussed above, there were strong main effects of autonomy on job satisfaction, and thus I examined whether PA Fit would mediate the relationship between the main effect of autonomy and job satisfaction. In order to test this relationship, I performed a test of mediation using the INDIRECT macro for SPSS (Preacher \& Hayes, 2008). The macro calculated a total indirect effect on job satisfaction of .30, with a $95 \%$ confidence interval of .14 to .45 using bootstrapped standard errors. The indirect effect is significant because the confidence interval does not cross zero. Moreover, the significant direct effect of autonomy on job satisfaction $(\beta=.36, t=6.35, p<.001)$ when calculated without PA Fit in the model was reduced and became non-significant $(\beta=.06, t=.65, p>.05)$ when PA Fit was entered into the equation. The effect of autonomy on job satisfaction was thus fully mediated by PA Fit. This result suggests that the way an individual experiences the perceived fit between the level of autonomy they have at work and the level they desire is more important than the amount of autonomy present in their work environment.

PJ Fit as a mediator between autonomy and job satisfaction. As discussed above and as Tables 13-19 indicate, the relationships between the facets of conscientiousness and PJ Fit were not significant. I had thought that, at a minimum, 


\section{Conscientiousness as a Moderator 94}

conscientiousness and its facets would be related to perceptions of job fit because I reasoned that individuals with different levels of conscientiousness would find different types of work satisfying. However, the data do not appear to support this assumption. The finding that conscientiousness was largely unrelated to PJ fit was especially surprising because PJ Fit was so highly correlated with job satisfaction $(r=$ $.75, p<.001)$, and as the results of the analysis of hypotheses showed, the facets of conscientiousness showed a strong and consistent pattern of associations with job satisfaction, but did not show associations with PJ Fit. Because PA Fit was already shown to be a mediator of autonomy on job satisfaction, I reasoned that PJ Fit may act as a mediator as well. However, because PJ Fit was largely unrelated to conscientiousness, I reasoned that PJ Fit might be operating as a mediator of environmental variables such as autonomy, but not dispositional variables, such as conscientiousness.

In order to more fully examine this relationship, I performed a test of mediation using the INDIRECT macro for SPSS (Preacher \& Hayes, 2008). Autonomy was entered as the predictor, PJ Fit the mediator, and job satisfaction the outcome. I also included conscientiousness as a covariate. Because PJ Fit was being treated as an antecedent of job satisfaction, I used the data for PJ Fit that was collected at $\mathrm{T} 1$ and the data for job satisfaction that was collected at T2. The macro calculated a total indirect effect of .26 , with a $95 \%$ confidence interval of .17 to .37 using bootstrapped standard errors. This indicates a significant effect because the confidence interval does not cross zero. Furthermore, the significant direct effect of 
Conscientiousness as a Moderator 95

autonomy on job satisfaction $(\beta=.35, t=6.35, p<.001)$ dropped to non-significance $(\beta=.09, t=1.45, p>.05)$ when PJ Fit was viewed as a mediator, indicating that PJ Fit fully mediates the effect of autonomy on job satisfaction. The effect of conscientiousness on job satisfaction was also significant $(\beta=.17, t=2.23, p<.001)$. These results support the notion that PJ Fit mediates the effect of autonomy on satisfaction, and that conscientiousness explains additional variance in satisfaction over and above this relationship.

Stepwise Regression on Satisfaction. I collected data regarding LMX and proactive personality as part of the data set used in the study conducted for this dissertation, although I did not make formal hypotheses regarding them. However, given the strong relationship between conscientiousness (an individual variable) and job satisfaction and the even stronger relationship between autonomy (an environmental variable) and job satisfaction, and given the fact that conscientiousness and autonomy were not significantly correlated with each other, I examined these additional individual and environmental variables to explore their relationship with job satisfaction. I included yearly earnings as a control variable because a) it is correlated with autonomy and b) because it could be argued that more complex jobs are both higher in autonomy and also pay more, thus leading to more satisfaction. I also included PA Fit because it appeared to mediate the effect of autonomy on job satisfaction. In order to explore these relationships, I performed stepwise (statistical) regression, using conscientiousness, autonomy, PA Fit, proactive personality, LMX, and earnings. In the final model, three predictors-PA Fit, LMX, and 
conscientiousness-collectively accounted for $35 \%$ of observed variance in job satisfaction. Moreover, each predictor explained significant incremental variance when added to the model. PA Fit alone explained $26 \%$ of variance $\left(R^{2}=.26, F(1\right.$, $157)=55.05, p<.001)$. LMX explained an additional $6 \%$ of variance when added to the model $\left(\Delta R^{2}=.06, F(1,156)=12.96, p<.001\right)$, and conscientiousness explained $3 \%$ of variance $\left(\Delta R^{2}=.03, F(1,155)=6.86, p<.01\right)$, over and above these other two variables when added to the model. Autonomy itself was not part of the model. Proactive personality, while related to satisfaction alone, was not significantly related to satisfaction when controlling for conscientiousness. Considering the numerous possible variables related to job satisfaction, it is interesting that such a substantial proportion of variance can be explained by only three variables: one individual (conscientiousness), and two that refer to the experience of fit between the individual and the environment (PA Fit and LMX). 
Conscientiousness as a Moderator 97

Chapter 8: Discussion

The study conducted for this dissertation examined three core propositions regarding a person's interaction with his or her work environment. First, I investigated whether conscientiousness and its facets would interact with autonomy in its association with job satisfaction and PJ Fit. Second, I examined whether the interactions would have differential effects on the outcomes. In the case of competence, orderliness, and achievement striving, the effect of the moderation on the outcomes was predicted to be positive. That is, the overall positive effect of autonomy on job satisfaction and PJ Fit would be increased when autonomy interacted with these facets. In the case of order, discipline, and deliberation, the effect of the moderation on the outcome was predicted to be negative. That is, while the overall effect of autonomy on job satisfaction and PJ Fit was predicted to be positive, it was predicted that the relationship between autonomy and the outcomes would be reversed when autonomy interacted with order, discipline and deliberation. Third, I investigated whether these moderated effects would then be mediated by PA Fit.

Unfortunately, the data did not support these predictions, although I did discover several interesting findings regarding job satisfaction, autonomy and personality by performing supplemental and exploratory analyses. Findings for each research question and hypothesis, as well as implications of the results of the supplementary and exploratory analysis are discussed more fully below. Implications for research and practice, study limitations, and directions for future research are then discussed. 
Conscientiousness as a Moderator 98

\section{Findings Regarding Job Satisfaction}

RQ 1 asked whether conscientiousness would interact with autonomy in its association with job satisfaction. H1a-c and $\mathrm{H} 3 \mathrm{a}-\mathrm{c}$ predicted that the facets of conscientiousness would interact with autonomy in their effects on job satisfaction, and specified the direction for these interactions. While none of these hypotheses was supported, there were strong main effects for both autonomy and conscientiousness and its facets on job satisfaction.

These results, which provide evidence of strong main effects but no interactions, echo previous research on the relationship between both autonomy and job satisfaction and conscientiousness and job satisfaction. Regarding autonomy, for example, Loher et al. (1985) performed a meta-analysis that found that autonomy and job satisfaction were related at $\rho=.46$ (corrected). As indicated in Table 4 , my study

found an uncorrected zero order correlation between autonomy and job satisfaction of $r=.43$, which is quite strong, and is also consistent with Loher et al's finding. Moreover, this effect remained strong even when other factors related to job satisfaction were included in the equation. For example, the regression equation used to answer RQ1 which included the 15 location variables, hours worked per week, salaried status, autonomy, conscientiousness and the autonomy x conscientiousness interaction, still produced a strong effect of autonomy on satisfaction $\left(\Delta R^{2}=.11, \beta=\right.$ $.42, p<.001)$. This finding is in keeping with a long line of research showing that autonomy is one of the most critically important antecedents to job satisfaction (e.g., Hackman \& Oldham, 1975; Vough \& Parker, 2008). 
Conscientiousness as a Moderator 99

Judge and colleagues (2002) explained the relationship between conscientiousness and job satisfaction as at least partially dispositional, and found a meta-analytic correlation between the two of $\rho=.28$. The results of this study provide additional support for their explanation. In addition to the significant zeroorder correlations between the conscientiousness facets and job satisfaction (see Table 4), conscientiousness and most of its facets explained significant variance in job satisfaction even when controlling for location, hours worked per week, salary status, autonomy, and the autonomy x conscientiousness interactions. As the results indicate, these significant effect sizes ranged from $\Delta R^{2}=.02, \beta=.15, p<.05$ for achievement to $\Delta R^{2}=.04, \beta=.20, p<.01$ for dutifulness. Moreover, evidence from an exploratory step-wise regression procedure showed that conscientiousness, as an individual difference variable, explained a significant portion of variance (3\%) in satisfaction. This effect occurred even in the presence of two variables-PA Fit and LMX - which refer to the interaction between the person and the environment, and which also collectively captured significant variance (32\%) in job satisfaction.

Taken together, these findings suggest that job satisfaction can be explained by both dispositional elements, such as conscientiousness, and environmental elements, such as autonomy. It also suggests that even though autonomy is a strong environmental predictor of job satisfaction, the subjective experience of that autonomy in the form of PA Fit is an even stronger predictor and fully mediates the effect of autonomy on satisfaction. More generally, elements that measure individuals' interaction with their environment, such as their attitudes regarding how well their 
autonomy fits their desires (i.e. PA Fit) and how well they get along with their boss (i.e. LMX) appear to be better predictors of job satisfaction than the environmental elements alone. However, the current study finds no evidence that conscientiousness and autonomy directly interact with each other in relation to job satisfaction. Perhaps the critical factor is whether a person receives the amount of autonomy that he or she desires, rather than whether their level of conscientiousness is associated with how much autonomy they desire.

\section{Findings Regarding PJ Fit}

RQ2 asked whether conscientiousness would interact with autonomy in its association with PJ Fit. H2a-c and $\mathrm{H} 4 \mathrm{a}-\mathrm{c}$ predicted that the facets of conscientiousness would interact with autonomy in their effects on PJ Fit, and specified the direction for these interactions. As with job satisfaction, none of these hypotheses was supported. As Table 7 indicates, there was a strong main effect of autonomy on PJ Fit with effect sizes ranging from $\Delta R^{2}=.12, \beta=.41, p<.001$ to $\Delta R^{2}$ $=.09, \beta=.36, p<.001$, depending on which facet of personality was included in the regression. However, unlike job satisfaction, the relationships between the facets of conscientiousness and PJ Fit were not significant.

These results suggest that the amount of autonomy provided by the job is an important part of workers' cognitive evaluations of PJ Fit. That is, workers who perceived more autonomy also agreed that their jobs fit them better. However, conscientiousness and its facets were largely unrelated to the experience of PJ Fit, which does not support the notion that conscientiousness affects individual's 
cognitions regarding fit with their job when controlling for autonomy. I had thought that, at a minimum, conscientiousness and its facets would be related to perceptions of job fit because I reasoned that individuals with different levels of conscientiousness would find different types of work satisfying. However, the data do not appear to support this assumption.

A potential explanation for the strong association between autonomy and PJ Fit but a relative lack of association between conscientiousness and PJ Fit is offered by the exploratory analysis testing PJ Fit as a possible mediator of the effect of autonomy on job satisfaction. As mentioned above, conscientiousness has been shown by past research and the current study to have a relatively stable relationship to job satisfaction, and this relationship is assumed to be dispositional in nature (Judge et al., 2002). The current study also provides evidence that job satisfaction and PJ Fit are very highly correlated at .75 , but also appear to be separate factors. I might speculate that the variance in job satisfaction that is not shared by PJ Fit is explained by conscientiousness and other unmeasured individual difference constructs. If this is true, PJ Fit would be operating as a mediator for the portion of job satisfaction that is influenced by environmental variables, but not for the portion that is influenced by dispositional variables. PJ Fit would thus function as a more proximal antecedent of job satisfaction, which would explain both its high correlation with job satisfaction and its relative lack of association with conscientiousness. These results of the exploratory analysis conducted above support the notion that PJ Fit mediates the effect of autonomy on satisfaction, and that conscientiousness explains additional variance in 
Conscientiousness as a Moderator 102

satisfaction over and above this relationship. However, it should be noted that these relationships were not hypothesized and should thus be interpreted with care.

\section{Research Implications}

The notion that individual differences moderate the effect of work design elements on outcomes has all but been thrown out by well respected researchers in work design (Morgeson \& Campion, 2003; Morgeson \& Humphrey, 2006). Prior to conducting this study, I thought that this conclusion was premature because individual differences were part of the original job characteristics model (Hackman \& Oldham, 1975) and several studies have suggested that individual differences moderate the effect of at least some work design elements on outcomes (e.g., Barrick \& Mount, 1993; Loher et al., 1985). The study performed for this dissertation found no evidence of an interaction between conscientiousness or its facets and autonomy.

The lack of support for conscientiousness as a moderator of autonomy appears to echo Morgeson and Campion's (2003) assertion that increased autonomy at work has an overall beneficial effect across individuals. However, it may still be too early to throw the proverbial baby out with the bathwater. That is, the role of individual differences as a moderator of the effects of job characteristics deserves further study. There remain several additional variables that can and should be examined as potential moderators of work design elements on attitudinal outcomes such as job satisfaction and PJ fit. For example, Grant, Fried, and Juillerat (2010) recommend a program of research into the interaction between individual differences and elements of work design that includes all of the Big Five factors. The study conducted for this 
dissertation provided a step in that direction by examining conscientiousness and its facets as potential moderators of autonomy. However, the interactions between other Big Five moderators and other work design elements can and should be studied. Other than the study conducted for this dissertation, there is only one published study that examines the interaction between work design and job satisfaction. In that study, deJong et al. (2001) provided evidence that openness to experience moderated the effect of skill variety (a job characteristic) on job satisfaction. Furthermore, Grant (2008) described an experiment in which conscientiousness was shown to moderate the relationship between task significance (a task-based job characteristic) and performance, such that the effect of task significance on performance was stronger for employees with lower conscientiousness. There is thus still reason to believe that Big Five personality constructs may interact with work design characteristics, even though my study did not provide evidence of the interaction between conscientiousness and autonomy on job satisfaction or PJ Fit.

Hough and Furnham (2003) also cite sixteen personality variables that are not contained within the Big Five taxonomy, which include variables such as rugged individualism, aggression and hostility, social adroitness and social insight, religiosity, villainy, orthodoxy, egotism, snobbery, aesthetic sensitivity, and positive and negative valence, which could also be considered as possible moderators of work design elements on a host of outcomes. In short, it may be that conscientiousness does not moderate the effect of autonomy on job satisfaction and PJ fit; however, this may not be true of all job characteristics and all individual differences. 
Conscientiousness as a Moderator 104

My study also examined personality as a moderator at the facet level and predicted differential effects for facets within the conscientiousness factor. There is reasonably strong agreement among personality psychologists regarding the utility of the Big Five global factors (Digman, 1990), and the I-O literature contains many studies that show the association of the Big Five with a host of important outcomes. However, research into the 30 facets that underlie the Big Five remains scant. This is unfortunate because the best constellation of predictors for a given criterion may be a selected group of narrow facets from several higher order factors, rather than all of the facets from one of the Big Five. Although research into the facets of the Big Five has been gaining steam, there are few studies that directly test all the facets of a single Big Five construct.

In the current study, I predicted that there would be differential effects on PJ Fit and job satisfaction by facet. This would have suggested that there was heterogeneity within the Big Five constructs, and would have provided reason to support the use of facets as predictors, rather than their global cousins. However, although there were differences in effect size by facet, the overall pattern of effects was consistent. For example, all of the facets of conscientiousness except for competence and orderliness were significantly related to job satisfaction, but none of the facets was significantly related to PJ Fit. And when there were differences in significance — as with competence and orderliness—it was difficult to determine whether this finding was due to a lack of a relationship or to measurement error. It is also possible that a different configuration of facets across the Big Five 
would have produced evidence of interactions between personality and autonomy. For example, Inceoglu and Warr (2011) note that the facets of Conscientiousness can be classified according to the level of activity implied by their item content, clustered around achievement orientation (active) and dependability (passive). In the current study, the strongest interaction effects between autonomy and conscientiousness on both job satisfaction were for achievement striving and deliberation. While these effects were not statistically significant, they were in the hypothesized direction and had $\Delta R^{2}$ values at or near .01. Moreover, these effects are consistent with the active/passive classification of facets suggested by Inceoglu and Warr.

In hindsight, it seems unlikely that there would exist sufficient heterogeneity among the facets to produce disordinal effects from each other at the facet level. This is because they are facets of a higher level construct, and are, by definition, fairly strongly intercorrelated with one another. Strong differences in their relationship to other constructs would thus be unlikely, especially with relatively broad constructs such as PJ Fit and job satisfaction. It should be noted that this homogeneity among facets may have been exacerbated by my practical choice to use only the positively worded items (also discussed in the limitations section below) from the facet scales. Due to practical concerns regarding survey length, I eliminated 29 negatively worded items from the original 60 item conscientiousness scale. This choice may have decreased the differences between facets, and increased the correlations among them.

Furthermore, several researchers (e.g. Hough \& Furnham, 2003; Paunonen et al., 1999) have suggested that the facets are best used as predictors when the criterion 
is on a similar level of specificity. By this logic, differences in facet-level associations with more narrow criteria than job satisfaction or PJ fit might have been found if more narrow criteria were selected. The new measure of PA fit, adapted from an existing measure of PJ fit originally developed by Cable and DeRue (1998), gestures in this direction. The PA fit measure used in my study had excellent internal consistency reliability $(\alpha=.93)$ and was shown via CFA to be distinct from the PJ fit measure from which it was adapted. Moreover, PA fit was shown to fully mediate the main effect of autonomy on satisfaction.

These results suggest that researchers may find it fruitful to examine how well individual characteristics fit individual work design elements. In the current study, I measured how well individuals felt they fit with a single work design element (autonomy), and found that the fit measure was a key predictor of job satisfaction. Based on the notion that narrow predictors are best suited to predicting narrow criteria, it would make sense to develop additional measures of how well an individual fits with relevant work design elements. For example, additional scales could be created to measures fit with work design elements such as skill variety, job complexity, information processing, and social support, to name a few.

A few other implications for research stem from the findings regarding mediation. Specifically, in the current study, both PA fit and PJ fit fully mediated the relationship between autonomy and job satisfaction. Although these mediated relationships were not directly hypothesized as part of this dissertation, PA fit was hypothesized to be a mediator of the autonomy by conscientiousness interaction and 
job satisfaction. It was also suggested theoretically that PJ fit may be a proximal antecedent to job satisfaction. Given the strong effect of autonomy on job satisfaction, it seemed prudent to investigate whether PA fit and PJ fit would mediate this relationship. In both cases, it appears that the individual experience of fit-whether with the relatively narrow aspect of autonomy or with the more broad job in generalis very important to the overall satisfaction with one's job. I would like to conclude that the subjective experience of fit, whether with autonomy or the job in general, is part of a causal chain wherein the amount of autonomy causes a perception of greater PA fit or PJ fit, which in turn cause a greater amount of satisfaction. However, the study design does not allow for such a conclusion. It is possible, for example, that both PA Fit and PJ Fit capture similar attitudes to job satisfaction, and what looks like causal mediation is just autonomy capturing the shared variance in both attitudes measures. Future research should clearly examine the mediating potential of both PJ fit and PA fit.

\section{Practical Implications}

The results of this study provide two key practical implications, both pertaining to job satisfaction, for the practice of work design and other workplace interventions. First, I had predicted that conscientiousness would interact with autonomy in its relationship to job satisfaction. If the data had supported these predictions, I would have suggested that jobs could be tuned to suit the individual. For example, I reasoned that some individuals may prefer higher levels of autonomy, while others might prefer lower levels, and that certain aspects of the job-such as the 
amount of autonomy—could be changed to suit each individual worker. However, my study did not provide evidence that this type of interaction exists. Instead, both autonomy and conscientiousness were significantly related to job satisfaction, with autonomy having a much stronger effect than conscientiousness. Although it is possible that other personality variables interact with autonomy in a similar way to that hypothesized in this dissertation, the consistent and substantial main effects of autonomy and conscientiousness cannot be denied.

As the results of my study show, organizations interested in providing an environment that is associated with high levels of satisfaction can do so by using the tools of selection and work design. First, organizations can use personality instruments to help them select workers that are highly conscientious. Because conscientiousness is associated with job satisfaction, and is believed to be dispositional in nature, selecting workers with higher conscientiousness may lead to an overall higher level of satisfaction across the organization. However, in my study, autonomy explained $11 \%$ of variance in satisfaction, while conscientiousness only explained 3\% when controlling for each other. These results suggest that organizations would be better off focusing on creating work environments that feature high levels of autonomy if job satisfaction is the goal.

Examples of these environments range from the simple to the complex: flexible scheduling, job sharing and the option to work from home offer higher levels of autonomy and can be implemented without great changes to organizational culture. Other, more complex interventions include the Results Only Workplace Environment 
(ROWE; Kelly, Ammons, Chermack \& Moen, 2010), a workplace culture that allocates total autonomy to workers. The ROWE completely eliminates mandatory meetings and monitored vacation time, and sets no limitations on the location from which an employee works. Employees can perform any and all aspects of their work wherever and whenever they want, as long as they meet their work objectives.

The second core implication for practice is suggested by a supplemental analysis I performed to investigate the best predictors of satisfaction. The notion that jobs can be viewed as set of linked tasks performed independently of the larger organizational context has permeated much of the work characteristics and job design literature (e.g., Hackman \& Oldham, 1971). This makes some sense as job design is primarily concerned with defining tasks and activities performed on the job. However, satisfaction with the job can be impacted not only by job tasks, but also by the person's interactions with his or her manager and coworkers, the work styles of one's supervisor and the norms of the larger organization.

Satisfaction may also be impacted by more instrumental and external rewards (e.g., pay, opportunities for promotion). I found that autonomy, LMX, and conscientiousness collectively accounted for $35 \%$ of the variance in job satisfaction, which is a very strong effect. Moreover, neither yearly earnings, nor salaried status, nor whether or not the employee was a manager was significantly related with job satisfaction when entered into the same regression as autonomy, LMX and conscientiousness. These results suggest that these instrumental rewards such as pay and promotions are less important to job satisfaction than having autonomy at work 
and a good relationship with one's boss. In fact, the data suggest that pay and promotion opportunities are largely irrelevant to job satisfaction, at least at this particular organization and with this set of jobs. Organizations interested in the job satisfaction of their workers may thus be advised to focus their efforts on work design elements such as autonomy, instead of instrumental rewards.

In keeping with the call from Weiss and Rupp (2010) for a more personcentered approach to research in I-O psychology, this study focused on job satisfaction as an end in itself. However, prior research has shown strong links using metaanalytic methods between satisfaction and outcomes beneficial to the organization such as motivation, citizenship behaviors, intentions to leave the organization, absenteeism, turnover, lateness, and both objective and subjective performance criteria (Kinicki et al., 2002). It would thus appear that individual job satisfaction is not only important to workers, but is also important to the "collective agenda" of the organization. As such, interventions that are thought to create high levels of job satisfaction (through enriched autonomy or better supervisor/supervisee relations, for example) are likely to be important not only to workers, but also to the "collective agenda" of the organization.

\section{Potential Limitations}

The proposed study does have some limitations that should be noted. First, although data were collected at two time points in order to minimize the effect of CMV, the study was not designed to detect change in the outcome variables. Thus, although there was some evidence of the mediating effect of PJ Fit and PA Fit, it was 
impossible to make causal inferences. In addition, the study design does not completely eliminate the possibility that CMV will lead to spurious correlations between study variables because the all data were collected using self report surveys. However, I took steps to control CMV by keeping the data collection anonymous and by separating data collection into two time points, both of which are suggested by Podsakof et al. (2003) as useful strategies for reducing its impact.

Second, although participants held a wide range of jobs, hailed from various locations throughout the United States, and worked at a number of independently owned locations, each location is part of a larger co-operative with a set of shared work processes and values. It is thus possible that some form of self-selection occurred-perhaps workers at this particular organization or in this particular industry are more satisfied with autonomy than pay, for example. The average number of years on the job and the average number of years with the company were also quite high at 6.3 and 9.7, respectively, which could have resulted in a restriction of range, as people with low job satisfaction or PJ fit leave the organization. Range restriction generally leads to smaller effect sizes, however, and the main effects of autonomy on PJ Fit of autonomy and the facets of conscientiousness on satisfaction were quite large, suggesting that range restriction was unlikely a problem.

Third, the matched data set had 181 cases, 75 fewer than the 256 cases recommended by the power analyses and it was not possible to collect more data at the organization that took part in the study. It is possible that this could have led to insufficient power to detect the interaction effects. However, as explained above, this 
is likely not the case. I tested the core analyses using a larger data set with 256 cases for which all data was collected at T1. No interaction was significant in the larger data set, and the effect sizes had only trivial differences. Moreover, the largest effect size obtained in the tests of hypotheses was for the effect of the achievement $\mathrm{x}$ autonomy interaction on job satisfaction, and it was trivial $\left(\Delta R^{2}=.006, \beta=.09, p>.05\right)$. While it would be possible to collect enough data to find significance with these small effect sizes, the magnitude of the interaction effects do not appear to be practically significant in either data set. Moreover, based on the large effect of autonomy on job satisfaction and PJ fit, it makes more practical sense for organizations interested in worker satisfaction to provide highly autonomous work environments rather than focusing on individual personality-based interactions with the work environment.

Fourth, as indicated above, I made a practical decision to limit the facet scales to their 31 positively worded items, rather than the 60 original items, which include the negatively worded items. This decision may have led to increased homogeneity among facets, and may have masked potential differences in facet level relationships that would have been apparent if the entire facet scale were used, which may have been a factor in the lack of significant findings for the interaction effects.

Perhaps most importantly, the study was limited to examining the interaction of a single Big Five variable and its facets with a single work design variable on a handful of attitudinal outcomes. While I had a theoretical basis for hypothesizing these interactions, the data did not appear to support my hypotheses. However, there are a host of potential individual differences and work design variables that were not 
included in this study, and some suggestions for future research into these other variables are discussed in the following suggestions for future research.

\section{Suggestions for Future Research}

The goal of this dissertation was to contribute to the literature by examining one of the Big Five factors and its facets as moderators of the effect of work design on attitudinal outcomes, as had been suggested by Grant and colleagues (2010). In order to accomplish this task, I selected a single Big Five factor (conscientiousness) and examined each of its facets as a potential moderator of the effect of a single work characteristic (autonomy) on job satisfaction and PJ Fit. My study did not provide evidence of these interactions, although it still seems likely that at least some individual differences interact with the environmental characteristics of the work place.

If this is the case, the question regarding which individual differences and which work characteristics—be they specific aspects of the job, aspects of the supervisor-supervisee relationship, or aspects of the organization-interact with each other remains. As discussed in the preceding section, one issue with my study may have been the narrow focus on a single Big Five factor and a single work design element. Future researchers interested in the moderating potential of individual differences on work environments may do well to start with an exploratory study that uses broad multi-dimensional measures of work design along with multi-dimensional measures of individual differences, so that potential moderators can be identified. Moreover, this type of exploratory study should be conducted on a large sample of 
participants holding a wide range of jobs at diverse organizations. Because different jobs contain different levels of work design characteristics such as autonomy, and a larger array of personality scores, it should be easier to detect interactions among these variables. Furthermore, because jobs are nested within the cultural and social aspects of an organization, a wide variety of organizations would further increase the variance. Future researchers may also wish to examine the interaction between other specific individual differences and other specific work design elements, many of which can be measured using the WDQ (Morgeson \& Humphrey, 2006). The individual differences include other Big Five personality factors, such as extraversion and openness to experience. For example, extraversion may interact with the social characteristics measured by the WDQ, such as social support and interdependence. Personality variables need not be limited to Big Five constructs, either. For example, adaptability may interact with autonomy, but may also interact with work design elements such as task variety, specialization, and job complexity. Finally, individual differences may include variables outside the personality domain. It is likely, for example, that cognitive ability or general mental ability would interact with work design elements such task variety, job complexity, information processing and problem solving.

Another direction for future research involves examining the personality and environmental interactions at different phases of tenure with an organization or one's career in general. The current study approached the interaction question using a crosssection of employees, with an average organizational tenure of 9.1 years. Although 
the standard deviation was quite large $(S D=7.2)$ relative to the mean, the long average tenure implies that at least some restriction of range in the outcomes may have occurred because highly dissatisfied workers or those who feel they do not fit their jobs likely self-selected out. Future researchers interested in an interactionist approach to work design may do well to focus on new workers in the organization who have not yet self-selected out of their jobs and likely have not yet had the opportunity for substantial job crafting.

The current study also focused exclusively on outcomes that are mostly of importance to the individual: person-job fit and job satisfaction. The study found that on-the-job autonomy was strongly related to job satisfaction and PJ Fit. Furthermore, these effects persisted even when controlling for variables such as salaried status, managerial status, and yearly earnings. Because these latter variables are indicative of pay and promotion, which tend also to be associated with higher levels of autonomy, the findings suggest that the effect of autonomy on job satisfaction may be causal in nature, but cannot definitively suggest cause. Future research should seek to determine whether increased autonomy and other work design interventions cause increased satisfaction by performing field experiments or quasi-experiments using organizational interventions. Furthermore, future research should investigate the behavioral outcomes that are believed to be related to job satisfaction, such as turnover, performance, and organizational citizenship behaviors. Ideally, these behavioral differences should then be linked to ROI by using objective measures. This research stream would also allow for more confident conclusions regarding the 
mediating roles of such variables as PJ Fit and PA Fit on these objective outcomes.

More research is also needed that simultaneously focuses on outcomes that are important to the organization, such as performance, turnover, and tenure, and to the individual, such as job satisfaction and motivation. Morgeson and Campion (2003) note that many researchers have uncovered a tension in work design interventions, such as those designed to increase autonomy, in which increasing satisfaction through work design appears to come at a cost of decreasing efficiency, and suggest possible reasons for this problem. However, a few studies (e.g. Edwards et al., 2000; Morgeson \& Campion, 2002) suggest that this is not the case as long as work is redesigned with both satisfaction and performance in mind. Future studies should further investigate these relationships with the goal of uncovering interventions that work on both sets of variables, or with the goal of illuminating the optimum point where both satisfaction and performance are maximized. This could be accomplished by including measures of performance, be they objective (e.g. sales performance, profitability) or subjective (e.g. supervisor ratings), along with attitudinal measures.

Additionally, while there are a number of studies that have shown that motivational interventions increase satisfaction, they have largely been conducted on entry level and manufacturing jobs (Morgeson \& Campion, 2003), for which traditional work design frameworks seem to be best-suited. The original Job Characteristics framework (Hackman \& Oldham, 1971) viewed work primarily as a linked set of tasks performed by independent workers. This view makes sense when considering industrial jobs, in which workers often perform a repetitive set of tasks 
using a limited skill set. However, as Oldham and Hackman (2010) noted, the nature of work and our understanding of the phenomena has changed. Knowledge workers must often perform complex tasks using a variety of divergent skill sets and learn new skills and techniques on the fly. They also noted that work today is characterized by higher levels of flexibility, social interaction, inconsistency and change. Future research should examine work design and its outcomes from this perspective, using multi-dimensional frameworks such as the WDQ.

\section{Conclusion}

My reasons for conducting the study contained in this dissertation stemmed from an intuitive belief that different people will respond to and prefer different work environments depending on their unique set of abilities, proclivities and personality characteristics. In order to examine this belief in a reasonably parsimonious way, I selected an oft-studied element of work design (autonomy) and hypothesized that it would interact with a single personality characteristic and its underlying facets (conscientiousness) to affect worker's job attitudes in the form of their job satisfaction and their cognitions regarding their person-job fit. I reasoned that certain facets of conscientiousness such as order, dutifulness and deliberation would lead to less satisfaction with autonomy because they implied more desire for structured environments. On the contrary, I thought, facets of satisfaction such as achievement striving, competence and self-disciplined would lead to greater satisfaction with autonomy because they implied a higher level of self-motivation and drive. However, my study did not uncover evidence of any such interactions in the case of these two 
isolated variables. Instead, autonomy was very highly related to job satisfaction, suggesting that in general workers find high levels of autonomy to be satisfying and to lead to a sense of fit with their jobs. I also found that conscientiousness was related to job satisfaction, but not PJ Fit, suggesting that workers with higher levels of conscientiousness may be dispositionally inclined to find work more satisfying.

In spite of the lack of support for my hypotheses, I do not believe that the interactionist approach to studying work should be abandoned. The original Five Factor Model of personality was derived using 4500 English adjectives to describe personality and cannot even begin to account for the full set of differences in abilities, desires, styles, proclivities, and tendencies among people. Similarly, any given job is made up of much more than the tasks that can be described by the factors of work design used to measure them. In addition to the set of tasks it demands, a job is a complex social phenomenon that differs in relation to other jobs in terms of its social characteristics, its supervisor-subordinate relationship, its social currency, and the values of the organization within which it exists, just to name a few. The lack of support for my hypotheses regarding the interactions may have been because I simply chose the wrong personality trait and/or the wrong work characteristic. However, it may also be that the interaction of such complex phenomena resists reduction to such a small set of descriptors and mechanisms. 
Table 1. Factors and Facets of Costa and McCrae (1992) Five Factor Model of Personality

\begin{tabular}{|c|c|}
\hline Label & Definition \\
\hline Conscientiousness & $\begin{array}{l}\text { Degree of organization, persistence, control and } \\
\text { motivation in goal-directed behavior }\end{array}$ \\
\hline C1: Competence & Belief in one's own self-efficacy \\
\hline C2: Order & Personal organization \\
\hline C3: Dutifulness & $\begin{array}{l}\text { Emphasis placed on importance of fulfilling moral } \\
\text { obligations }\end{array}$ \\
\hline C4: Achievement Striving & Need for personal achievement and sense of direction \\
\hline C5: Self Discipline & $\begin{array}{l}\text { Capacity to begin tasks and follow through to } \\
\text { completion despite boredom or distractions }\end{array}$ \\
\hline C6: Deliberation & $\begin{array}{l}\text { Tendency to think things through before acting or } \\
\text { speaking }\end{array}$ \\
\hline Extraversion & $\begin{array}{l}\text { Quantity and intensity of energy directed outwards } \\
\text { into the social world }\end{array}$ \\
\hline E1: Warmth & Interest in and friendliness toward others \\
\hline E2: Gregariousness & Preference for the company of others \\
\hline E3: Assertiveness & Social ascendancy and forcefulness of expression \\
\hline E4: Activity & Pace of living \\
\hline E5: Excitement seeking & Need for environmental stimulation \\
\hline E6: Positive Emotions & Tendency to experience positive emotions \\
\hline Openness to Experience & $\begin{array}{l}\text { The active seeking and appreciation of experiences } \\
\text { for their own sake }\end{array}$ \\
\hline O1: Fantasy & Receptivity to the inner world of imagination \\
\hline O2: Aesthetics & Appreciation of art and beauty \\
\hline O3: Feelings & Openness to inner feelings and emotions \\
\hline O4: Actions & Openness to new experiences on a practical level \\
\hline O5: Ideas & Intellectual curiosity \\
\hline O6: Values & $\begin{array}{l}\text { Readiness to re-examine own values and those of } \\
\text { authority figures }\end{array}$ \\
\hline Agreeableness & $\begin{array}{l}\text { The kinds of interactions an individual prefers, from } \\
\text { compassion to tough mindedness }\end{array}$ \\
\hline A1: Trust & Belief in the sincerity and good intentions of others \\
\hline A2: Straightforwardness & Frankness in expression \\
\hline A3: Altruism & Active concern for the welfare of others \\
\hline A4: Compliance & $\begin{array}{l}\text { Tendency to avoid and quickly resolve interpersonal } \\
\text { conflict }\end{array}$ \\
\hline A5: Modesty & $\begin{array}{l}\text { Tendency to down play one's own achievements and be } \\
\text { humble }\end{array}$ \\
\hline A6: Tender mindedness & Attitude of sympathy toward others \\
\hline
\end{tabular}


Conscientiousness as a Moderator 120

Table 1. Factors and Facets of Costa and McCrae (1992) Five Factor Model of Personality (continued)

\begin{tabular}{ll}
\hline Label & Definition \\
\hline Neuroticism & Individuals who are prone to psychological distress \\
N1: Anxiety & $\begin{array}{l}\text { Level of free floating anxiety } \\
\text { Tendency to experience anger and related states such as } \\
\text { frustration and bitterness }\end{array}$ \\
N2: Angry Hostility & $\begin{array}{l}\text { Tendency to experience feelings of guilt, sadness, } \\
\text { despondency, and loneliness }\end{array}$ \\
N3: Depression & $\begin{array}{l}\text { Shyness or social anxiety } \\
\text { Tendency to act on cravings and urges rather than } \\
\text { reigning them in and delaying gratification }\end{array}$ \\
N5: Impulsiveness & General susceptibility to stress
\end{tabular}

Note. Adapted from "Who Am I? Well, It Depends: How Frame-of-Reference Imposes Context In Non-Contextualized Personality Inventories," by E. A. McCune. Unpublished Dissertation. 
Conscientiousness as a Moderator 121

Table 2. Hypotheses Regarding Personality as a Moderator of the Relationship between Autonomy and Job Satisfaction

\begin{tabular}{llll}
\hline Hypothesis & Moderator & Outcome & Direction \\
\hline RQ1 & Conscientiousness (C) & Job Satisfaction & unspecified RQ \\
RQ2 & C & Person Job (PJ) Fit & unspecified RQ \\
1a & orderliness & Job Satisfaction & Negative \\
1b & dutifulness & Job Satisfaction & Negative \\
$1 \mathrm{c}$ & deliberation & Job Satisfaction & Negative \\
2a & orderliness & PJ Fit & Negative \\
2b & dutifulness & PJ Fit & Negative \\
2c & deliberation & PJ Fit & Negative \\
$3 \mathrm{a}$ & achievement striving & Job Satisfaction & Positive \\
$3 \mathrm{~b}$ & competence & Job Satisfaction & Positive \\
$3 \mathrm{c}$ & self-discipline & Job Satisfaction & Positive \\
$4 \mathrm{a}$ & achievement striving & PJ Fit & Positive \\
$4 \mathrm{~b}$ & competence & PJ Fit & Positive \\
$4 \mathrm{c}$ & self-discipline & PJ Fit & Positive \\
\hline
\end{tabular}


Conscientiousness as a Moderator 122

Table 3. Hypotheses Regarding PJ Fit as a Mediator of the Autonomy x Personality Interaction

\begin{tabular}{llll}
\hline Hypothesis & Moderator & Mediator & Outcome \\
\hline 5 & Conscientiousness (C) & Person-Autonomy (PA) fit & Job Satisfaction \\
6 & C & PA fit & Person Job (PJ) Fit \\
$7 \mathrm{a}$ & orderliness & PA fit & Job Satisfaction \\
$7 \mathrm{~b}$ & dutifulness & PA fit & Job Satisfaction \\
$7 \mathrm{c}$ & deliberation & PA fit & Job Satisfaction \\
$7 \mathrm{~d}$ & achievement striving & PA fit & Job Satisfaction \\
$7 \mathrm{e}$ & competence & PA fit & Job Satisfaction \\
$7 \mathrm{f}$ & self-discipline & PA fit & Job Satisfaction \\
$8 \mathrm{a}$ & orderliness & PA fit & PJ Fit \\
$8 \mathrm{~b}$ & dutifulness & PA fit & PJ Fit \\
$8 \mathrm{c}$ & deliberation & PA fit & PJ Fit \\
$8 \mathrm{~d}$ & achievement striving & PA fit & PJ Fit \\
$8 \mathrm{e}$ & competence & PA fit & PJ Fit \\
$8 \mathrm{f}$ & self-discipline & PA fit & PJ Fit \\
\hline
\end{tabular}


Table 4. Intercorrelations and Alpha Reliability Statistics for Study Variables

\begin{tabular}{|c|c|c|c|c|c|c|c|c|c|c|c|c|c|}
\hline Variable & 1 & 2 & 3 & 4 & 5 & 6 & 7 & 8 & 9 & 10 & 11 & 12 & 13 \\
\hline 1. PJ Fit & $(.89)$ & & & & & & & & & & & & \\
\hline 2. Job Satisfaction & $.75^{* *}$ & $(.84)$ & & & & & & & & & & & \\
\hline 3. Gender & .07 & .02 & - & & & & & & & & & & \\
\hline 4. Age & .03 & .06 & $-.15^{*}$ & - & & & & & & & & & \\
\hline 5. Education & -.13 & -.02 & $-.16^{*}$ & .01 & - & & & & & & & & \\
\hline 6. Years at Firm & .14 & .01 & .04 & $.40^{* *}$ & -.08 & - & & & & & & & \\
\hline 7. Years at Current Job & $.15^{*}$ & -.03 & .01 & $.44^{* *}$ & $-.19^{*}$ & $.69^{* *}$ & - & & & & & & \\
\hline 8. Supervisor & .14 & .12 & .10 & $.15^{*}$ & .05 & $.31^{* *}$ & .03 & - & & & & & \\
\hline 9. Manager & .07 & .12 & .05 & .14 & .11 & $.34^{* *}$ & .03 & $.71^{* *}$ & - & & & & \\
\hline 10. Salaried & .12 & $.19^{* *}$ & .09 & $.25^{* *}$ & $.23^{* *}$ & $.19^{* *}$ & .02 & $.47^{* *}$ & $.63^{* *}$ & - & & & \\
\hline 11. Earnings & .12 & .12 & .03 & $.24^{* *}$ & $.28^{* *}$ & $.24^{* *}$ & .03 & $.47^{* *}$ & $.57^{* *}$ & $.69^{* *}$ & - & & \\
\hline 12. Hours Per Week & $.15^{*}$ & $.18^{*}$ & $.19^{*}$ & .12 & .07 & .02 & -.14 & $.31^{* *}$ & $.39^{* *}$ & $.50^{* *}$ & $.49^{* *}$ & - & \\
\hline 13. Competence & .03 & $.15^{*}$ & $-.20^{* *}$ & .02 & .04 & -.04 & -.09 & $.23^{* *}$ & $.16^{*}$ & $.17^{*}$ & .12 & .05 & $(0.84)$ \\
\hline
\end{tabular}


Table 4. Intercorrelations and Alpha Reliability Statistics for Study Variables (continued)

\begin{tabular}{|c|c|c|c|c|c|c|c|c|c|c|c|c|c|}
\hline Variable & 1 & 2 & 3 & 4 & 5 & 6 & 7 & 8 & 9 & 10 & 11 & 12 & 13 \\
\hline 14. Order & .00 & .11 & $-.17^{*}$ & -.04 & -.05 & -.09 & -.02 & .14 & .01 & .00 & -.07 & -.12 & $.49^{* *}$ \\
\hline 15. Duty & .09 & $.22^{* *}$ & -.10 & .07 & .04 & -.09 & -.13 & $.15^{*}$ & .09 & .15 & .08 & .06 & $.62^{* *}$ \\
\hline 16. Achievement & .11 & $.21^{* *}$ & -.14 & .05 & .01 & -.04 & -.09 & $.28^{* *}$ & $.17^{*}$ & $.18^{*}$ & .14 & $.20^{* *}$ & $.77^{* *}$ \\
\hline 17. Discipline & $.17^{*}$ & $.21^{* *}$ & -.14 & .13 & -.08 & -.06 & -.01 & .09 & -.04 & -.07 & -.03 & .01 & $.58^{* *}$ \\
\hline 18. Deliberation & .11 & $.23^{* *}$ & -.10 & .08 & .06 & -.05 & -.06 & .10 & .01 & .07 & -.01 & -.01 & $.55^{* *}$ \\
\hline 19. Conscientiousness & .10 & $.23^{* *}$ & $-.18^{*}$ & .06 & -.00 & -.07 & -.08 & $.21^{* *}$ & .09 & .11 & .05 & .05 & $.82^{* *}$ \\
\hline 20. Decision Autonomy & $.40^{* *}$ & $.41^{* *}$ & .11 & .00 & .06 & $.16^{*}$ & .06 & $.26^{* *}$ & $.21^{* *}$ & $.28^{* *}$ & $.32^{* *}$ & $.23^{* *}$ & .08 \\
\hline 21. Scheduling Autonomy & $.44^{* *}$ & $.39^{* *}$ & .06 & .13 & .01 & $.16^{*}$ & $.16^{*}$ & .11 & .11 & $.29^{* *}$ & $.25^{* *}$ & $.25^{* *}$ & .07 \\
\hline 22. Methods Autonomy & $.32^{* *}$ & $.35^{* *}$ & .06 & .06 & -.01 & $.18^{*}$ & .11 & .14 & $.15^{*}$ & $.28^{* *}$ & $.24^{* *}$ & $.16^{*}$ & .04 \\
\hline 23. Autonomy & $.43^{* *}$ & $.43^{* *}$ & .09 & .07 & .03 & $.19^{*}$ & .12 & $.19^{* *}$ & $.18^{*}$ & $.32^{* *}$ & $.31^{* *}$ & $.24^{* *}$ & .07 \\
\hline 24. Person Autonomy Fit & $.71^{* *}$ & $.51^{* *}$ & .09 & -.02 & .00 & .13 & .04 & $.15^{*}$ & .12 & $.18^{*}$ & $.26^{* *}$ & $.16^{*}$ & .11 \\
\hline 25. Proactive Personality & .03 & $.16^{*}$ & .06 & -.01 & .04 & -.06 & -.11 & .14 & $.23^{* *}$ & $.25^{* *}$ & .15 & $.16^{*}$ & $.34^{* *}$ \\
\hline 26. LMX & $.42^{* *}$ & $.40^{* *}$ & -.07 & .04 & .09 & .01 & -.05 & .11 & .14 & $.20^{* *}$ & .15 & .09 & $.15^{*}$ \\
\hline
\end{tabular}

Note. $\mathrm{N}=181$.Values in parenthesis are Alpha statistics. For Gender, Male $=1$, Female $=0$. For supervisor, Yes $=1, \mathrm{No}=0$. For Salaried, $1=$ Yes, $0=$ No. $* p<.05 . * * p<.01$. 
Table 4. Intercorrelations and Alpha Reliability Statistics for Study Variables (continued)

\begin{tabular}{|c|c|c|c|c|c|c|c|c|c|c|c|c|c|}
\hline Variable & 14 & 15 & 16 & 17 & 18 & 19 & 20 & 21 & 22 & 23 & 24 & 25 & 26 \\
\hline 14. Order & $(0.87)$ & & & & & & & & & & & & \\
\hline 15. Duty & $.58^{* *}$ & $(0.80)$ & & & & & & & & & & & \\
\hline 16. Achievement & $.58^{* *}$ & $.68^{* *}$ & $(0.88)$ & & & & & & & & & & \\
\hline 17. Discipline & $.59^{* *}$ & $.52^{* *}$ & $.70^{* *}$ & $(0.87)$ & & & & & & & & & \\
\hline 18. Deliberation & $.54^{* *}$ & $.57^{* *}$ & $.59^{* *}$ & $.65^{* *}$ & $(0.76)$ & & & & & & & & \\
\hline 19. Conscientiousness & $.78^{* *}$ & $.80^{* *}$ & $.90^{* *}$ & $.83^{* *}$ & $.76^{* *}$ & $(0.95)$ & & & & & & & \\
\hline 20. Decision Autonomy & -.06 & .04 & .08 & .02 & .09 & .05 & $(0.92)$ & & & & & & \\
\hline 21. Scheduling Autonomy & -.07 & .04 & .06 & .08 & .03 & .04 & $.61^{* *}$ & $(0.85)$ & & & & & \\
\hline 22. Methods Autonomy & -.05 & .02 & .06 & .04 & .07 & .03 & $.79^{* *}$ & $.70^{* *}$ & $(0.92)$ & & & & \\
\hline 23. Autonomy & -.07 & .03 & .08 & .06 & .07 & .05 & $.89^{* *}$ & $.87^{* *}$ & $.92^{* *}$ & $(0.94)$ & & & \\
\hline 24. Person Autonomy Fit & .00 & .09 & .13 & .11 & .14 & .12 & $.68^{* *}$ & $.72^{* *}$ & $.73^{* *}$ & $.79^{* *}$ & $(0.93)$ & & \\
\hline 25. Proactive Personality & $.23^{* *}$ & $.24^{* *}$ & $.37^{* *}$ & $.27^{* *}$ & $.27^{* *}$ & $.35^{* *}$ & .05 & -.01 & .01 & .02 & .03 & $(0.90)$ & \\
\hline 26. LMX & .06 & .11 & .08 & -.01 & .04 & .09 & $.29^{* *}$ & $.30^{* * *}$ & $.26^{* *}$ & $.32^{* *}$ & $.38^{* *}$ & $.18^{*}$ & $(0.96)$ \\
\hline
\end{tabular}

Note. $\mathrm{N}=181$. Values in parenthesis are Alpha statistics. For Gender, Male $=1$, Female $=0$. For supervisor, Yes $=1$, No $=0$. For Salaried, $1=$ Yes, $0=$ No. $* p<.05 . * * p<.01$. 
Conscientiousness as a Moderator 126

Table 5. Means and Standard Deviations for All Study Variables

\begin{tabular}{lrr}
\hline Variable & M & \multicolumn{1}{c}{ SD } \\
\hline \hline Gender & 0.74 & 0.44 \\
Age & 44.86 & 11.63 \\
Years at Firm & 9.13 & 7.27 \\
Tenure & 6.94 & 6.52 \\
Supervisor & 0.33 & 0.47 \\
Salaried & 0.41 & 0.49 \\
Yearly Earnings & 44,038 & 19,732 \\
Hours Worked per Week & 44.39 & 7.35 \\
Competence & 4.36 & 0.53 \\
Order & 4.19 & 0.70 \\
Dutifulness & 4.49 & 0.56 \\
Achievement & 4.31 & 0.53 \\
Discipline & 3.97 & 0.65 \\
Deliberation & 3.98 & 0.64 \\
Conscientiousness & 4.24 & 0.48 \\
Decision Autonomy & 3.94 & 0.85 \\
Schedule Autonomy & 3.80 & 0.88 \\
Work Methods Autonomy & 3.88 & 0.81 \\
Autonomy & 3.87 & 0.76 \\
PA Fit & 3.63 & 0.93 \\
T1 PJ Fit & 3.66 & 0.85 \\
T2 PJ Fit & 3.74 & 0.76 \\
T2 Satisfaction & 3.93 & 0.64 \\
Proactive Personality & 3.79 & 0.55 \\
LMX & 3.75 & 0.92 \\
\hline Note. N & & \\
& &
\end{tabular}

Note. $\mathrm{N}=181$. For gender, Male $=1$, Female $=0$. For supervisor, Yes $=1$, No $=0$. For salaried, $1=$ Yes, $0=$ No. $\mathrm{T}=$ Time. 
Table 6. Summary of Hierarchical Regression Analysis for Variables Used to Answer RQ1 Regarding the Interaction between Conscientiousness and Autonomy on Job Satisfaction.

\begin{tabular}{|c|c|c|c|c|}
\hline Variable & $\Delta R^{2}$ & $F$ for $\Delta R^{2}$ & $\beta$ & $t$ \\
\hline Step 1: Location & $.16^{*}$ & 2.00 & & \\
\hline Oregon & & & -.23 & -1.93 \\
\hline California & & & $-.27 *$ & -2.59 \\
\hline Illinois & & & -.04 & -.52 \\
\hline Iowa & & & -.22 & -1.49 \\
\hline Michigan & & & -.23 & -1.23 \\
\hline Missouri & & & -.09 & -.83 \\
\hline Nebraska & & & -.22 & -1.67 \\
\hline New Jersey & & & -.11 & -.84 \\
\hline North Dakota & & & -.25 & -2.27 \\
\hline Ohio & & & $-.43^{*}$ & -2.50 \\
\hline South Dakota & & & -.06 & -.67 \\
\hline Texas & & & -.15 & -1.42 \\
\hline Washington & & & -.15 & -1.03 \\
\hline Nevada Corporate & & & -.14 & -1.25 \\
\hline Oregon Corporate & & & $-.49 *$ & -2.28 \\
\hline Step 2: Controls & .02 & 2.26 & & \\
\hline Years at Current Job & & & -.06 & -.88 \\
\hline Salary Status & & & .03 & .36 \\
\hline Step 3: Predictors & $.17 * * *$ & 13.45 & & \\
\hline Autonomy (A) & $.12 * * *$ & & $.43 * * *$ & 5.35 \\
\hline Conscientiousness (C) & $.03^{* *}$ & & $.18^{* *}$ & 2.67 \\
\hline CX A & .00 & & -.01 & -.10 \\
\hline
\end{tabular}

Note. $\mathrm{N}=181$. Outcome is job satisfaction. $R^{2}$ for final equation $=.35$. Betas are for the final equation. $\Delta R^{2}$ statistic for individual variables in step 3 indicate the magnitude of the change in $\mathrm{R}^{2}$ if the single variable was added to the regression equation in the final step.

$* \mathrm{p}<.05 * . * * \mathrm{p}<.01 . * * * \mathrm{p}<.001$. 
Conscientiousness as a Moderator 128

Table 7. Summary of Hierarchical Regression Analysis for Variables Used to Answer Hla Regarding the Interaction between Orderliness and Autonomy on Job Satisfaction.

\begin{tabular}{|c|c|c|c|c|}
\hline Variable & $\Delta R^{2}$ & $F$ for $\Delta R^{2}$ & $\beta$ & $t$ \\
\hline Step 1: Location & $.16^{*}$ & 2.00 & & \\
\hline Oregon & & & -.23 & -1.83 \\
\hline California & & & $-.26^{*}$ & -2.44 \\
\hline Illinois & & & -.04 & -.51 \\
\hline Iowa & & & -.21 & -1.41 \\
\hline Michigan & & & -.21 & -1.11 \\
\hline Missouri & & & -.09 & -.82 \\
\hline Nebraska & & & -.23 & -1.70 \\
\hline New Jersey & & & -.09 & -.72 \\
\hline North Dakota & & & $-.24 *$ & -2.15 \\
\hline Ohio & & & $-.44 *$ & -2.47 \\
\hline South Dakota & & & -.05 & -.53 \\
\hline Texas & & & -.14 & -1.28 \\
\hline Washington & & & -.16 & -1.03 \\
\hline Nevada Corporate & & & -.13 & -1.12 \\
\hline Oregon Corporate & & & $-.47 *$ & -2.14 \\
\hline Step 2: Controls & .02 & 2.26 & & \\
\hline Years at Current Job & & & -.07 & -1.01 \\
\hline Salary Status & & & .03 & .44 \\
\hline Step 3: Predictors & $.15^{* * *}$ & 11.61 & & \\
\hline Autonomy (A) & $.13 * * *$ & & $.45^{* * *}$ & 5.50 \\
\hline $\operatorname{Order}(\mathrm{O})$ & .01 & & .12 & 1.61 \\
\hline $\mathrm{O} \times \mathrm{A}$ & .00 & & -.04 & -.47 \\
\hline
\end{tabular}

Note. $\mathrm{N}=181$. Outcome is job satisfaction. $R^{2}$ for final equation $=.33$. Betas are for the final equation. $\Delta R^{2}$ statistic for individual variables in step 3 indicate the magnitude of the change in $\mathrm{R}^{2}$ if the single variable was added to the regression equation in the final step.

$* \mathrm{p}<.05 * * * \mathrm{p}<.01 . * * * \mathrm{p}<.001$. 
Conscientiousness as a Moderator 129

Table 8. Summary of Hierarchical Regression Analysis for Variables Used to Answer $H 1 b$ Regarding the Interaction between Dutifulness and Autonomy on Job Satisfaction.

\begin{tabular}{|c|c|c|c|c|}
\hline Variable & $\Delta R^{2}$ & $F$ for $\Delta R^{2}$ & $\beta$ & $t$ \\
\hline Step 1: Location & $.16^{*}$ & 2.00 & & \\
\hline Oregon & & & $-.24 *$ & -2.03 \\
\hline California & & & $-.28 * *$ & -2.64 \\
\hline Illinois & & & -.06 & -.67 \\
\hline Iowa & & & -.22 & -1.51 \\
\hline Michigan & & & -.26 & -1.41 \\
\hline Missouri & & & -.09 & -.80 \\
\hline Nebraska & & & -.24 & -1.87 \\
\hline New Jersey & & & -.11 & -.86 \\
\hline North Dakota & & & $-.27 *$ & -2.40 \\
\hline Ohio & & & $-.46 * *$ & -2.67 \\
\hline South Dakota & & & -.06 & -.72 \\
\hline Texas & & & -.15 & -1.42 \\
\hline Washington & & & -.16 & -1.05 \\
\hline Nevada Corporate & & & -.14 & -1.27 \\
\hline Oregon Corporate & & & $-.51 *$ & -2.38 \\
\hline Step 2: Controls & .02 & 2.26 & & \\
\hline Years at Current Job & & & -.04 & -.66 \\
\hline Salary Status & & & .01 & .18 \\
\hline Step 3: Predictors & $.18 * * *$ & 14.41 & & \\
\hline Autonomy (A) & $.14 * * *$ & & $.43 * * *$ & 5.81 \\
\hline Duty (D) & $.04 * *$ & & $.20 * *$ & 2.94 \\
\hline $\mathrm{D} X \mathrm{~A}$ & .00 & & .02 & .35 \\
\hline
\end{tabular}

Note. $\mathrm{N}=181$. Outcome is job satisfaction. $R^{2}$ for final equation $=.34$. Betas are for the final equation. $\Delta R^{2}$ statistic for individual variables in step 3 indicate the magnitude of the change in $\mathrm{R}^{2}$ if the single variable was added to the regression equation in the final step.

$* \mathrm{p}<.05 * * * \mathrm{p}<.01 . * * * \mathrm{p}<.001$. 
Conscientiousness as a Moderator 130

Table 9. Summary of Hierarchical Regression Analysis for Variables Used to Answer Hlc Regarding the Interaction between Deliberation and Autonomy on Job Satisfaction.

\begin{tabular}{|c|c|c|c|c|}
\hline Variable & $\Delta R^{2}$ & $F$ for $\Delta R^{2}$ & $\beta$ & $t$ \\
\hline Step 1: Location & $.16^{*}$ & 2.00 & & \\
\hline Oregon & & & -.22 & -1.84 \\
\hline California & & & $-.28 * *$ & -2.74 \\
\hline Illinois & & & -.04 & -.54 \\
\hline Iowa & & & -.24 & -1.62 \\
\hline Michigan & & & -.21 & -1.15 \\
\hline Missouri & & & -.09 & -.79 \\
\hline Nebraska & & & -.21 & -1.61 \\
\hline New Jersey & & & -.09 & -.74 \\
\hline North Dakota & & & $-.25^{*}$ & -2.29 \\
\hline Ohio & & & $-.42 *$ & -2.46 \\
\hline South Dakota & & & -.05 & -.60 \\
\hline Texas & & & -.14 & -1.37 \\
\hline Washington & & & -.12 & -.82 \\
\hline Nevada Corporate & & & -.13 & -1.22 \\
\hline Oregon Corporate & & & $-.48 *$ & -2.26 \\
\hline Step 2: Controls & .02 & 2.26 & & \\
\hline Years at Current Job & & & -.06 & -.97 \\
\hline Salary Status & & & .03 & .39 \\
\hline Step 3: Predictors & $.18 * * *$ & 14.48 & & \\
\hline Autonomy (A) & $.14 * * *$ & & $.44 * * *$ & 5.87 \\
\hline Deliberation (D) & $.04 * *$ & & $.20^{* *}$ & 2.97 \\
\hline D X A & .01 & & -.09 & -1.24 \\
\hline
\end{tabular}

Note. $\mathrm{N}=181$. Outcome is job satisfaction. $R^{2}$ for final equation $=.36$. Betas are for the final equation. $\Delta R^{2}$ statistic for individual variables in step 3 indicate the magnitude of the change in $\mathrm{R}^{2}$ if the single variable was added to the regression equation in the final step.

$* \mathrm{p}<.05 *{ }^{*} * \mathrm{p}<.01 . * * * \mathrm{p}<.001$. 
Conscientiousness as a Moderator 131

Table 10. Summary of Hierarchical Regression Analysis for Variables Used to Answer H3a Regarding the Interaction between Achievement and Autonomy on Job Satisfaction.

\begin{tabular}{|c|c|c|c|c|}
\hline Variable & $\Delta R^{2}$ & $F$ for $\Delta R^{2}$ & $\beta$ & $t$ \\
\hline Step 1: Location & $.16^{*}$ & 2.00 & & \\
\hline Oregon & & & -.23 & -1.91 \\
\hline California & & & $-.27 *$ & -2.60 \\
\hline Illinois & & & -.05 & -.55 \\
\hline Iowa & & & -.21 & -1.41 \\
\hline Michigan & & & -.23 & -1.24 \\
\hline Missouri & & & -.10 & -.92 \\
\hline Nebraska & & & -.22 & -1.63 \\
\hline New Jersey & & & -.10 & -.82 \\
\hline North Dakota & & & $-.27 *$ & -2.39 \\
\hline Ohio & & & $-.44 *$ & -2.53 \\
\hline South Dakota & & & -.07 & -.87 \\
\hline Texas & & & -.15 & -1.42 \\
\hline Washington & & & -.17 & -1.15 \\
\hline Nevada Corporate & & & -.15 & -1.37 \\
\hline Oregon Corporate & & & $-.51 *$ & -2.33 \\
\hline Step 2: Controls & .02 & 2.26 & & \\
\hline Years at Current Job & & & -.06 & -.83 \\
\hline Salary Status & & & .02 & .31 \\
\hline Step 3: Predictors & $.16 * * *$ & 13.01 & & \\
\hline Autonomy (A) & $.10 * * *$ & & $.39 * * *$ & 4.97 \\
\hline Achievement (Ach) & $.02 *$ & & $.15^{*}$ & 2.11 \\
\hline Ach X A & .01 & & .09 & 1.20 \\
\hline
\end{tabular}

Note. $\mathrm{N}=181$. Outcome is job satisfaction. $R^{2}$ for final equation $=.34$. Betas are for the final equation. $\Delta R^{2}$ statistic for individual variables in step 3 indicate the magnitude of the change in $\mathrm{R}^{2}$ if the single variable was added to the regression equation in the final step.

$* \mathrm{p}<.05 * * * \mathrm{p}<.01 . * * * \mathrm{p}<.001$. 
Conscientiousness as a Moderator 132

Table 11. Summary of Hierarchical Regression Analysis for Variables Used to Answer $\mathrm{H} 3 \mathrm{~b}$ Regarding the Interaction between Competence and Autonomy on Job Satisfaction.

\begin{tabular}{|c|c|c|c|c|}
\hline Variable & $\Delta R^{2}$ & $F$ for $\Delta R^{2}$ & $\beta$ & $t$ \\
\hline Step 1: Location & $.16^{*}$ & 2.00 & & \\
\hline Oregon & & & $-.26^{*}$ & -2.07 \\
\hline California & & & $-.27 \&$ & -2.50 \\
\hline Illinois & & & -.05 & -.54 \\
\hline Iowa & & & -.24 & -1.58 \\
\hline Michigan & & & -.25 & -1.30 \\
\hline Missouri & & & -.11 & -.94 \\
\hline Nebraska & & & -.23 & -1.75 \\
\hline New Jersey & & & -.12 & -.91 \\
\hline North Dakota & & & $-.27 *$ & -2.36 \\
\hline Ohio & & & $-.47 * *$ & -2.68 \\
\hline South Dakota & & & -.07 & -.77 \\
\hline Texas & & & -.14 & -1.32 \\
\hline Washington & & & -.18 & -1.21 \\
\hline Nevada Corporate & & & -.15 & -1.35 \\
\hline Oregon Corporate & & & $-.52 *$ & -2.38 \\
\hline Step 2: Controls & .02 & 2.26 & & \\
\hline Years at Current Job & & & -.06 & -.93 \\
\hline Salary Status & & & .03 & .37 \\
\hline Step 3: Predictors & $.15^{* * *}$ & 11.39 & & \\
\hline Autonomy (A) & $.12 * * *$ & & $.42 * * *$ & 5.35 \\
\hline Competence (C) & .01 & & .10 & 1.44 \\
\hline C X A & .00 & & -.01 & -.18 \\
\hline
\end{tabular}

Note. $\mathrm{N}=181$. Outcome is job satisfaction. $R^{2}$ for final equation $=.33$. Betas are for the final equation. $\Delta R^{2}$ statistic for individual variables in step 3 indicate the magnitude of the change in $\mathrm{R}^{2}$ if the single variable was added to the regression equation in the final step.

$* \mathrm{p}<.05 * * * \mathrm{p}<.01 . * * * \mathrm{p}<.001$. 
Conscientiousness as a Moderator 133

Table 12. Summary of Hierarchical Regression Analysis for Variables Used to Answer H3c Regarding the Interaction between Discipline and Autonomy on Job Satisfaction.

\begin{tabular}{llllr}
\hline \multicolumn{1}{c}{ Variable } & $\Delta R^{2}$ & $F$ for $\Delta R^{2}$ & \multicolumn{1}{c}{$\beta$} & $t$ \\
\hline Step 1: Location & $.16^{*}$ & 2.00 & & \\
Oregon & & & -.22 & -1.84 \\
California & & & $-.29 * *$ & -2.71 \\
Illinois & & & -.03 & -.39 \\
Iowa & & -.22 & -1.49 \\
Michigan & & -.23 & -1.21 \\
Missouri & & -.11 & -1.03 \\
Nebraska & & -.23 & -1.74 \\
New Jersey & & & -.11 & -.91 \\
North Dakota & & & $-.25 *$ & -2.26 \\
Ohio & & & $-.44 *$ & -2.55 \\
South Dakota & & & -.06 & -.67 \\
Texas & & & -.15 & -1.40 \\
Washington & & & -.17 & -1.15 \\
Nevada Corporate & & & -.15 & -1.32 \\
Oregon Corporate & & & $-.49 *$ & -2.28 \\
Step 2: Controls & .02 & 2.26 & & \\
Years at Current Job & & & -.07 & -1.06 \\
Salary Status & & & .06 & .82 \\
Step 3: Predictors & $.17 * * *$ & 13.39 & & \\
Autonomy (A) & $.11^{* * *}$ & & $.41^{* * *}$ & 5.17 \\
Discipline (D) & $.03 * *$ & & $.18^{* *}$ & 2.63 \\
D X A & .00 & & .00 & -.03 \\
\hline
\end{tabular}

Note. $\mathrm{N}=181$. Outcome is job satisfaction. $R^{2}$ for final equation $=.35$. Betas are for the final equation. $\Delta R^{2}$ statistic for individual variables in step 3 indicate the magnitude of the change in $\mathrm{R}^{2}$ if the single variable was added to the regression equation in the final step.

$* \mathrm{p}<.05 * * * \mathrm{p}<.01 . * * * \mathrm{p}<.001$. 
Conscientiousness as a Moderator 134

Table 13. Summary of Hierarchical Regression Analysis for Variables Used to Answer RQ2 Regarding the Interaction between Conscientiousness and Autonomy on PJ Fit.

\begin{tabular}{llllc}
\hline \multicolumn{1}{c}{ Variable } & $\Delta R^{2}$ & $F$ for $\Delta R^{2}$ & $\beta$ & $t$ \\
\hline Step 1: Location & $.20^{* *}$ & 2.60 & & \\
Oregon & & & $-.29 *$ & -2.44 \\
California & & & $-.21^{*}$ & -2.06 \\
Illinois & & -.06 & -.77 \\
Iowa & & -.20 & -1.31 \\
Michigan & & -.21 & -1.12 \\
Missouri & & -.05 & -.42 \\
Nebraska & & -.12 & -.88 \\
New Jersey & & -.04 & -.35 \\
North Dakota & & -.22 & -1.97 \\
Ohio & & $-.42^{*}$ & -2.41 \\
South Dakota & & -.09 & -1.11 \\
Texas & & -.16 & -1.54 \\
Washington & & & -.18 & -1.23 \\
Nevada Corporate & & & -.14 & -1.27 \\
Oregon Corporate & & & $-.52^{*}$ & -2.39 \\
Step 2: Controls & .02 & 2.45 & & \\
Years at Current Job & & & .11 & 1.60 \\
Salary Status & & & -.03 & -.48 \\
Step 3: Predictors & $.14 * * *$ & 11.02 & & \\
Autonomy (A) & $.12^{* * *}$ & & $.42^{* * *}$ & 5.35 \\
Conscientiousness (C) & .01 & & .09 & 1.36 \\
C X A & .00 & & -.04 & -.56 \\
\hline Note. N = & & & \\
\hline
\end{tabular}

Note. $\mathrm{N}=181$. Outcome is person job fit (PJ fit).$R^{2}$ for final equation $=.36$. Betas are for the final equation. $\Delta R^{2}$ statistic for individual variables in step 3 indicate the magnitude of the change in $\mathrm{R}^{2}$ if the single variable was added to the regression equation in the final step.

$* \mathrm{p}<.05 * . * \mathrm{p}<.01 . * * * \mathrm{p}<.001$. 
Conscientiousness as a Moderator 135

Table 14. Summary of Hierarchical Regression Analysis for Variables Used to Answer H2 a Regarding the Interaction between Orderliness and Autonomy on PJ Fit.

\begin{tabular}{|c|c|c|c|c|}
\hline Variable & $\Delta R^{2}$ & $F$ for $\Delta R^{2}$ & $\beta$ & $t$ \\
\hline Step 1: Location & $.20^{* *}$ & 2.60 & & \\
\hline Oregon & & & $-.29 *$ & -2.43 \\
\hline California & & & $-.21^{*}$ & -1.99 \\
\hline Illinois & & & -.07 & -.80 \\
\hline Iowa & & & -.20 & -1.32 \\
\hline Michigan & & & -.20 & -1.08 \\
\hline Missouri & & & -.05 & -.46 \\
\hline Nebraska & & & -.13 & -.98 \\
\hline New Jersey & & & -.04 & -.29 \\
\hline North Dakota & & & $-.23^{*}$ & -2.05 \\
\hline Ohio & & & -.43 & -2.47 \\
\hline South Dakota & & & -.10 & -1.22 \\
\hline Texas & & & -.15 & -1.43 \\
\hline Washington & & & -.19 & -1.27 \\
\hline Nevada Corporate & & & -.14 & -1.25 \\
\hline Oregon Corporate & & & $-.51 *$ & -2.36 \\
\hline Step 2: Controls & .02 & 2.45 & & \\
\hline Years at Current Job & & & .11 & 1.58 \\
\hline Salary Status & & & -.04 & -.53 \\
\hline Step 3: Predictors & $.13 * * *$ & 10.73 & & \\
\hline Autonomy (A) & $.13 * * *$ & & $.44 * * *$ & 5.54 \\
\hline $\operatorname{Order}(\mathrm{O})$ & .00 & & .02 & .30 \\
\hline $\mathrm{O} \times \mathrm{A}$ & .01 & & -.09 & -1.13 \\
\hline
\end{tabular}

Note. $\mathrm{N}=181$. Outcome is person job fit (PJ fit).$R^{2}$ for final equation $=.35$. Betas are for the final equation. $\Delta R^{2}$ statistic for individual variables in step 3 indicate the magnitude of the change in $\mathrm{R}^{2}$ if the single variable was added to the regression equation in the final step.

${ }^{*} \mathrm{p}<.05 * * * \mathrm{p}<.01 . * * * \mathrm{p}<.001$. 
Conscientiousness as a Moderator 136

Table 15. Summary of Hierarchical Regression Analysis for Variables Used to Answer H2b Regarding the Interaction between Dutifulness and Autonomy on PJ Fit.

\begin{tabular}{|c|c|c|c|c|}
\hline Variable & $\Delta R^{2}$ & $F$ for $\Delta R^{2}$ & $\beta$ & $t$ \\
\hline Step 1: Location & $.20 * *$ & 2.60 & & \\
\hline Oregon & & & $-.30^{*}$ & -2.45 \\
\hline California & & & $-.21^{*}$ & -2.06 \\
\hline Illinois & & & -.07 & -.87 \\
\hline Iowa & & & -.20 & -1.32 \\
\hline Michigan & & & -.22 & -1.20 \\
\hline Missouri & & & -.04 & -.37 \\
\hline Nebraska & & & -.13 & -.97 \\
\hline New Jersey & & & -.05 & -.37 \\
\hline North Dakota & & & $-.22 *$ & -2.02 \\
\hline Ohio & & & $-.43^{*}$ & -2.51 \\
\hline South Dakota & & & -.09 & -1.13 \\
\hline Texas & & & -.16 & -1.56 \\
\hline Washington & & & -.18 & -1.23 \\
\hline Nevada Corporate & & & -.14 & -1.27 \\
\hline Oregon Corporate & & & $-.53 *$ & -2.45 \\
\hline Step 2: Controls & .02 & 2.45 & & \\
\hline Years at Current Job & & & .12 & 1.72 \\
\hline Salary Status & & & -.04 & -.52 \\
\hline Step 3: Predictors & $.14 * * *$ & 11.25 & & \\
\hline Autonomy (A) & $.13 * * *$ & & $.42 * * *$ & 5.65 \\
\hline Duty (D) & .01 & & .11 & 1.60 \\
\hline D X A & .00 & & -.03 & -.42 \\
\hline
\end{tabular}

Note. $\mathrm{N}=181$. Outcome is person job fit (PJ fit).$R^{2}$ for final equation $=.36$. Betas are for the final equation. $\Delta R^{2}$ statistic for individual variables in step 3 indicate the magnitude of the change in $\mathrm{R}^{2}$ if the single variable was added to the regression equation in the final step.

$* \mathrm{p}<.05 * . * \mathrm{p}<.01 . * * * \mathrm{p}<.001$. 
Conscientiousness as a Moderator 137

Table 16. Summary of Hierarchical Regression Analysis for Variables Used to Answer H2c Regarding the Interaction between Deliberation and Autonomy on PJ Fit.

\begin{tabular}{|c|c|c|c|c|}
\hline Variable & $\Delta R^{2}$ & $F$ for $\Delta R^{2}$ & $\beta$ & $t$ \\
\hline Step 1: Location & $.20^{* *}$ & 2.60 & & \\
\hline Oregon & & & $-.29 *$ & -2.41 \\
\hline California & & & $-.22 *$ & -2.15 \\
\hline Illinois & & & -.06 & -.78 \\
\hline Iowa & & & -.20 & -1.35 \\
\hline Michigan & & & -.20 & -1.07 \\
\hline Missouri & & & -.04 & -.39 \\
\hline Nebraska & & & -.11 & -.83 \\
\hline New Jersey & & & -.03 & -.27 \\
\hline North Dakota & & & $-.22 *$ & -2.01 \\
\hline Ohio & & & $-.41 *$ & -2.39 \\
\hline South Dakota & & & -.09 & -1.12 \\
\hline Texas & & & -.16 & -1.49 \\
\hline Washington & & & -.17 & -1.11 \\
\hline Nevada Corporate & & & -.14 & -1.25 \\
\hline Oregon Corporate & & & $-.51 *$ & -2.39 \\
\hline Step 2: Controls & .02 & 2.45 & & \\
\hline Years at Current Job & & & .10 & 1.53 \\
\hline Salary Status & & & -.03 & -.42 \\
\hline Step 3: Predictors & $.14 * * *$ & 11.47 & & \\
\hline Autonomy (A) & $.13 * * *$ & & $.43 * * *$ & 5.71 \\
\hline Deliberation (D) & .01 & & .09 & 1.33 \\
\hline D X A & .01 & & -.09 & -1.28 \\
\hline
\end{tabular}

Note. $\mathrm{N}=181$. Outcome is person job fit (PJ fit).$R^{2}$ for final equation $=.36$. Betas are for the final equation. $\Delta R^{2}$ statistic for individual variables in step 3 indicate the magnitude of the change in $\mathrm{R}^{2}$ if the single variable was added to the regression equation in the final step.

$* \mathrm{p}<.05 * * * \mathrm{p}<.01 . * * * \mathrm{p}<.001$. 
Conscientiousness as a Moderator 138

Table 17. Summary of Hierarchical Regression Analysis for Variables Used to Answer H4a Regarding the Interaction between Achievement and Autonomy on PJ Fit.

\begin{tabular}{|c|c|c|c|c|}
\hline Variable & $\Delta R^{2}$ & $F$ for $\Delta R^{2}$ & $\beta$ & $t$ \\
\hline Step 1: Location & $.20^{* *}$ & 2.60 & & \\
\hline Oregon & & & $-.29 *$ & -2.44 \\
\hline California & & & $-.22 *$ & -2.13 \\
\hline Illinois & & & -.07 & -.84 \\
\hline Iowa & & & -.18 & -1.24 \\
\hline Michigan & & & -.22 & -1.18 \\
\hline Missouri & & & -.06 & -.51 \\
\hline Nebraska & & & -.11 & -.81 \\
\hline New Jersey & & & -.05 & -.37 \\
\hline North Dakota & & & $-.23 *$ & -2.07 \\
\hline Ohio & & & $-.42 *$ & -2.45 \\
\hline South Dakota & & & -.11 & -1.27 \\
\hline Texas & & & -.17 & -1.63 \\
\hline Washington & & & -.20 & -1.38 \\
\hline Nevada Corporate & & & -.16 & -1.43 \\
\hline Oregon Corporate & & & $-.54 *$ & -2.49 \\
\hline Step 2: Controls & .02 & 2.45 & & \\
\hline Years at Current Job & & & .11 & 1.65 \\
\hline Salary Status & & & -.03 & -.48 \\
\hline Step 3: Predictors & $.14 * * *$ & 11.39 & & \\
\hline Autonomy (A) & $.10 * * *$ & & $.38 * * *$ & 4.88 \\
\hline Achievement (Ach) & .01 & & .09 & 1.31 \\
\hline Ach X A & .00 & & .08 & 1.04 \\
\hline
\end{tabular}

Note. $\mathrm{N}=181$. Outcome is person job fit (PJ fit).$R^{2}$ for final equation $=.36$. Betas are for the final equation. $\Delta R^{2}$ statistic for individual variables in step 3 indicate the magnitude of the change in $\mathrm{R}^{2}$ if the single variable was added to the regression equation in the final step.

$* \mathrm{p}<.05 * . * \mathrm{p}<.01 . * * * \mathrm{p}<.001$. 
Conscientiousness as a Moderator 139

Table 18. Summary of Hierarchical Regression Analysis for Variables Used to Answer H4b Regarding the Interaction between Competence and Autonomy on PJ Fit.

\begin{tabular}{|c|c|c|c|c|}
\hline Variable & $\Delta R^{2}$ & $F$ for $\Delta R^{2}$ & $\beta$ & $t$ \\
\hline Step 1: Location & $.20 * *$ & 2.60 & & \\
\hline Oregon & & & $-.31 *$ & -2.52 \\
\hline California & & & $-.21^{*}$ & -2.06 \\
\hline Illinois & & & -.07 & -.80 \\
\hline Iowa & & & -.20 & -1.36 \\
\hline Michigan & & & -.22 & -1.18 \\
\hline Missouri & & & -.06 & -.51 \\
\hline Nebraska & & & -.12 & -.92 \\
\hline New Jersey & & & -.05 & -.40 \\
\hline North Dakota & & & $-.23 *$ & -2.02 \\
\hline Ohio & & & $-.44 *$ & -2.53 \\
\hline South Dakota & & & -.10 & -1.14 \\
\hline Texas & & & -.16 & -1.52 \\
\hline Washington & & & -.20 & -1.37 \\
\hline Nevada Corporate & & & -.15 & -1.36 \\
\hline Oregon Corporate & & & $-.54 *$ & -2.48 \\
\hline Step 2: Controls & .02 & 2.45 & & \\
\hline Years at Current Job & & & .10 & 1.54 \\
\hline Salary Status & & & -.03 & -.44 \\
\hline Step 3: Predictors & $.13 * * *$ & 10.43 & & \\
\hline Autonomy (A) & $.12 * * *$ & & $.41 * * *$ & 5.30 \\
\hline Competence (C) & .00 & & .05 & .69 \\
\hline CXA & .00 & & -.02 & -.30 \\
\hline
\end{tabular}

Note. $\mathrm{N}=181$. Outcome is person job fit (PJ fit).$R^{2}$ for final equation $=.35$. Betas are for the final equation. $\Delta R^{2}$ statistic for individual variables in step 3 indicate the magnitude of the change in $\mathrm{R}^{2}$ if the single variable was added to the regression equation in the final step.

${ }^{*} \mathrm{p}<.05 * * * \mathrm{p}<.01 . * * * \mathrm{p}<.001$. 
Conscientiousness as a Moderator 140

Table 19. Summary of Hierarchical Regression Analysis for Variables Used to Answer H4c Regarding the Interaction between Discipline and Autonomy on PJ Fit.

\begin{tabular}{|c|c|c|c|c|}
\hline Variable & $\Delta R^{2}$ & $F$ for $\Delta R^{2}$ & $\beta$ & $t$ \\
\hline Step 1: Location & $.20^{* *}$ & 2.60 & & \\
\hline Oregon & & & $-.29 *$ & -2.38 \\
\hline California & & & $-.22 *$ & -2.16 \\
\hline Illinois & & & -.06 & -.69 \\
\hline Iowa & & & -.19 & -1.31 \\
\hline Michigan & & & -.21 & -1.13 \\
\hline Missouri & & & -.06 & -.54 \\
\hline Nebraska & & & -.12 & -.88 \\
\hline New Jersey & & & -.05 & -.40 \\
\hline North Dakota & & & $-.22 *$ & -1.98 \\
\hline Ohio & & & $-.42 *$ & -2.42 \\
\hline South Dakota & & & -.09 & -1.12 \\
\hline Texas & & & -.16 & -1.57 \\
\hline Washington & & & -.20 & -1.33 \\
\hline Nevada Corporate & & & -.15 & -1.34 \\
\hline Oregon Corporate & & & $-.52 *$ & -2.40 \\
\hline Step 2: Controls & .02 & 2.45 & & \\
\hline Years at Current Job & & & .10 & 1.51 \\
\hline Salary Status & & & -.01 & -.19 \\
\hline Step 3: Predictors & $.14 * * *$ & 11.63 & & \\
\hline Autonomy (A) & $.11 * * *$ & & $.41 * * *$ & 5.21 \\
\hline Discipline (D) & .01 & & .12 & 1.77 \\
\hline D X A & .00 & & -.03 & -.39 \\
\hline
\end{tabular}

Note. $\mathrm{N}=181$. Outcome is person job fit (PJ fit).$R^{2}$ for final equation $=.35$. Betas are for the final equation. $\Delta R^{2}$ statistic for individual variables in step 3 indicate the magnitude of the change in $\mathrm{R}^{2}$ if the single variable was added to the regression equation in the final step.

$* \mathrm{p}<.05 * . * \mathrm{p}<.01 . * * * \mathrm{p}<.001$. 
Figure 1. Different Ways of Conceptualizing PE Fit
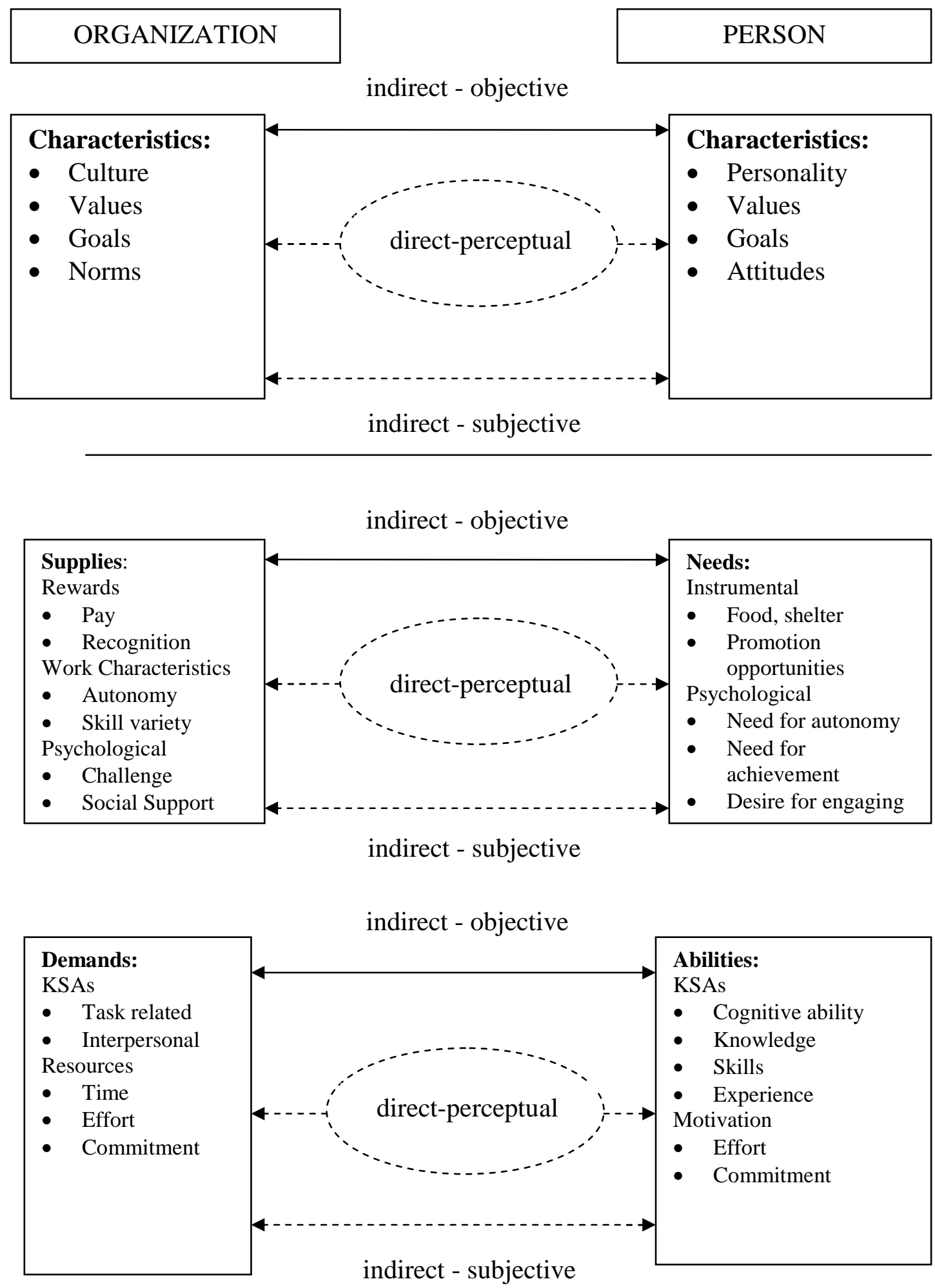
Conscientiousness as a Moderator 142

Figure 2. Conceptual model of relationships hypothesized in this dissertation

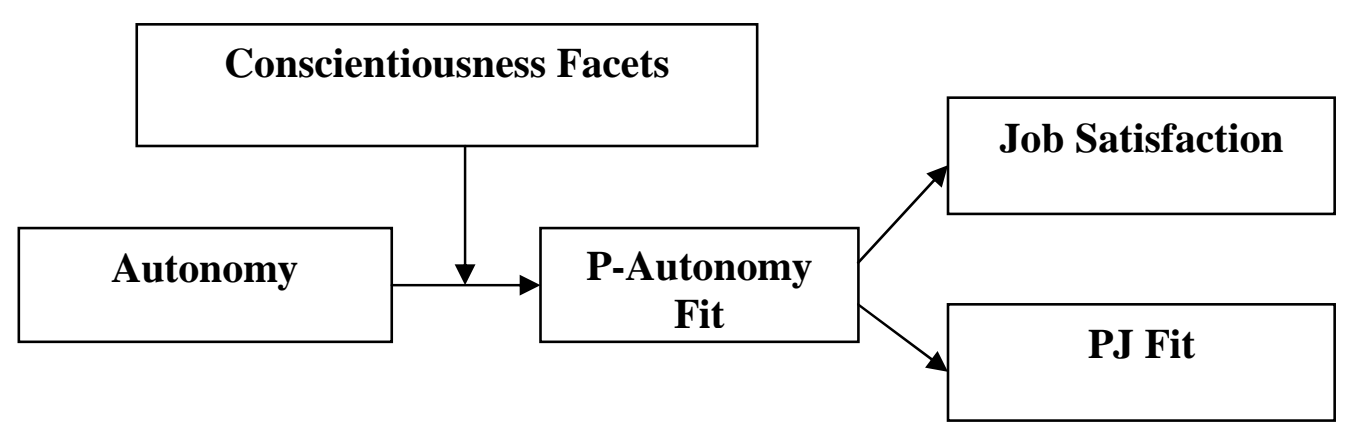


Figure 3. Personality as a Moderator of the Relationship between Autonomy and the Outcomes of Job Satisfaction and PJ Fit.

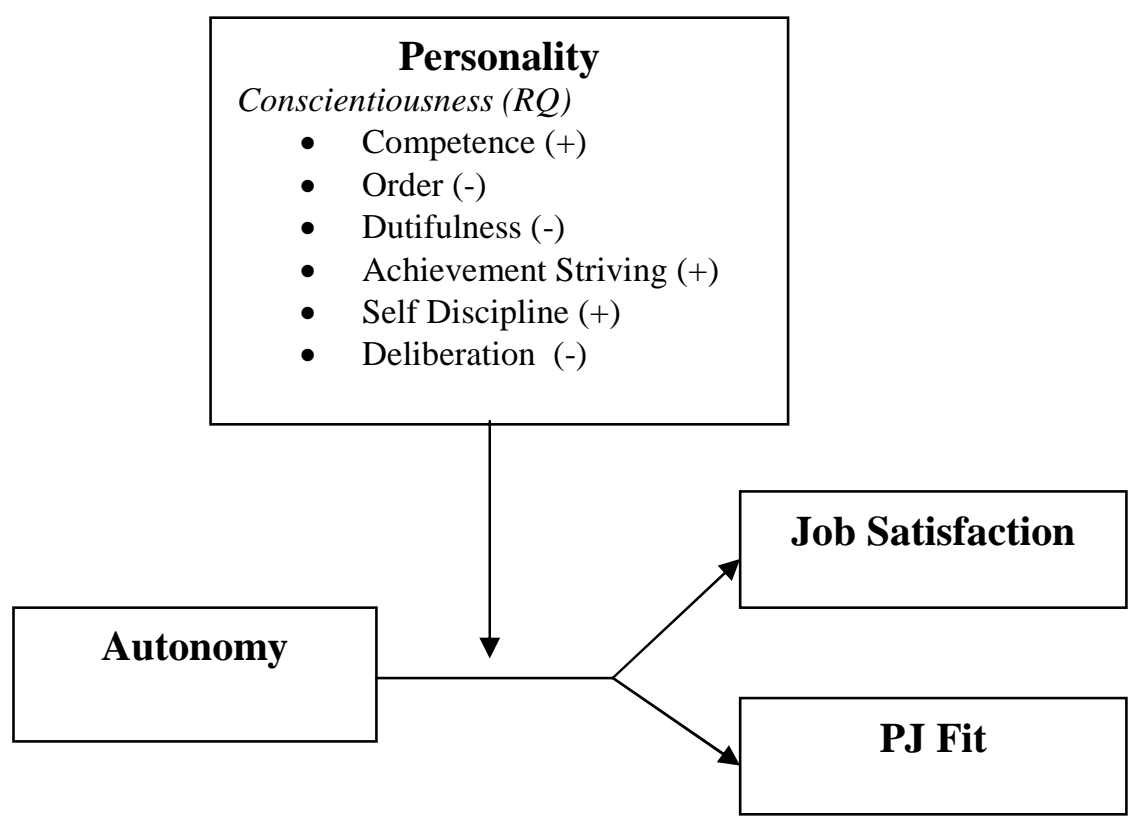

Note. The "+" symbol indicates a positive moderation effect. The "“-"symbol indicates a negative moderation effect. "RQ" indicates a research question in which the direction of moderation is not specified. 
Conscientiousness as a Moderator 144

Figure 4. Example of Disordinal Interaction Based on Hypothesis 1a that Order Will Moderate the Relationship between Autonomy and Job Satisfaction.

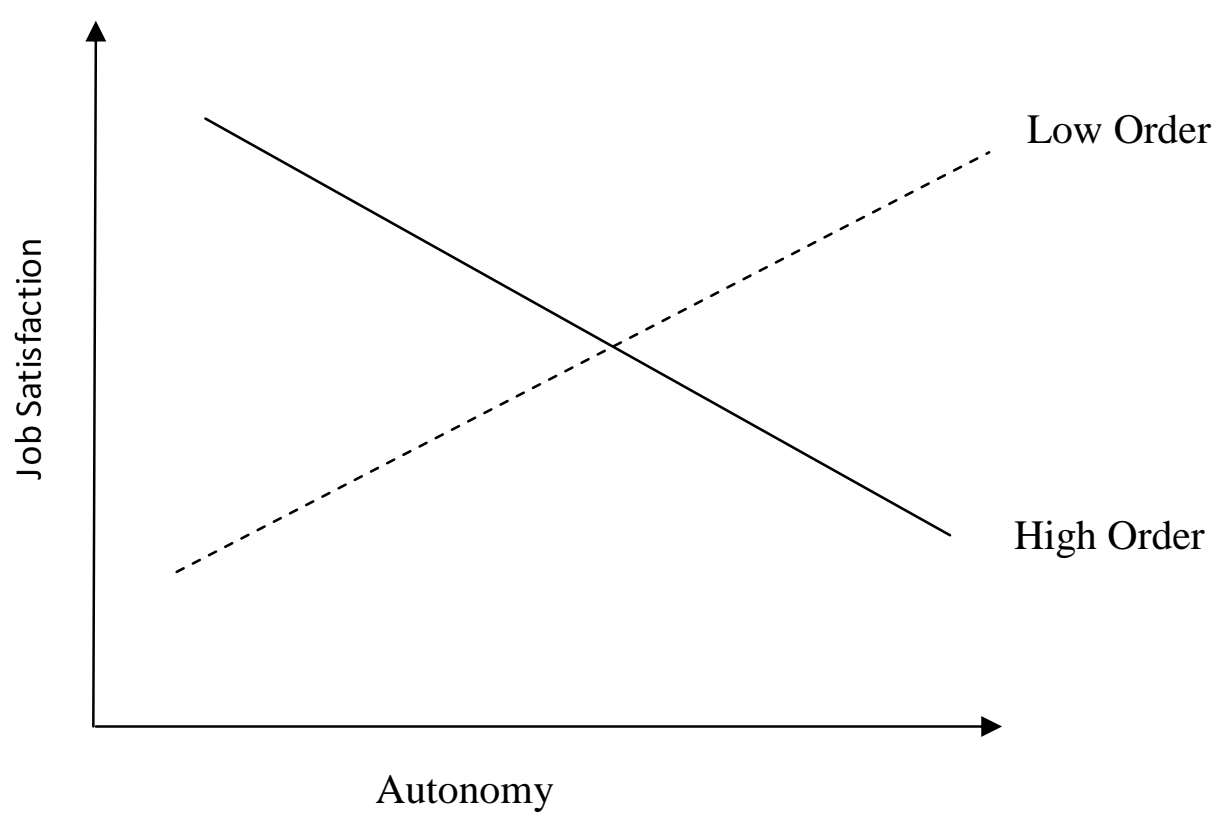


Figure 5. Person-Autonomy Fit as a Mediator of the Autonomy x Personality Interaction

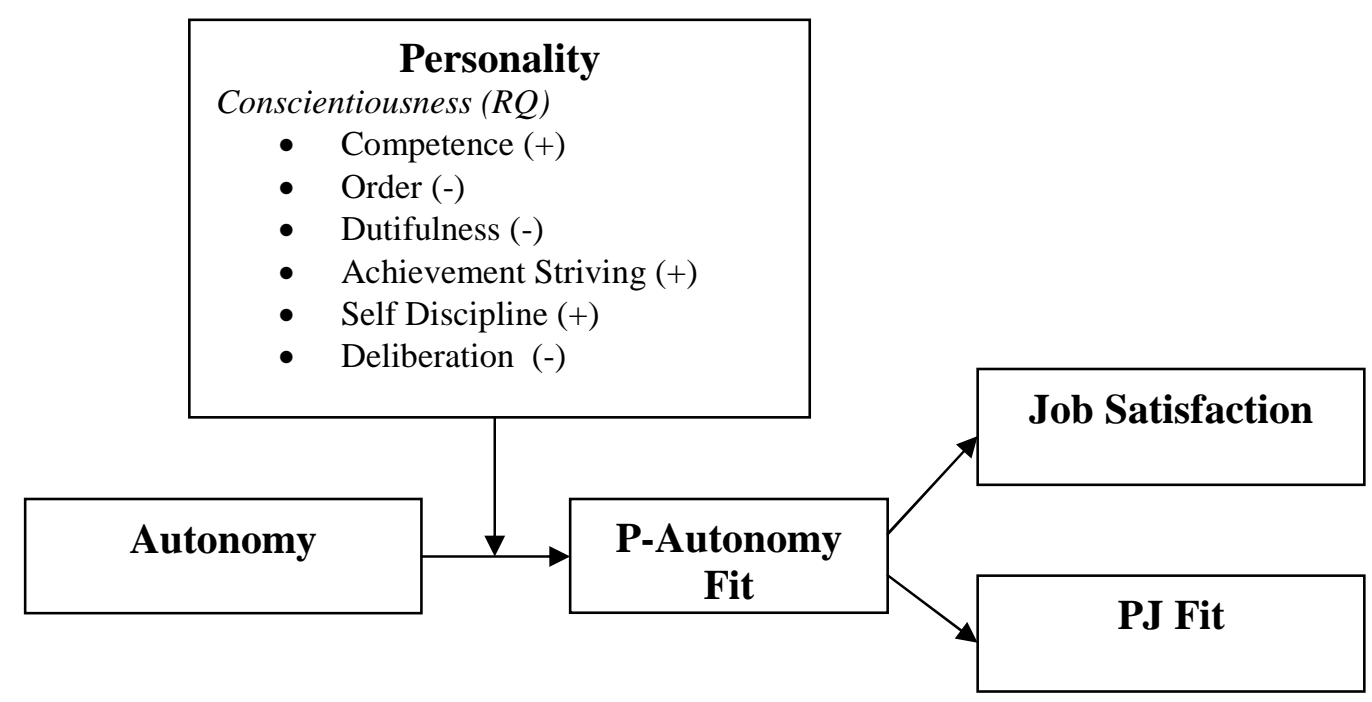




\section{Study Design}

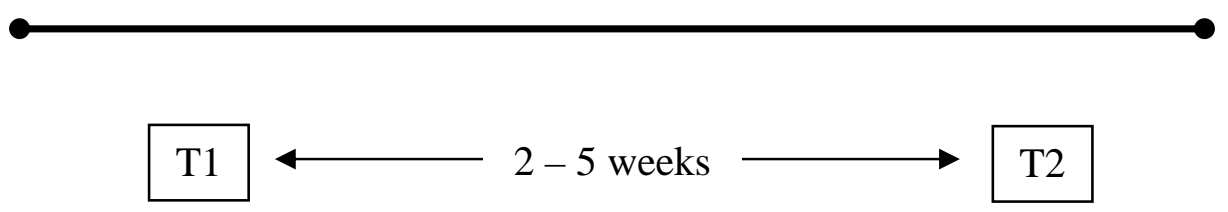

Variables Collected at Time 1

- Conscientiousness facets (31 items)

- Work autonomy (9 items)

- Person-autonomy fit perceptions (3 items)

- Controls and participant information

- Basic demographics

- Region

- Job level

- Salary category

- Job satisfaction (5 items)

- Person-job fit perceptions (3 items)

Total: 51 items + demographics

\section{Variables Collected at} Time 2

- Job satisfaction (5 items)

- Person-job fit perceptions (3 items)

- $\quad$ LMX (12 items)

- Proactive Personality (10 items)

Total: 30 items

Note. Variables in italics were used for exploratory and supplemental analyses beyond the scope of the dissertation. 


\section{References}

Allport, G. W., \& Odbert, H. S. (1936). Trait-names: A psycho-lexical study. Psychological Monographs, 47 (No. 211).

Argyris, C. (1959). The individual and organization: An empirical test. Administrative Science Quarterly, 4, 145-167.

Ajzen, I., \& Fishbein, M. (1977). Attitude-behavior relations: A theoretical analysis and review of empirical research. Psychological Bulletin, 84, 888-918.

Barrick, M. R., \& Mount, M. K. (1991). The Big Five personality dimensions and job performance: A meta-analysis. Personnel Psychology, 44, 1-26.

Barrick, M. R., \& Mount, M. K. (1993). Autonomy as a moderator of the relationships between the Big Five personality dimensions and job performance. Journal of Applied Psychology, 78, 111-118.

Barrick, M. R., Mount, M. K., \& Judge, T. A. (2001). Personality and performance at the beginning of the new millennium: What do we know and where do we go next? International Journal of Selection and Assessment, 9, 9-30.

Bauer, T. N., \& Green, S. G. (1996). Development of leader-member exchange: A longitudinal test. The Academy of Management Journal, 39, 1538-1567.

Berry, C. M., Ones, D. S., \& Sackett, P. R. (2007). Interpersonal deviance, organizational deviance, and their common correlates: A review and metaanalysis. Journal of Applied Psychology, 92, 410-424.

Block, J. (1995). A contrarian view of the five-factor approach to personality description. Psychological Bulletin, 117, 187-215. 
Conscientiousness as a Moderator 148

Bogg, T., \& Roberts, B. W. (2004). Conscientiousness and health behaviors: A metaanalysis of the leading behavioral contributors to mortality. Psychological Bulletin, 130, 887-919.

Bono, J. E., \& Judge, T. A. (2004). Personality and transformational and transactional leadership: A meta-analysis. Journal of Applied Psychology, 89, 901-910.

Cable, D. M., \& DeRue, D. S. (2002). The convergent and discriminant validity of subjective fit perceptions. Journal of Applied Psychology, 87, 875-884.

Cable, D. M., \& Judge, T. A. (1996). Person-organization fit, job choice decisions, and organizational entry. Organizational Behavior and Human Decision Processes, 67, 294-311.

Campion, M. A. (1988). Interdisciplinary approaches to job design: A constructive replication with extensions. Journal of Applied Psychology, 73, 467-481.

Cattell, R. B., Marshall, M.B., Georgiades, S. (1957). Personality and motivation: Structure and measurement. Journal of Personality Disorders, 19, 53-67.

Colquitt, J. A., LePine, J. A., \& Noe, R. A. (2000). Toward an integrative theory of training motivation: A meta-analytic path analysis of 20 years of research. Journal of Applied Psychology, 85, 678-707.

Cooper-Hakim, A., \& Viswesvaran, C. (2002). A meta-analytic review of the MacAndrew Alcoholism scale. Educational and Psychological Measurement, $62,818-829$.

Costa, P., \& McCrae, R. (1992). NEO-PI-R and NEO-FFI professional manual. Odessa, FL: Psychological Assessment Resources. 
Conscientiousness as a Moderator 149

Costa Jr, P. T., \& McCrae, R. R. (1995). Domains and facets: Hierarchical personality assessment using the revised NEO Personality Inventory. Journal of Personality Assessment, 64, 21-51.

de Jong, R. D., van der Velde, M. E. G., \& Jansen, P. G. W. (2001). Openness to Experience and Growth Need Strength as moderators between job characteristics and satisfaction International Journal of Selection \& Assessment, 9, 350-357.

de Lange, A. H., Taris, T. W., Kompier, M. A. J., Houtman, I. L. D., \& Bongers, P. M. (2003). "The very best of the millennium": Longitudinal research and the demand-control-(support) model. Journal of Occupational Health Psychology, $8,282-305$.

Digman, J. M. (1990). Personality structure: Emergence of the five-factor model. Annual Review of Psychology, 41, 417-441.

Dudley, N. M., Orvis, K. A., Lebiecki, J. E., \& Cortina, J. M. (2006). A meta-analytic investigation of Conscientiousness in the prediction of job performance: Examining the intercorrelations and the incremental validity of narrow traits. Journal of Applied Psychology, 91, 40-57.

Dunnette, M. D., Campbell, J. P., \& Hakel, M. D. (1967). Factors contributing to job satisfaction and job dissatisfaction in six occupational groups. Organizational Behavior and Human Performance, 2, 143-174.

Edwards, J.R. (1991). Person-job fit: A conceptual integration, literature review and methodological critique. International Review of Industrial/Organizational 
Conscientiousness as a Moderator 150

Psychology (pp. 283-357). London: Wiley.

Edwards, J. R. (1996). An examination of competing versions of the personenvironment fit approach to stress. Academy of Management Journal, 39, 292339.

Edwards, J. R., Caplan, R. D., \& Van Harrison, R. (1998). Person-environment fit theory: Conceptual foundations, empirical evidence, and directions for future research. In C. L. Cooper (Ed.), Theories of organizational stress (pp. 28-67). Oxford, England: Oxford University Press.

Edwards, J. R., Scully, J. A., \& Brtek, M. D. (2000). The nature and outcomes of work: A replication and extension of interdisciplinary work-design research. Journal of Applied Psychology, 85, 860-868.

Ellingson, J. E., Sackett, P. R., \& Connelly, B. S. (2007). Personality assessment across selection and development contexts: Insights into response distortion. Journal of Applied Psychology, 92, 386-395.

Faul, F., Erdfelder, E., Lang, A.G., \& Buchner, A. (2007). G*Power 3: A flexible statistical power analysis for the social, behavioral, and biomedical sciences. Behavior Research Methods, 39, 175-191.

Feist, G. J. (1998). A meta-analysis of personality in scientific and artistic creativity. Personality and Social Psychology Review, 2, 290-309.

Fried, Y., \& Ferris, G. R. (1987). The validity of the Job Characteristics Model: A review and meta-analysis. Personnel Psychology, 40, 287-322.

Galton, F. (1884). Measurement of character. Fortnightly Review, 36, 179-185. 
Gilbreth, E. B. (1911). Motion study: A method for increasing the efficiency of the workman. New York: Van Nostrand.

Glick, W. H., Jenkins, G. D., Jr., \& Gupta, N. (1986). Method versus substance: How strong are underlying relationships between job characteristics and attitudinal outcomes? Academy of Management Journal, 29, 441-464.

Goldberg, L. R. (1981). Language and individual differences: The search for universals in personality lexicons. In L. Wheeler (Ed.), Review of Personality and Social Psychology (pp. 141-65). Beverly Hills, CA: Sage.

Goldberg, L. R. (1990). An alternative description of personality: The Big-Five factor structure. Journal of Personality \& Social Psychology, 59, 1216-1229.

Goldberg, L. R. (1999). A broad-bandwidth, public-domain, personality inventory measuring the lower-level facets of several five-factor models. In I. Mervielde, I. Deary, F. De Fruyt, \& F. Ostendorf (Eds.), Personality Psychology in Europe (Vol. 7, pp. 7-28). Tilburg, The Netherlands: Tilburg University Press.

Goldberg, L. R., Johnson, J. A., Eber, H. W., Hogan, R., Ashton, M. C., Cloninger, C. R., \& Gough, H. C. (2006). The International Personality Item Pool and the future of public-domain personality measures. Journal of Research in Personality, 40, 84-96.

Grant, A. M. (2008). The significance of task significance: Job performance effects, relational mechanisms, and boundary conditions. Journal of Applied Psychology, 93, 108-124.

Grant, A. M., Fried, Y., \& Juillerat, T. 2010. Work matters: Job design in classic and 
Conscientiousness as a Moderator 152

contemporary perspectives. In S. Zedeck (Ed.), APA handbook of industrial and organizational psychology (Vol. 1, pp. 417-453). Washington, DC:

American Psychological Association.

Griffin, R. W., Bateman, T. S., Wayne, S. J., \& Head, T. C. (1987). Objective and social factors as determinants of task perceptions and responses: An integrated perspective and empirical investigation. Academy of Management Journal, 30, 501-523.

Hackman, J. R., \& Lawler, E. E., III. (1971) Employee reactions to job characteristics. Journal of Applied Psychology Monograph, 55, 259-286.

Hackman, J. R., \& Oldham, G. R. (1975). Development of the Job Diagnostic Survey. Journal of Applied Psychology, 60, 159-170.

Herzberg, E. (1966). Work and the nature of man. Cleveland, OH: World.

Hofstee, W. K. B., de Raad, B., \& Goldberg, L. R. (1992). Integration of the Big Five and circumplex approaches to trait structure. Journal of Personality and Social Psychology, 63, 146-163.

Hogan, R. (1986). Hogan Personality Inventory manual. Minneapolis: National Computer Systems.

Hogan, J., Barrett, P., \& Hogan, R. (2007). Personality measurement, faking, and employment selection. Journal of Applied Psychology, 92, 1270-1285.

Hough, L. M. (1992). The “'Big Five’” personality variables-construct confusion: Description versus prediction. Human Performance, 5, 139-155.

Hough, L. M., Eaton, N. K., Dunnette, M. D., Kamp, J. D., \& McCloy, R. A. (1990). 
Criterion-related validities of personality constructs and the effect of response distortion on those validities. Journal of Applied Psychology, 75, 581-595.

Hough, L. M., \& Furnham, A. (2003). Use of personality variables in work settings. In W. C. Borman, D. R. Ilgen, \& R. J. Klimoski (Eds.), Handbook of psychology, Volume 12, Industrial and organizational psychology (pp. 131-169).

Hough, L. M., \& Ones, D. S. (2001). The structure, measurement, validity, and use of personality variables in industrial, work, and organizational psychology. In N. Anderson, D. S. Ones, H. K. Sinangil, \& C. Viswesvaran (Eds.), Handbook of Industrial, Work and Organizational Psychology (Vol. 1, pp. 233-377). London: Sage.

Hough, L. M., Ones, D. S., \& Viswesvaran, C. (1998, April). Personality correlates of managerial performance constructs. In R. Page (Chair), Personality determinants of managerial potential, performance, progression and ascendancy. Symposium conducted at 13th Annual Conference of the Society for Industrial and Organizational Psychology, Dallas, TX.

Hough, L. M., \& Oswald, F. L. (2008). Personality testing and industrialorganizational psychology: Reflections, progress, and prospects. Industrial and Organizational Psychology, 1, 272-290.

Hu, L., \& Bentler, P.M. (1999). Cutoff criteria for fit indexes in covariance structure analysis: Conventional criteria versus new alternatives. Structural Equation Modeling, 6, 1-55.

Hulin, C. L., \& Blood, M. R. (1968). Job enlargement, individual differences, and 
worker responses. Psychological Bulletin, 69, 41-55.

Humphrey, S. E., Nahrgang, J. D., \& Morgeson, F. P. (2007). Integrating motivational, social, and contextual work design features: A meta-analytic summary and theoretical extension of the work design literature. Journal of Applied Psychology, 92, 1332-1356.

Ilgen, D. R. \& Hollenbeck, J.R. (1991). The structure of work: Job design and roles. In M. D. Dunnette, L. Hough (Eds.), Handbook of Industrial and Organizational Psychology (pp. 165-207). Palo Alto: Consulting Psychologists Press.

Inceoglu, I., \& Warr, P. (2011). Personality and job engagement. Journal of Personnel Psychology, 10(4), 177-181.

Janz, B.D., Colquitt J. A., and Noe, R.A. (1997). Knowledge worker team effectiveness: The role of autonomy, interdependence, team development, and contextual support variables. Personnel Psychology, 50, 877-904.

Johns, G., Jia Lin, X., \& Yongqing, F. (1992). Mediating and moderating effects in job design. Journal of Management, 18, 657-676.

Johnson, J. V., \& Hall, E. M. (1988). Job strain, work place social support, and cardiovascular disease: A cross-sectional study of a random sample of the Swedish working population. American Journal of Public Health, 78, 13361342.

Joreskog K.G., \& Sorbom D. (1989). LISREL 7: A guide to the program and applications. Chicago: SPSS.

Judge, T. A., Higgins, C. A., Thoresen, C. J., \& Barrick, M. R. (1999). The Big Five 
personality traits, general mental ability, and career success across the life span. Personnel Psychology, 52, 621-652.

Judge, T. A., Heller, D., \& Mount, M. K. (2002). Five-Factor Model of personality and job satisfaction: A meta-analysis. Journal of Applied Psychology, 87, 530541.

Judge, T. A., Parker, S., Colbert, A. E., Heller, D., \& Ilies, R. (2001). Job satisfaction: A cultural review. In N. Anderson, D. S. Ones, H. K. Sinangil, \& C. Visweswaran (Eds.), Handbook of industrial, work, and organizational psychology (Vol. 2, pp. 25-52). London: Sage.

Karasek, R. A. (1979). Job demands, job decision latitude, and mental strain: Implications for job redesign. Administrative Science Quarterly, 24, 285-308.

Karasek, R. (1990). Lower health risk with increased job control among white collar workers. Journal of Organizational Behavior, 11, 171-185.

Kelly, E. L., Ammons, S. K., Chermack, K., \& Moen, P. (2010). Gendered challenge, gendered response. Gender \& Society, 24, 281-303.

Kinicki, A. J., McKee-Ryan, F. M., Schriesheim, C. A., \& Carson, K. P. (2002). Assessing the construct validity of the Job Descriptive Index: A review and meta-analysis. Journal of Applied Psychology, 87, 14-32.

Kline, R. B. (1998). Principles and practice of structural equation modeling. NY: Guilford Press.

Kristof, A. L. (1996). Person-organization fit: An integrative review of its conceptualizations, measurement, and implications. Personnel Psychology, 49, 
Conscientiousness as a Moderator 156 $1-49$.

Kristof-Brown, A. L., Zimmerman, R. D., \& Johnson, E. C. (2005). Consequences of individual's fit at work: A meta-analysis of person-job, person-organization, person-group, and person-supervisor fit. Personnel Psychology, 58, 281-342.

Lee, C., Ashford, S. J., \& Bobko, P. (1990). Interactive effects of "Type A" behavior and perceived control on worker performance, job satisfaction, and somatic complaints. Academy of Management Journal, 33, 870-881.

Leary, T. (1957). Interpersonal diagnosis of personality. New York: Ronald Press.

Liden, R. C., \& Maslyn, J. M. (1998). Multidimensionality of leader-member exchange: An empirical assessment through scale development. Journal of Management, 24, 43-72.

Loher, B. T., Noe, R. A., Moeller, N. L., \& Fitzgerald, M. P. (1985). A meta-analysis of the relation of job characteristics to job satisfaction. Journal of Applied Psychology, 70, 280-289.

Major, D. A., Turner, J. E., \& Fletcher, T. D. (2006). Linking proactive personality and the Big Five to motivation to learn and development activity. Journal of Applied Psychology, 91, 927-935.

McCrae, R. R., Costa, P. T., Jr., \& Busch, C. M. (1986). Evaluating comprehensiveness in personality systems: The California Q-set and the fivefactor model. Journal of Personality, 54, 430-446.

McCrae, R. R., \& John, O. P. (1992). An introduction to the Five-Factor Model and its applications. Journal of Personality, 60, 175-215. 
McFarland, L. A., \& Ryan, A. M. (2000). Variance in faking across noncognitive measures. Journal of Applied Psychology, 85, 812-821.

Morgeson, F. P., \& Campion, M. A. (2002). Minimizing tradeoffs when redesigning work: Evidence from a longitudinal quasi-study. Personnel Psychology, 55, 589-612.

Morgeson, F. P., \& Campion, M. A. (2003). Work design. In W. C. Borman, D. R. Ilgen, \& R. J. Klimoski (Eds.), Handbook of Psychology: Industrial and Organizational Psychology (Vol. 12, pp. 423-452). Hoboken, NJ: John Wiley \& Sons.

Morgeson, F. P., Campion, M. A., Dipboye, R. L., Hollenbeck, J. R., Murphy, K., \& Schmitt, N. (2007). Reconsidering the use of personality tests in personnel selection contexts. Personnel Psychology, 60, 683-729.

Morgeson, F. P., \& Humphrey, S. E. (2006). The Work Design Questionnaire (WDQ): Developing and validating a comprehensive measure for assessing job design and the nature of work. Journal of Applied Psychology, 91, 1321-1339.

Muchinsky, P. M., \& Monahan, C. J. (1987). What is person-environment congruence? Supplementary versus complementary models of fit. Journal of Vocational Behavior, 31, 268-277.

Muller, D., Judd, C. M., \& Yzerbyt, V. Y. (2005). When moderation is mediated and mediation is moderated. Journal of Personality \& Social Psychology, 89, 852863.

Norman, W. T. (1963). Toward an adequate taxonomy of personality attributes: 
Conscientiousness as a Moderator 158

Replicated factor structure in peer nomination personality ratings. Journal of Abnormal and Social Psychology, 66, 574-583.

Oldham, G. R., \& Hackman, J. R. (2010). Not what it was and not what it will be: The future of job design research. Journal of Organizational Behavior, 31, 463479.

Ones, D. S., Dilchert, S., Viswesvaran, C., \& Judge, T. A. (2007). In support of personality assessment in organizational settings. Personnel Psychology, 60, 995-1027.

Ones, D. S., \& Viswesvaran, C. (1996). What do pre-employment customer service scales measure? Explorations in construct validity and implications for personnel selection. Paper presented at the 11th Annual Conference of the Society for Industrial and Organizational Psychology, San Diego, CA.

Paunonen, S. V., \& Ashton, M. C. (2001). Big Five Factors and facets and the prediction of behavior. Journal of Personality \& Social Psychology, 81, 524539.

Paunonen, S. V., Rothstein, M. G., \& Jackson, D. N. (1999). Narrow reasoning about the use of broad personality measures for personnel selection. Journal of Organizational Behavior, 20, 389-405.

Peterson, N. G., Mumford, M. D., Borman, W. C., Jeanneret, P. R., Fleishman, E. A., Levin, K. Y., et al. (2001). Understanding work using the Occupational Information Network $(\mathrm{O} * \mathrm{NET})$ : Implications for practice and research. Personnel Psychology, 54, 451-492. 
Plutchik, R. (1997). The circumplex as a general model of the structure of emotions and personality. In R. Plutchik \& H. R. Conte (Eds.), Circumplex Models of Personality and Emotions (pp. 1-14). Washington, DC: American Psychological Association.

Podsakoff, P. M., MacKenzie, S. B., Jeong-Yeon, L., \& Podsakoff, N. P. (2003). Common method biases in behavioral research: A critical review of the literature and recommended remedies. Journal of Applied Psychology, 88, 879903.

Preacher, K. J., \& Hayes, A. F. (2008). Asymptotic and resampling strategies for assessing and comparing indirect effects in multiple mediator models. Behavior Research Methods, 40, 879-891.

Roberts, B. W., Kuncel, N. R., Shiner, R., Caspi, A., \& Goldberg, L. R. (2007). The power of personality: The comparative validity of personality traits, socioeconomic status, and cognitive ability for predicting important life outcomes. Perspectives on Psychological Science, 2, 313-345.

Rosse, J. G., Stecher, M. D., Miller, J. L., \& Levin, R. A. (1998). The impact of response distortion on preemployment personality testing and hiring decisions. Journal of Applied Psychology, 83, 634-644.

Ruh, R. A., White, J. K., \& Wood, R. R. (1975). Job involvement, values, personal background, participation in decision making, and job attitudes. Academy of Management Journal, 18, 300-312.

Salancik, G. R., \& Pfeffer, J. (1978). A social information processing approach to job 
attitudes and task design. Administrative Science Quarterly, 23, 224-253.

Sanchez, J. I., \& Viswesvaran, C. (2002). The effects of temporal separation on the relations between self-reported work stressors and strains. Organizational Research Methods, 5, 173-183.

Schaufeli, W. B., \& Bakker, A. B. (2004). Job demands, job resources, and their relationship with burnout and engagement: A multi-sample study. Journal of Organizational Behavior, 25, 293-315.

Schmidt, F. L., \& Hunter, J. E. (1998). The validity and utility of selection methods in personnel psychology: Practical and theoretical implications of 85 years of research findings. Psychological Bulletin, 124, 262-274.

Schneider, B. 1987. The people make the place. Personnel Psychology, 40, 437-453.

Schneider, J., \& Locke, E. A. (1971). A critique of Herzberg's incident classification system and a suggested revision. Organizational Behavior and Human Performance, 6, 441-457.

Sonnentag, S., \& Frese, M. (2003). Stress in organizations. In W. C. Borman, D. R. Ilgen, \& R. J. Klimoski (Eds.), Handbook of psychology, Volume 12, Industrial and organizational psychology (pp. 453-491). Hoboken: Wiley. Spector, P. E. (2006). Method variance in organizational research. Organizational Research Methods, 9, 221-232.

Steel, P., Schmidt, J., \& Shulz, J. (2008). Refining the relationship between personality and subjective well-being. Psychological Bulletin, 134, 138-161.

Steers, R. M. (1975). Task-goal attributes, $\mathrm{n}$ achievement, and supervisory 
Conscientiousness as a Moderator 161 performance. Organizational Behavior and Human Performance, 13, 392-403.

Steers, R. M., \& Spencer, D. G. (1977). The role of achievement motivation in job design. Journal of Applied Psychology, 62, 472-479.

Srivastava, A., Locke, E. A., Judge, T. A., \& Adams, J. W. (2010). Core selfevaluations as causes of satisfaction: The mediating role of seeking task complexity. Journal of Vocational Behavior, 77, 255-265.

Taylor, F. W. (1911). The principles of scientific management. New York: W.W. Norton.

Tett, R. P., \& Burnett, D. B. (2003). A personality trait-based interactionist model of job performance. Journal of Applied Psychology, 88, 500-517.

Tett, R. P., \& Christiansen, N.D. (2007). Personality tests at the crossroads: A response to Morgeson, Campion, Dipboye, Hollenbeck, Murphy, and Schmitt (2007). Personnel Psychology, 60, 967-993.

Tett, R. P., \& Guterman, H. A. (2000). Situation trait relevance, trait expression, and cross-situational consistency: Testing a principle of trait activation. Journal of Research in Personality, 34, 397-423.

Tett, R. P., Jackson, D. N., \& Rothstein, M. (1991). Personality measures as predictors of job performance: A meta-analytic review. Personnel Psychology, 44, 703742.

Thurstone, L. L. (1934). The vectors of the mind. Psychological Review, 41, 1-32.

Tiegs, R. B., Tetrick, L. E., \& Fried, Y. (1992). Growth Need Strength and context satisfactions as moderators of the relations of the Job Characteristics Model. 
Conscientiousness as a Moderator 162

Journal of Management, 18, 575-593.

Tupes, E. C., \& Christal, R. E. (1961). Recurrent personality factors based on trait ratings. USAF ASD Tech. Rep. No. 61-97, Lackland Airforce Base, TX: U. S. Air Force.

Turner, A. N., \& Lawrence, P. R. (1965) Industrial jobs and the worker. Boston: Harvard University Graduate School of Business Administration.

Verquer, M. L., Beehr, T. A., \& Wagner, S. H. (2003). A meta-analysis of relations between person-organization fit and work attitudes. Journal of Vocational Behavior, 63, 473-489.

Vinchur, A.J., Schippmann, J.S., Switzer, F.S., \& Roth, P.L. (1998). A meta-analytic review of predictors of job performance for salespeople. Journal of Applied Psychology, 83, 586-597.

Vough, H., \& Parker, S. K. (2008). Work design research: Still going strong. In C.L. Cooper \& J. Barling (Eds.), Handbook of Organizational Behavior. Thousand Oaks, CA: Sage Publications.

Walker, C. R., \& Marriott, R. (1951) A study of attitudes to factory work. Occupational Psychology, 25, 181-191.

Weiss, H. M., \& Rupp, D. E. (2011). Experiencing work: An essay on a person-centric work psychology. Industrial and Organizational Psychology, 4, 83-97.

Wrzesniewski, A., \& Dutton, J. E. (2001). Crafting a job: Revisioning employees as active crafters of their work. Academy of Management Review, 26, 179-201.

Zalesny, M. D., \& Ford, J. K. (1990). Extending the social information processing 
Conscientiousness as a Moderator 163

perspective: New links to attitudes, behaviors, and perceptions. Organizational

Behavior and Human Decision Processes, 47, 205-246.

Zhao, H., \& Seibert, S. E. (2006). The Big Five personality dimensions and entrepreneurial status: A meta-analytical review. Journal of Applied Psychology, 91, 259-271. 
Appendix A: Items Used in the Dissertation

The following items were collected for the current study:

\section{Conscientiousness Facets}

\section{Competence}

- Complete tasks successfully.

- Excel in what I do.

- Handle tasks smoothly.

- Am sure of my ground.

- Come up with good solutions.

- Know how to get things done.

Orderliness

- Like order.

- Like to tidy up.

- Want everything to be "just right."

- Love order and regularity.

- Do things according to a plan.

Dutifulness

- Try to follow the rules.

- Keep my promises.

- Pay my bills on time.

- Tell the truth.

- Listen to my conscience.

Achievement Striving

- Go straight for the goal.

- Work hard.

- Turn plans into actions.

- Plunge into tasks with all my heart.

- Do more than what's expected of me.

- Set high standards for myself and others.

- Demand quality

Self-Discipline

- Get chores done right away.

- Am always prepared.

- Start tasks right away.

- Get to work at once.

- Carry out my plans

Deliberation

- Like order.

- Like to tidy up. 
- Want everything to be "just right."

- Love order and regularity.

- Do things according to a plan.

\section{Work Autonomy}

\section{Work Scheduling Autonomy}

- The job allows me to make my own decisions about how

- to schedule my work.

- The job allows me to decide on the order in which things

- are done on the job.

\section{Decision Making Autonomy}

- The job gives me a chance to use my personal initiative or judgment in carrying out the work.

- The job allows me to make a lot of decisions on my own.

- The job provides me with a lot of freedom to make decisions.

Work Methods Autonomy

- The job allows me to make decisions about what methods I use to complete my work.

- The job gives me considerable opportunity for independence and freedom in how I do the work.

- The job allows me to decide on my own how to go about doing my work.

\section{Job Satisfaction}

- I feel fairly satisfied with my present job.

- Most days I am enthusiastic about my work.

- Each day at work seems like it will never end.

- I find real enjoyment in my work.

- I consider my job to be rather unpleasant.

\section{Person-Job Fit}

- There is a good fit between what my job offers me and what I am looking for in a job.

- The things that I look for in a job are fulfilled very well by my present job.

- The job that I have now gives me just about everything that I want from a job.

\section{Person-Autonomy Fit}

- There is a good fit between how much freedom I have at work and how much freedom I want in my job. 
Conscientiousness as a Moderator 166

- The amount of independence I look for in a job is fulfilled very well by my present job.

- The job that I have now gives me just about all the freedom I want in my job. 


\section{Appendix B: Survey Mockups}

\section{T1 Survey Mockup}

The following series of questions asks about your thoughts and feelings regarding yourself and your job. Please answer as honestly as possible. Your individual responses are completely anonymous and will not be shared with anyone at Johnstone Supply. At the end of each page click the ">>" button on the lower right hand corner of the page to move on to the next page.

There are phrases below describing people's behaviors. Please use the rating scale below to indicate how accurately each statement describes YOU by clicking on the appropriate bubble. When you make your answer, think about how you generally are, NOT how you would like to be or how you think others see you. Please remember that your answers will be kept confidential.

\begin{tabular}{|c|c|c|c|c|c|}
\hline & $\begin{array}{c}\text { Very } \\
\text { Inaccurate }\end{array}$ & $\begin{array}{l}\text { Moderately } \\
\text { Inaccurate }\end{array}$ & $\begin{array}{c}\text { Neither } \\
\text { Inaccurate } \\
\text { nor } \\
\text { Accurate }\end{array}$ & $\begin{array}{l}\text { Moderately } \\
\text { Accurate }\end{array}$ & $\begin{array}{c}\text { Very } \\
\text { Accurate }\end{array}$ \\
\hline $\begin{array}{l}\text { Complete tasks } \\
\text { successfully. }\end{array}$ & $\mathrm{O}$ & O & O & 0 & $\mathrm{O}$ \\
\hline Excel in what I do. & $\mathrm{O}$ & $\mathrm{O}$ & $\mathrm{O}$ & $\mathrm{O}$ & $\mathrm{O}$ \\
\hline $\begin{array}{l}\text { Handle tasks } \\
\text { smoothly. }\end{array}$ & O & O & O & O & O \\
\hline $\begin{array}{l}\text { Am sure of my } \\
\text { ground. }\end{array}$ & 0 & $\mathrm{O}$ & 0 & $\mathrm{O}$ & O \\
\hline $\begin{array}{l}\text { Come up with good } \\
\text { solutions. }\end{array}$ & $\mathrm{O}$ & O & $\mathrm{O}$ & $\mathrm{O}$ & O \\
\hline $\begin{array}{l}\text { Know how to get } \\
\text { things done. }\end{array}$ & $\mathrm{O}$ & O & $\mathrm{O}$ & $\mathrm{O}$ & O \\
\hline Like order. & $\mathrm{O}$ & O & $\mathrm{O}$ & $\mathrm{O}$ & $\mathrm{O}$ \\
\hline Like to tidy up. & $\mathrm{O}$ & $\mathrm{O}$ & $\mathrm{O}$ & $\mathrm{O}$ & O \\
\hline $\begin{array}{l}\text { Want everything to be } \\
\text { "just right." }\end{array}$ & $\mathrm{O}$ & $\mathrm{O}$ & $\mathrm{O}$ & $\mathrm{O}$ & $\mathrm{O}$ \\
\hline $\begin{array}{l}\text { Love order and } \\
\text { regularity. }\end{array}$ & $\mathrm{O}$ & $\mathrm{O}$ & $\mathrm{O}$ & $\mathrm{O}$ & $\mathrm{O}$ \\
\hline $\begin{array}{l}\text { Do things according } \\
\text { to a plan. }\end{array}$ & $\mathrm{O}$ & 0 & $\mathrm{O}$ & 0 & $\mathrm{O}$ \\
\hline $\begin{array}{l}\text { Try to follow the } \\
\text { rules. }\end{array}$ & $\mathrm{O}$ & O & O & O & O \\
\hline Keep my promises. & $\mathrm{O}$ & $\mathrm{O}$ & $\mathrm{O}$ & $\mathrm{O}$ & O \\
\hline Pay my bills on time. & $\mathrm{O}$ & O & $\mathrm{O}$ & $\mathrm{O}$ & O \\
\hline Tell the truth. & $\mathrm{O}$ & $\mathrm{O}$ & O & $\mathrm{O}$ & O \\
\hline $\begin{array}{l}\text { Listen to my } \\
\text { conscience. }\end{array}$ & $\mathrm{O}$ & O & $\mathrm{O}$ & $\mathrm{O}$ & $\mathrm{O}$ \\
\hline
\end{tabular}


Conscientiousness as a Moderator 168

\begin{tabular}{|c|c|c|c|c|c|}
\hline & $\begin{array}{c}\text { Very } \\
\text { Inaccurate }\end{array}$ & $\begin{array}{l}\text { Moderately } \\
\text { Inaccurate }\end{array}$ & $\begin{array}{c}\text { Neither } \\
\text { Inaccurate } \\
\text { nor Accurate }\end{array}$ & $\begin{array}{l}\text { Moderately } \\
\text { Accurate }\end{array}$ & $\begin{array}{c}\text { Very } \\
\text { Accurate }\end{array}$ \\
\hline $\begin{array}{l}\text { Go straight for the } \\
\text { goal. }\end{array}$ & O & O & 0 & $\mathrm{O}$ & O \\
\hline Work hard. & $\mathrm{O}$ & $\mathrm{O}$ & $\mathrm{O}$ & $\mathrm{O}$ & $\mathrm{O}$ \\
\hline $\begin{array}{l}\text { Turn plans into } \\
\text { actions. }\end{array}$ & $\mathrm{O}$ & $\mathrm{O}$ & O & O & $\mathrm{O}$ \\
\hline $\begin{array}{l}\text { Plunge into tasks with } \\
\text { all my heart. }\end{array}$ & $\mathrm{O}$ & $\mathrm{O}$ & $\mathrm{O}$ & $\mathrm{O}$ & O \\
\hline $\begin{array}{l}\text { Do more than what's } \\
\text { expected of me. }\end{array}$ & O & $\mathrm{O}$ & $\mathrm{O}$ & O & O \\
\hline $\begin{array}{l}\text { Set high standards for } \\
\text { myself and others. }\end{array}$ & $\mathrm{O}$ & O & O & O & $\mathrm{O}$ \\
\hline Demand quality. & $\mathrm{O}$ & $\mathrm{O}$ & $\mathrm{O}$ & $\mathrm{O}$ & O \\
\hline $\begin{array}{l}\text { Get chores done right } \\
\text { away. }\end{array}$ & $\mathrm{O}$ & $\mathrm{O}$ & O & $\mathrm{O}$ & O \\
\hline Am always prepared. & $\mathrm{O}$ & $\mathrm{O}$ & $\mathrm{O}$ & $\mathrm{O}$ & $\mathrm{O}$ \\
\hline $\begin{array}{l}\text { Start tasks right } \\
\text { away. }\end{array}$ & $\mathrm{O}$ & O & O & $\mathrm{O}$ & $\mathrm{O}$ \\
\hline Get to work at once. & $\mathrm{O}$ & O & $\mathrm{O}$ & $\mathrm{O}$ & $\mathrm{O}$ \\
\hline Carry out my plans. & $\mathrm{O}$ & $\mathrm{O}$ & $\mathrm{O}$ & $\mathrm{O}$ & $\mathrm{O}$ \\
\hline Avoid mistakes. & O & $\mathrm{O}$ & O & $\mathrm{O}$ & $\mathrm{O}$ \\
\hline $\begin{array}{l}\text { Choose my words } \\
\text { with care. }\end{array}$ & O & O & O & $\mathrm{O}$ & $\mathrm{O}$ \\
\hline $\begin{array}{l}\text { Stick to my chosen } \\
\text { path. }\end{array}$ & O & $\mathrm{O}$ & O & $\mathrm{O}$ & $\mathrm{O}$ \\
\hline
\end{tabular}

The next set of questions asks about how much freedom you have at work. Please select the appropriate response to show how much you agree or disagree with each of the statements about the amount and type of freedom you have at YOUR job. Please remember that your answers will be kept confidential.

\begin{tabular}{|c|c|c|c|c|c|}
\hline & $\begin{array}{l}\text { Strongly } \\
\text { Disagree }\end{array}$ & Disagree & $\begin{array}{l}\text { Neither } \\
\text { Agree nor } \\
\text { Disagree }\end{array}$ & Agree & $\begin{array}{l}\text { Strongly } \\
\text { Agree }\end{array}$ \\
\hline $\begin{array}{l}\text { WORK SCHEDULING } \\
\text { FREEDOM }\end{array}$ & & & & & \\
\hline $\begin{array}{l}\text { The job allows me to make } \\
\text { my own decisions about how I } \\
\text { schedule my work. }\end{array}$ & $\mathrm{O}$ & 0 & O & O & O \\
\hline $\begin{array}{l}\text { The job allows me to decide on } \\
\text { the order in which things are } \\
\text { done on the job. }\end{array}$ & O & 0 & O & O & O \\
\hline
\end{tabular}


Conscientiousness as a Moderator 169

\begin{tabular}{|c|c|c|c|c|c|}
\hline $\begin{array}{l}\text { The job allows me to plan how } \\
\text { I do my work. }\end{array}$ & 0 & 0 & 0 & 0 & 0 \\
\hline $\begin{array}{l}\text { DECISION MAKING } \\
\text { FREEDOM } \\
\text { The job gives me a chance to } \\
\text { use my personal initiative or } \\
\text { judgment in carrying out the } \\
\text { work. }\end{array}$ & $O$ & 0 & 0 & 0 & 0 \\
\hline $\begin{array}{l}\text { The job allows me to make a } \\
\text { lot of decisions on my own. }\end{array}$ & 0 & 0 & 0 & 0 & 0 \\
\hline $\begin{array}{l}\text { The job provides me with a lot } \\
\text { of freedom to make decisions. }\end{array}$ & 0 & 0 & 0 & 0 & 0 \\
\hline $\begin{array}{l}\text { FREEDOM OVER WORK } \\
\text { METHODS } \\
\text { The job allows me to make } \\
\text { decisions about what methods } \\
\text { I use to complete my work. }\end{array}$ & 0 & 0 & 0 & 0 & 0 \\
\hline $\begin{array}{l}\text { The job gives me considerable } \\
\text { opportunity for independence } \\
\text { and freedom in how I do the } \\
\text { work. }\end{array}$ & 0 & 0 & 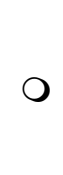 & 0 & 0 \\
\hline $\begin{array}{l}\text { The job allows me to decide on } \\
\text { my own how to go about doing } \\
\text { my work. }\end{array}$ & 0 & 0 & 0 & 0 & 0 \\
\hline
\end{tabular}

The next set of questions asks about how well you fit with the amount of freedom you have at work. For each statement, please indicate your level of agreement or disagreement by selecting the appropriate response.

\begin{tabular}{|c|c|c|c|c|c|}
\hline & $\begin{array}{l}\text { Strongly } \\
\text { Disagree }\end{array}$ & Disagree & $\begin{array}{c}\text { Neither Agree } \\
\text { nor Disagree }\end{array}$ & Agree & $\begin{array}{l}\text { Strongly } \\
\text { Agree }\end{array}$ \\
\hline $\begin{array}{l}\text { There is a good fit between } \\
\text { how much freedom I have at } \\
\text { work and how much freedom } \\
\text { I want in my job. }\end{array}$ & O & 0 & 0 & 0 & O \\
\hline $\begin{array}{l}\text { The amount of independence } \\
\text { I look for in a job is fulfilled } \\
\text { very well by my present job. }\end{array}$ & 0 & 0 & 0 & 0 & 0 \\
\hline $\begin{array}{l}\text { The job that I have now } \\
\text { gives me just about all the } \\
\text { freedom I want in my job. }\end{array}$ & 0 & 0 & 0 & 0 & 0 \\
\hline
\end{tabular}


The next set of statements asks how about how satisfied in general you are with your job. For each statement, please rate your level of agreement or disagreement by selecting the appropriate response. Remember that your responses are confidential.

\begin{tabular}{|l|c|c|c|c|c|}
\hline & $\begin{array}{l}\text { Strongly } \\
\text { Disagree }\end{array}$ & Disagree & $\begin{array}{c}\text { Neither Agree } \\
\text { nor Disagree }\end{array}$ & Agree & $\begin{array}{c}\text { Strongly } \\
\text { Agree }\end{array}$ \\
\hline $\begin{array}{l}\text { I feel fairly satisfied with my } \\
\text { present job. }\end{array}$ & O & 0 & 0 & 0 & 0 \\
$\begin{array}{l}\text { Most days I am enthusiastic } \\
\text { about my work. }\end{array}$ & 0 & 0 & 0 & 0 & 0 \\
$\begin{array}{l}\text { Each day at work seems like it } \\
\text { will never end. }\end{array}$ & 0 & 0 & 0 & 0 & 0 \\
$\begin{array}{l}\text { I find real enjoyment in my } \\
\text { work. }\end{array}$ & 0 & 0 & 0 & 0 & 0 \\
$\begin{array}{l}\text { I consider my job to be rather } \\
\text { unpleasant. }\end{array}$ & 0 & 0 & 0 & 0 & 0 \\
\hline
\end{tabular}

The next set of questions asks about how well you fit with your job in general. For each statement, please indicate your level of agreement or disagreement by selecting the appropriate response.

\begin{tabular}{|c|c|c|c|c|c|}
\hline & $\begin{array}{l}\text { Strongly } \\
\text { Disagree }\end{array}$ & Disagree & $\begin{array}{c}\text { Neither Agree } \\
\text { nor Disagree }\end{array}$ & Agree & $\begin{array}{l}\text { Strongly } \\
\text { Agree }\end{array}$ \\
\hline $\begin{array}{l}\text { There is a good fit between } \\
\text { what my job offers me and } \\
\text { what I am looking for in a job. }\end{array}$ & O & O & O & O & O \\
\hline $\begin{array}{l}\text { The things that I look for in a } \\
\text { job are fulfilled very well by } \\
\text { my present job. }\end{array}$ & $\mathrm{O}$ & O & O & O & O \\
\hline $\begin{array}{l}\text { The job that I have now gives } \\
\text { me just about everything that I } \\
\text { want from a job. }\end{array}$ & O & O & $\mathrm{O}$ & O & O \\
\hline
\end{tabular}

The next set of questions pertains to demographic information about you and your job. Please keep in mind that your individual responses are completely confidential and will not be shared with anyone at Johnstone Supply.

\section{ABOUT YOU}

What is your gender? 
O Male

O Female

What is your age? (Please enter a two digit number)

Click the text box to enter your age

What is your race? (Check all that apply.)

- Caucasian or White

口 African American or Black

a Asian

- Hispanic or Latino/a

- Native Hawaiian or other Pacific Islander

- American Indian or Alaskan native

O Other

What is the highest level of education you have completed?

O Some high school

O High school diploma or GED

O Some college or associate's degree

O Bachelor's degree

O Graduate degree

\section{ABOUT YOUR JOB}

How many years have you worked at Johnstone Supply? (Please enter a one or two digit number. If you have worked at Johnstone less than one year, please enter 0)

Click the text box to enter the number of years

How many years have you worked in your current position? (Please enter a one or two digit number. If you have worked in your current position less than one year, please enter 0)

Click the text box to enter the number of years

Do you currently supervise or manage other employees?

O Yes

O No 
Conscientiousness as a Moderator 172

What category BEST describes your job?

O Executive: e.g. Owner/Officer/President/Vice-President

Manager (non-store): e.g. Manager/Director

O Store / Branch Manager

O Sales Manager

O Outside Sales

O Counter Salesperson

O Warehouse/Driver

O Office Worker

Other (Please enter your job title in the box below)

Which best describes your pay structure?

O Hourly

O Salary

What is your wage per hour? (Please enter your hourly wage as a number only. For example if your wage is $\$ 9.25$ / Hour, you would enter 9.25.)

Click the text box to enter your hourly wage

What is your yearly salary? (Please enter your yearly salary as a number)

Click the text box to enter yearly salary

How many hours do you currently work per week (on average)? (Please enter your hours per week as a two digit number)

Click the text box to enter number of hours

In which state do you currently work? Please select an option from the crop down menu.

The following information is needed only to match your survey with the survey you will take in a few weeks. It will not be used for any other purpose. 


\section{Conscientiousness as a Moderator 173}

Please enter:

- A. The first two letters of your mother's maiden name. (For example, if your mother's maiden name is SMITH, enter SM.)

- B. The first two letters of your father's first name. (For example, if your father's first name is JOHN, enter JO.)

- C. The number of brothers and sisters that you have as a two digit number. (For example, if you have two brothers and one sister, enter 03. If you do not have any siblings, enter 00.) You do not have to remember this code.

We will ask the same three questions during the next survey and will match the data based on your answers. 


\section{T2 Survey Mockup}

The following series of questions asks about your thoughts and feelings regarding your job. Please answer as honestly as possible. Your individual responses are completely anonymous and will not be shared with anyone at Johnstone Supply. At the end of each page click the ">>" button on the lower right hand corner of the page to move on to the next page.

This set of statements asks about how well you fit with your job in general. For each statement, please indicate your level of agreement or disagreement by selecting the appropriate response. Remember that your responses are confidential.

\begin{tabular}{|l|c|c|c|c|c|}
\hline $\begin{array}{l}\text { Strongly } \\
\text { Disagree }\end{array}$ & Disagree & $\begin{array}{c}\text { Neither Agree } \\
\text { nor Disagree }\end{array}$ & Agree & $\begin{array}{c}\text { Strongly } \\
\text { Agree }\end{array}$ \\
$\begin{array}{l}\text { what my job offers me and } \\
\text { job. }\end{array}$ & 0 & 0 & 0 & 0 & 0 \\
$\begin{array}{l}\text { The things that I look for in } \\
\text { a job are fulfilled very well } \\
\text { by my present job. }\end{array}$ & 0 & 0 & 0 & 0 & 0 \\
$\begin{array}{l}\text { The job that I have now } \\
\text { gives me just about } \\
\text { everything that I want from } \\
\text { a job. }\end{array}$ & 0 & 0 & 0 & 0 & 0 \\
\hline
\end{tabular}

The next set of statements asks how about how satisfied in general you are with your job. For each statement, please rate your level of agreement or disagreement by selecting the appropriate response. Remember that your responses are confidential.

\begin{tabular}{|l|c|c|c|c|c|}
\hline & $\begin{array}{c}\text { Strongly } \\
\text { Disagree }\end{array}$ & Disagree & $\begin{array}{c}\text { Neither Agree } \\
\text { nor Disagree }\end{array}$ & Agree & $\begin{array}{c}\text { Strongly } \\
\text { Agree }\end{array}$ \\
\hline $\begin{array}{l}\text { I feel fairly satisfied with my } \\
\text { present job. }\end{array}$ & O & 0 & 0 & 0 & 0 \\
$\begin{array}{l}\text { Most days I am enthusiastic } \\
\text { about my work. }\end{array}$ & 0 & 0 & 0 & 0 & 0 \\
$\begin{array}{l}\text { Each day at work seems like } \\
\text { it will never end. }\end{array}$ & O & 0 & 0 & 0 & 0 \\
$\begin{array}{l}\text { I find real enjoyment in my } \\
\text { work. }\end{array}$ & 0 & 0 & 0 & 0 & 0 \\
$\begin{array}{l}\text { I consider my job to be } \\
\text { rather unpleasant. }\end{array}$ & 0 & 0 & 0 & 0 & 0 \\
\hline
\end{tabular}


There are phrases below describing people's behaviors. Please use the rating scale below to indicate how accurately each statement describes YOU by clicking on the appropriate bubble. When you make your answer, think about how you generally are, NOT how you would like to be or how you think others see you. Please remember that your answers will be kept confidential.

\begin{tabular}{|c|c|c|c|c|c|}
\hline & $\begin{array}{c}\text { Very } \\
\text { Inaccurate }\end{array}$ & $\begin{array}{l}\text { Moderately } \\
\text { Inaccurate }\end{array}$ & $\begin{array}{c}\text { Neither } \\
\text { Inaccurate } \\
\text { nor Accurate }\end{array}$ & $\begin{array}{l}\text { Moderately } \\
\text { Accurate }\end{array}$ & $\begin{array}{c}\text { Very } \\
\text { Accurate }\end{array}$ \\
\hline $\begin{array}{l}\text { I am constantly on the } \\
\text { lookout for new ways } \\
\text { to improve my life. }\end{array}$ & 0 & 0 & 0 & 0 & 0 \\
\hline $\begin{array}{l}\text { Wherever I have been, } \\
\text { I have been a } \\
\text { powerful force for } \\
\text { constructive change. }\end{array}$ & 0 & 0 & $O$ & 0 & 0 \\
\hline $\begin{array}{l}\text { Nothing is more } \\
\text { exciting than seeing } \\
\text { my ideas turn into } \\
\text { reality. }\end{array}$ & O & 0 & 0 & $O$ & 0 \\
\hline $\begin{array}{l}\text { If I see something I } \\
\text { don't like, I fix it. }\end{array}$ & 0 & 0 & 0 & 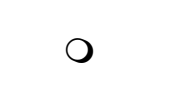 & 0 \\
\hline $\begin{array}{l}\text { No matter what the } \\
\text { odds, if I believe in } \\
\text { something I will make } \\
\text { it happen. }\end{array}$ & 0 & O & 0 & 0 & 0 \\
\hline $\begin{array}{l}\text { I love being a } \\
\text { champion for my } \\
\text { ideas, even against } \\
\text { others' opposition. }\end{array}$ & 0 & 0 & 0 & 0 & 0 \\
\hline $\begin{array}{l}\text { I excel at identifying } \\
\text { opportunities. }\end{array}$ & 0 & 0 & $O$ & 0 & 0 \\
\hline $\begin{array}{l}\text { I am always looking } \\
\text { for better ways to do } \\
\text { things. }\end{array}$ & 0 & 0 & 0 & $O$ & 0 \\
\hline $\begin{array}{l}\text { If I believe in an idea, } \\
\text { no obstacle will } \\
\text { prevent me from } \\
\text { making it happen. }\end{array}$ & 0 & 0 & 0 & 0 & 0 \\
\hline $\begin{array}{l}\text { I can spot a good } \\
\text { opportunity long } \\
\text { before others can. }\end{array}$ & 0 & 0 & $O$ & 0 & $O$ \\
\hline
\end{tabular}


Please use the rating scale below to indicate how accurately each statement describes the relationship between YOU AND YOUR manager or supervisor by clicking on the appropriate bubble. Please remember that your answers will be kept confidential.

\begin{tabular}{|c|c|c|c|c|c|}
\hline & $\begin{array}{c}\text { Very } \\
\text { Inaccurate }\end{array}$ & $\begin{array}{l}\text { Moderately } \\
\text { Inaccurate }\end{array}$ & $\begin{array}{l}\text { Neither } \\
\text { Inaccurate nor } \\
\text { Accurate }\end{array}$ & $\begin{array}{l}\text { Moderately } \\
\text { Accurate }\end{array}$ & $\begin{array}{c}\text { Very } \\
\text { Accurate }\end{array}$ \\
\hline $\begin{array}{l}\text { I usually know where I } \\
\text { stand with my } \\
\text { supervisor. }\end{array}$ & $\mathrm{O}$ & $\mathrm{O}$ & $\mathrm{O}$ & $\mathrm{O}$ & $\mathrm{O}$ \\
\hline $\begin{array}{l}\text { I usually know how } \\
\text { satisfied my supervisor } \\
\text { is with me. }\end{array}$ & O & $\mathrm{O}$ & $\mathrm{O}$ & O & $\mathrm{O}$ \\
\hline $\begin{array}{l}\text { My supervisor uses } \\
\text { his/her power to help } \\
\text { me solve problems at } \\
\text { work. }\end{array}$ & $\mathrm{O}$ & O & O & O & $\mathrm{O}$ \\
\hline $\begin{array}{l}\text { I justify my } \\
\text { supervisor's decisions } \\
\text { to others when he/she } \\
\text { is not present to do so. }\end{array}$ & $\mathrm{O}$ & O & O & $\mathrm{O}$ & $\mathrm{O}$ \\
\hline $\begin{array}{l}\text { My supervisor } \\
\text { recognizes my } \\
\text { potential. }\end{array}$ & $\mathrm{O}$ & $\mathrm{O}$ & $\mathrm{O}$ & $\mathrm{O}$ & $\mathrm{O}$ \\
\hline $\begin{array}{l}\text { I can count on my } \\
\text { supervisor to "bail me } \\
\text { out" even at his or her } \\
\text { expense when I really } \\
\text { need it. }\end{array}$ & $\mathrm{O}$ & O & O & O & O \\
\hline $\begin{array}{l}\text { My supervisor } \\
\text { understands my } \\
\text { problems and needs. }\end{array}$ & $\mathrm{O}$ & $\mathrm{O}$ & O & $\mathrm{O}$ & O \\
\hline $\begin{array}{l}\text { I have an effective } \\
\text { working relationship } \\
\text { with my supervisor. }\end{array}$ & 0 & $\mathrm{O}$ & O & $\mathrm{O}$ & $\mathrm{O}$ \\
\hline $\begin{array}{l}\text { I can count on my } \\
\text { supervisor to be } \\
\text { trustworthy. }\end{array}$ & $\mathrm{O}$ & $\mathrm{O}$ & $\mathrm{O}$ & $\mathrm{O}$ & $\mathrm{O}$ \\
\hline $\begin{array}{l}\text { Usually I can trust my } \\
\text { supervisor. }\end{array}$ & $\mathrm{O}$ & O & O & O & O \\
\hline $\begin{array}{l}\text { I feel that my } \\
\text { supervisor can be } \\
\text { trusted. }\end{array}$ & $\mathrm{O}$ & $\mathrm{O}$ & $\mathrm{O}$ & 0 & $\mathrm{O}$ \\
\hline I trust my supervisor. & O & $\mathrm{O}$ & O & $\mathrm{O}$ & O \\
\hline
\end{tabular}

The following information is needed only to match your survey with the survey you will take in a few 


\section{Conscientiousness as a Moderator 177}

weeks. It will not be used for any other purpose.

Please enter:

- A. The first two letters of your mother's maiden name. (For example, if your mother's maiden name is SMITH, enter SM.)

- B. The first two letters of your father's first name. (For example, if your father's first name is JOHN, enter JO.)

- C. The number of brothers and sisters that you have as a two digit number. (For example, if you have two brothers and one sister, enter 03. If you do not have any siblings, enter 00.) You do not have to remember this code. 